\title{
Sulfuric Acid Removal Process Evaluation: Short-term Results
}

\author{
Topical Report
}

Cooperative Agreement No.: DE-FC26-99FT40718

\author{
Prepared for: \\ William W. Aljoe \\ U.S Department of Energy \\ National Energy Technology Laboratory \\ 626 Cochrans Mill Road \\ Pittsburgh, Pennsylvania 15236 \\ Prepared by: \\ Gary M. Blythe \\ Richard McMillan \\ URS Corporation \\ 9400 Amberglen Boulevard \\ Austin, Texas 78729
}

February 4, 2002 


\section{DISCLAIMER OF WARRANTIES AND LIMITATION OF LIABILITIES}

This report was prepared as an account of work sponsored by an agency of the United States Government. Neither the United States Government nor any agency thereof, nor any of their employees, makes any warranty, express or implied, or assumes any legal liability or responsibility for the accuracy, completeness, or usefulness of any information, apparatus, product, or process disclosed, or represents that its use would not infringe privately owned rights. Reference herein to any specific commercial product, process, or service by trade name, trademark, manufacturer, or otherwise does not necessarily constitute or imply its endorsement, recommendation, or favoring by the United States Government or any agency thereof. The views and opinions of authors expressed herein do not necessarily state or reflect those of the United States Government or any agency thereof. 


\section{ABSTRACT}

The objective of this project is to demonstrate the use of alkaline reagents injected into the furnace of coal-fired boilers as a means of controlling sulfuric acid emissions. The project is being co-funded by the U.S. DOE National Energy Technology Laboratory, under Cooperative Agreement DE-FC26-99FT40718, along with EPRI, the American Electric Power Company, FirstEnergy Corporation, the Tennessee Valley Authority, and Dravo Lime, Inc.

Sulfuric acid controls are becoming of increasing interest to utilities with coal-fired units for a number of reasons. Sulfuric acid is a Toxic Release Inventory species, a precursor to acid aerosol/condensable emissions, and can cause a variety of plant operation problems such as air heater plugging and fouling, back-end corrosion, and plume opacity. These issues will likely be exacerbated with the retrofit of SCR for $\mathrm{NO}_{\mathrm{X}}$ control on some coal-fired plants, as SCR catalysts are known to further oxidize a portion of the flue gas $\mathrm{SO}_{2}$ to $\mathrm{SO}_{3}$.

The project is testing the effectiveness of furnace injection of four different calcium- and/or magnesium-based alkaline sorbents on full-scale utility boilers. These reagents have been tested during four one- to two-week tests conducted on two FirstEnergy Bruce Mansfield Plant units. One of the sorbents tested was a magnesium hydroxide slurry produced from a wet flue gas desulfurization system waste stream, from a system that employs a Thiosorbic ${ }^{\circledR}$ Lime scrubbing process. The other three sorbents are available commercially and include dolomite, pressurehydrated dolomitic lime, and commercial magnesium hydroxide. The dolomite reagent was injected as a dry powder through out-of-service burners, while the other three reagents were injected as slurries through air-atomizing nozzles into the front wall of upper furnace, either across from the nose of the furnace or across from the pendant superheater tubes.

After completing the four one- to two-week tests, the most promising sorbents were selected for longer-term (approximately 25-day) full-scale tests. The longer-term tests are being conducted to confirm the effectiveness of the sorbents tested over extended operation and to determine balance-of-plant impacts.

This reports presents the results of the short-term tests; the long-term test results will be reported in a later document. The short-term test results showed that three of the four reagents tested, dolomite powder, commercial magnesium hydroxide slurry, and byproduct magnesium hydroxide slurry, were able to achieve $90 \%$ or greater removal of sulfuric acid compared to baseline levels. The molar ratio of alkali to flue gas sulfuric acid content (under baseline conditions) required to achieve $90 \%$ sulfuric acid removal was lowest for the byproduct magnesium hydroxide slurry. However, this result may be confounded because this was the only one of the three slurries tested with injection near the top of the furnace across from the pendant 
superheater platens. Injection at the higher level was demonstrated to be advantageous for this reagent over injection lower in the furnace, where the other slurries were tested. 


\section{CONTENTS}

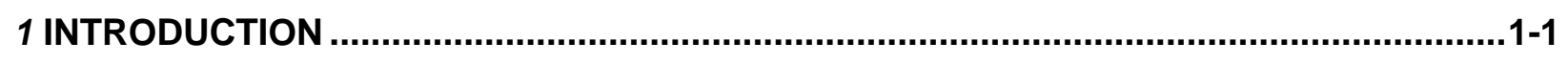

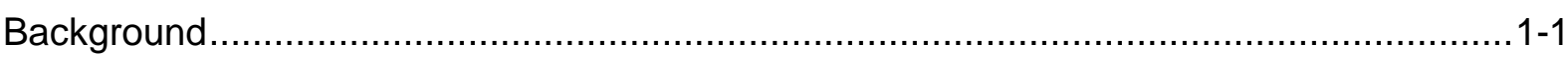

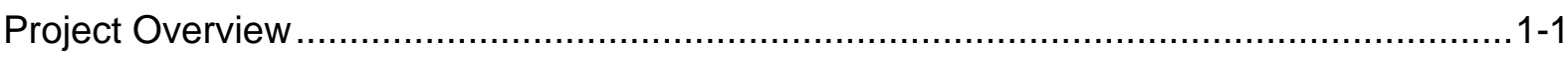

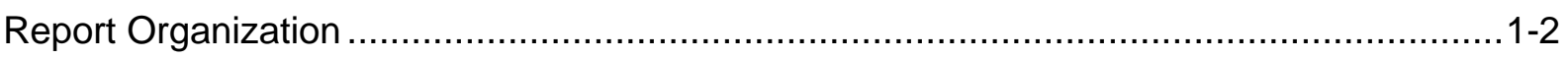

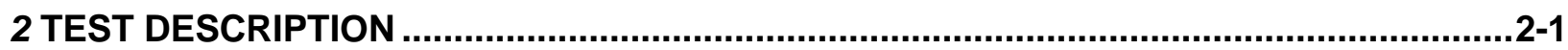

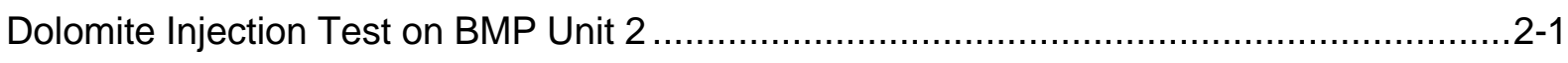

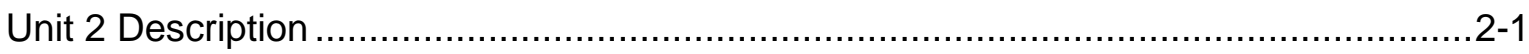

Unit 2 Operating Conditions.............................................................................. $2-3$

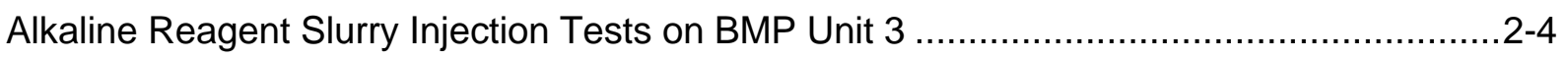

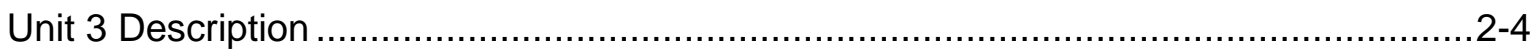

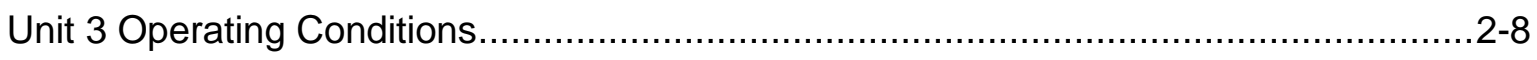

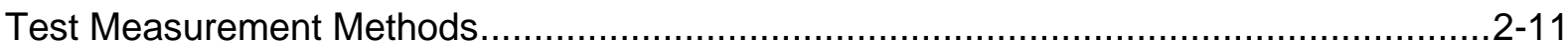

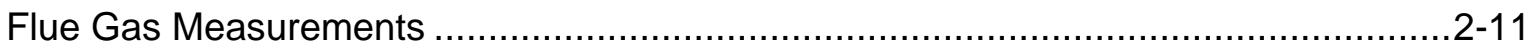

$\mathrm{H}_{2} \mathrm{SO}_{4}$ Vapor by Controlled Condensation ...................................................... $2-11$

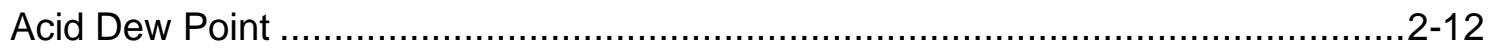

Method 26a-Hydrogen Halide and Halogen Emissions (chloride and fluoride) .......2-12

Solid and Slurry Sample Analyses ...................................................................... $2-13$

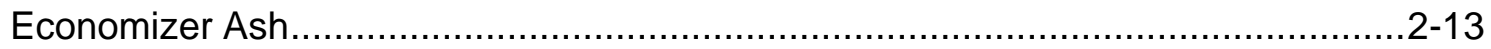

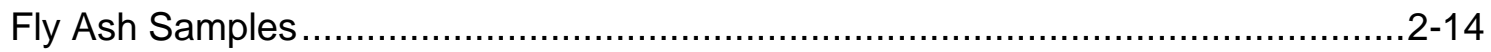

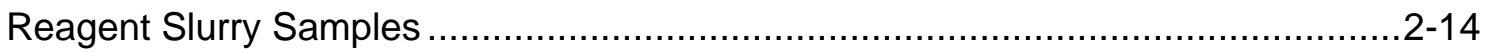

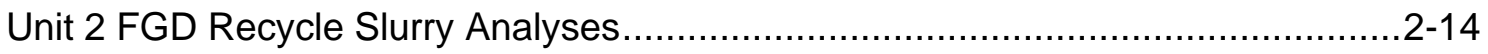

3 RESULTS OF DOLOMITE POWDER INJECTION TEST ................................................... $3-1$

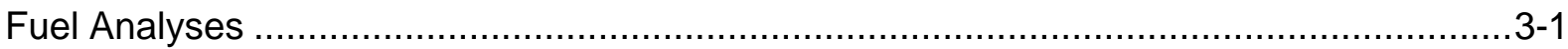

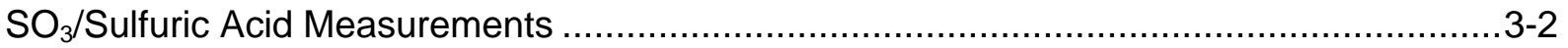

Method 26a —Hydrogen Halide and Halogen Concentration Results...................................3-8

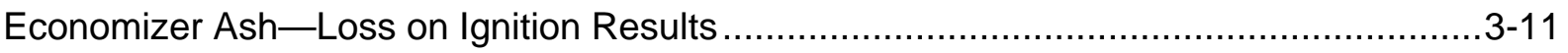


Unit Performance, General Observations and Slag Formation Observations

Scrubber Performance Results

4 RESULTS FROM SLURRY INJECTION TESTS ...........................................................

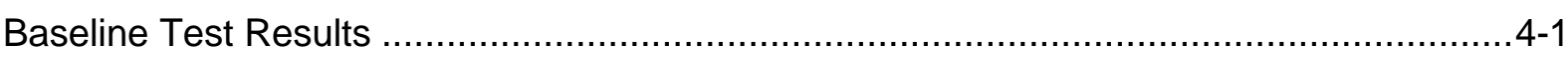

PHDL Sorbent Injection Test Results ................................................................ 4-4

Commercial Mg Sorbent Injection Test Results.................................................4-11

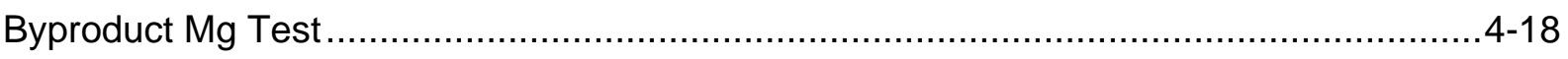

Effects of Temperature on Sorbent-Specific Surface Area .......................................4-25

Balance of Plant Effects ............................................................................... $4-26$

Impacts of Sorbent Injection and $\mathrm{SO}_{3}$ Removal on ESP Operation ..........................4-26

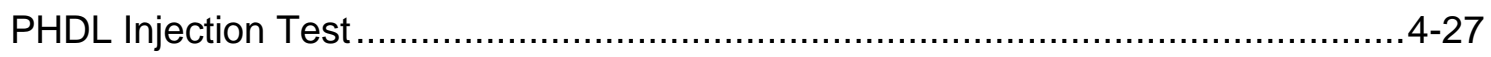

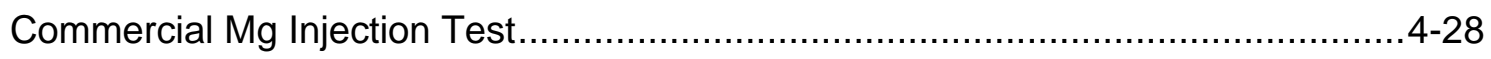

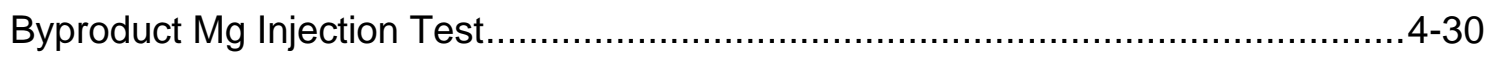

ESP Outlet Particulate Loading ............................................................ 4-32

Flue Gas Halogen Species Concentrations ................................................... $4-32$

5 SUMMARY AND CONCLUSIONS …..............................................................................

Dolomite Powder Injection Test.................................................................... $5-1$

Alkaline Sorbent Slurry Injection Tests .............................................................. $5-4$

Comparison of Alkaline Sorbent Performance ...................................................... $5-5$ 


\section{LIST OF FIGURES}

Figure 2-1 Illustration of Flue Gas Path for BMP Unit 2 ................................................2-2

Figure 2-2 Boiler Load and Dolomite Injection Rate during the Test Period ...........................2-4

Figure 2-3 Illustration of Flue Gas Path for BMP Unit 3 .............................................. $2-6$

Figure 2-4 Illustration of Slurry Injection Levels........................................................ $2-7$

Figure 2-5 Illustration of Slurry Injection Locations - Plan View .........................................

Figure 2-6 Controlled Condensation Sulfuric Acid Vapor Train .......................................2-11

Figure 2-7 EPA Method 5/Method 26a Sampling Train .................................................2-13

Figure 3-1 CCS SO 3 Measurement Data .................................................................

Figure 3-2 $\mathrm{CCS} \mathrm{SO}_{3}$ Measurements Compared to Acid Dew-Point Measurements .................3-6

Figure 4-1 Summary of Baseline CCS Measurements at BMP Unit 3 .................................4-3

Figure 4-2 Results from the First Week of the PHDL Test................................................... 4-7

Figure 4-3 Results from the Second Week of the PHDL Test...........................................4-8

Figure 4-4 Results from the First Week of the Commercial Mg Test ................................4-15

Figure 4-5 Results from the Second Week of the Commercial Mg Test ..............................4-16

Figure 4-6 Illustration of Magnesium Concentrations in ESP Hopper Ash Samples ..............4-18

Figure 4-7 Results from the First Week of the Byproduct Mg Test (11 ${ }^{\text {th }}$ Floor Injection) .........4-22

Figure 4-8 Results from the Second Week of the Byproduct Mg Test (14 ${ }^{\text {th }}$ Floor Injection) ....4-23

Figure 4-9 Observed Effect of PHDL Injection on ESP B and C Secondary Currents ...........4-28

Figure 4-10 Observed Effect of Commercial Mg Injection on ESP B and C Secondary Currents and ESP B Particulate Emissions

Figure 4-11 Observed Effect of Byproduct Mg Injection on ESP B Particulate Emissions ......4-30

Figure 4-12 ESP Outlet Emissions Data from the Byproduct Mg Injection Test....................4-31 


\section{LIST OF TABLES}

Table 2-1 Summary of Operating Conditions during Dolomite Injection Tests 2-5

Table 2-2 Unit 3 Operating Conditions during Baseline and Short-term Slurry Injection

Tests 2-9

Table 3-1 Fuel Analyses (as received basis, except as noted) ........................................ $3-2$

Table 3-2 Results of CCS and Acid Dew-Point Meter Measurements ....................................

Table 3-3 Summary of Method 26a Data ...........................................................................

Table 3-4 Hydrogen Halide and Halogen Mass Rates ............................................... 3-10

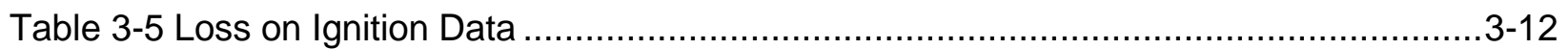

Table 3-6 Unit 2 FGD Slurry Solids Analyses............................................................. $3-15$

Table 3-7 FGD Slurry Liquor Analyses................................................................... $3-16$

Table 4-1 Summary of Flue Gas $\mathrm{SO}_{3}$ Concentrations Measured for Unit 3 Baseline

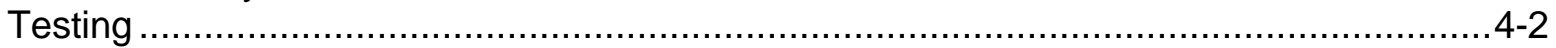

Table 4-2 Ultimate Analyses of Coal Samples from the Unit 3 Baseline Test.........................4-4

Table 4-3 Flue Gas $\mathrm{SO}_{3}$ Concentration and Slurry Injection Rate Data for the PHDL Test.......4-5

Table 4-4 Ultimate Analyses of Coal Samples from the Unit 3 PHDL Test.............................4-9

Table 4-5 Furnace Gas Temperature Measurements on Unit 3 Boiler at Full and Reduced Load.

Table 4-6 Flue Gas $\mathrm{SO}_{3}$ Concentration and Slurry Injection Rate Data for the

Commercial Mg Test ..................................................................................... $4-13$

Table 4-7 Ultimate Analyses of Coal Samples from the Commercial Mg Test.......................4-17

Table 4-8 Summary of Results from Short-term Byproduct Mg Test on Unit 3 .....................4-20

Table 4-9 Ultimate Analyses of Coal Samples from the Byproduct Mg Test........................4-24

Table 4-10 Results of Laboratory Investigation of the Effect of Temperature on the Specific Surface Area of Calcined Sorbents ...................................................... 4-26

Table 4-11 Summary of ESP B Outlet Baseline Particulate Loading Measurements.............4-33

Table 4-12 Summary of Method 26a Data ................................................................... 4-35

Table 4-13 Hydrogen Halide and Halogen Mass Rates.................................................4-36

Table 5-1 Comparison of Furnace Injected Alkaline Sorbents for Sulfuric Acid Control (based on short-term test results). 


\section{1 \\ INTRODUCTION}

This document is an interim report for the project "Furnace Injection of Alkaline Sorbents for Sulfuric Acid Control." The objective of this project is to demonstrate the use of alkaline reagents injected into the furnace of coal-fired boilers as a means of controlling sulfuric acid emissions. The coincident removal of hydrochloric acid $(\mathrm{HCl})$ and hydrofluoric acid $(\mathrm{HF})$ is also being determined, as is the removal of arsenic, a known poison for $\mathrm{NO}_{\mathrm{X}}$ selective catalytic reduction (SCR) catalysts. The project is being co-funded by the U.S. DOE National Energy Technology Laboratory, under Cooperative Agreement DE-FC26-99FT40718, along with EPRI, the American Electric Power Company, FirstEnergy Corporation, the Tennessee Valley Authority, and Dravo Lime, Inc. URS Corporation (formerly Radian International) is the prime contractor.

\section{Background}

Sulfuric acid is present in most flue gases from coal combustion because a small percentage of the $\mathrm{SO}_{2}$ produced from the sulfur in the coal (approximately $0.5 \%$ to $1.5 \%$ ) is further oxidized to form $\mathrm{SO}_{3}$. The $\mathrm{SO}_{3}$ combines with flue gas moisture to form vapor-phase or condensed sulfuric acid at temperatures below $500^{\circ} \mathrm{F}\left(260^{\circ} \mathrm{C}\right)$.

Besides being a Toxic Release Inventory substance and a potential precursor to acid aerosol/condensable emissions from coal-fired boilers, sulfuric acid in the flue gas can lead to power plant operating problems. These can include boiler air heater plugging and fouling, corrosion in the air heater and downstream, and reduced power plant efficiency if air heater outlet flue gas temperatures are raised to avoid these problems. Also, the formation of a visible plume can be an issue, particularly for plants with wet flue gas desulfurization (FGD) systems. These issues will likely be exacerbated with the retrofit of SCR for $\mathrm{NO}_{\mathrm{X}}$ control on some coalfired plants, as SCR catalysts are known to further oxidize a portion of the flue gas $\mathrm{SO}_{2}$ to $\mathrm{SO}_{3}$.

\section{Project Overview}

The project is testing the effectiveness of furnace injection of four different calcium- and/or magnesium-based alkaline sorbents on full-scale utility boilers. These reagents have been tested during four one- to two-week tests conducted on two FirstEnergy Bruce Mansfield Plant (BMP) units. One of the sorbents tested was a magnesium hydroxide slurry produced from a wet FGD waste stream, from a system that employs a Thiosorbic ${ }^{\circledR}$ Lime scrubbing process. The other three sorbents are available commercially and include dolomite, pressure-hydrated dolomitic lime, and commercial magnesium hydroxide. These reagents are described later in the report. The dolomite 
was injected as a powder into the furnace of BMP Unit 2, while the other three reagents were injected as slurries into the upper furnace of BMP Unit 3.

After completing the four one- to two-week tests, the most promising sorbents were selected for longer-term (approximately 25-day) full-scale tests. The longer-term tests are being conducted to confirm the effectiveness of the sorbents tested over extended operation and to determine balance-of-plant impacts. Two longer-term tests are being conducted, one on FirstEnergy's BMP Unit 3 and the second on American Electric Power's Gavin Station Unit 1.

\section{Report Organization}

This report provides a detailed discussion of technical results from the short-term sorbent screening tests conducted at BMP. Results from the longer-term tests will be presented and discussed in a later report. Section 2 provides a test description, including a description of the host site, the conditions for each of the four short-term tests, and the measurement methods used in conducting the project. Section 3 presents results from the short-term dolomite powder injection test, and Section 4 presents results from the short-term reagent slurry injection tests. Section 5 provides a summary and conclusions from the short-term tests. 


\section{2 \\ TEST DESCRIPTION}

The first short-term test evaluated dolomite injected into the furnace of BMP Unit 2 through outof-service burners, while the second through fourth tests evaluated calcium- and/or magnesiumbased alkaline slurries injected through air-atomizing nozzles into the upper furnace of BMP Unit 3. This section describes each of the four tests and is divided into three subsections; the first describes the dolomite injection test on BMP Unit 2, the second describes the three slurry injection tests conducted on BMP Unit 3, and the third describes measurement methods used in the conduct of these tests.

\section{Dolomite Injection Test on BMP Unit 2}

The first short-term sorbent injection test was conducted the week of April 18, 2000, and investigated the effects of injecting dolomite $\left(\mathrm{CaCO}_{3} \bullet \mathrm{MgCO}_{3}\right)$, a mineral similar to limestone, as a dry powder into the furnace of BMP Unit 2. During the test program, various analytical techniques were used to assess the effects of sorbent injection. These primarily included sampling with the Controlled Condensation System (CCS) for determining flue gas $\mathrm{SO}_{3}$ content and an acid dew-point meter for determining the sulfuric acid dew point (and, indirectly, the sulfuric acid concentration) of the flue gas. EPA Reference Method 26a was used for determining hydrochloric acid and hydrofluoric acid, as well and chlorine $\left(\mathrm{Cl}_{2}\right)$ and fluorine $\left(\mathrm{F}_{2}\right)$ concentrations in the flue gas. Unburned carbon in fly ash was determined by loss on ignition (LOI). Coal and FGD slurry samples were also collected and analyzed for a variety of parameters. Finally, visual observations were made of boiler furnace and superheater surfaces prior to and during sorbent injection.

As mentioned in the introduction, one objective of the project is to measure the effects of sorbent injection on vapor-phase arsenic concentrations at the economizer outlet location. Arsenic is a known SCR catalyst poison, and removal of vapor-phase arsenic from SCR inlet flue gas would be a benefit from sorbent injection. However, the project plan called for arsenic testing only during the later long-term tests.

\section{Unit 2 Description}

Unit 2 is one of three coal-fired units at BMP; Units 1 and 2 are rated at 780 net MW, and Unit 3 is rated at 800 net MW. Unit 2 has an opposed-wall fired, supercritical boiler rated at approximately $6,415,000$ pounds of steam per hour $(2,916,000 \mathrm{~kg} / \mathrm{hr})$ at $3785 \mathrm{psig}(26,100 \mathrm{kPa})$ and $1005 / 1005^{\circ} \mathrm{F}\left(541 / 541^{\circ} \mathrm{C}\right)$ superheat and reheat temperatures. The boiler has 16 burners each on the front and back walls of the furnace. Unit 2 has been retrofitted with low $\mathrm{NO}_{\mathrm{X}}$ burners and over-fire air. The burners are arranged in four horizontal rows on each wall, with four burners 
per row. One ball mill pulverizer provides the pulverized fuel for each row. Depending on fuel quality and mill condition, full load can generally be achieved with six of the eight mills in operation (and thus six of eight rows of burners in service).

All three units at BMP typically burn 2.0 to $4.5 \%$ sulfur coal. Coal blends are typically fired, predominantly blends of a McElroy-type coal. The facility also has permission to burn up to $20 \%$ of the fuel as petroleum coke. During the period of this short-term test on Unit 2, a standard coal blend was used (i.e., no petroleum coke co-firing).

Unit 2 was brought into service in the mid-1970s. The 780-net-MW unit operates as a swing unit to meet the load demands of the grid. The boiler is equipped with two air heaters following the economizer section. The average flue gas temperature at the outlet of the air heaters is controlled to about $320^{\circ} \mathrm{F}\left(160^{\circ} \mathrm{C}\right)$ due to acid dew-point considerations.

Figure 2-1 illustrates the flue gas path for Unit 2, and notes the gas sampling locations used during this test. Flue gas from the two air heaters passes enters a plenum, then exits through six circular ducts to six venturi scrubbers that remove particulate material and $\mathrm{SO}_{2}$. The six scrubber inlet ducts are labeled A, B, C, D, E, and F from east to west. The scrubbers use a magnesiumenhanced, Thiosorbic ${ }^{\circledR}$ lime slurry reagent and produce a calcium sulfite hemihydrate $\left(\mathrm{CaSO}_{3} \bullet 1 / 2 \mathrm{H}_{2} \mathrm{O}\right)$ byproduct. The flue gas then passes through induced draft fans, one per scrubber module. The six scrubbed flue gas streams are combined in two ducts that each lead to separate flues in the stack. The gas from scrubber ducts A, B, and C combine to go to flue A, and ducts D, $\mathrm{E}$, and $\mathrm{F}$ go to flue $\mathrm{B}$.

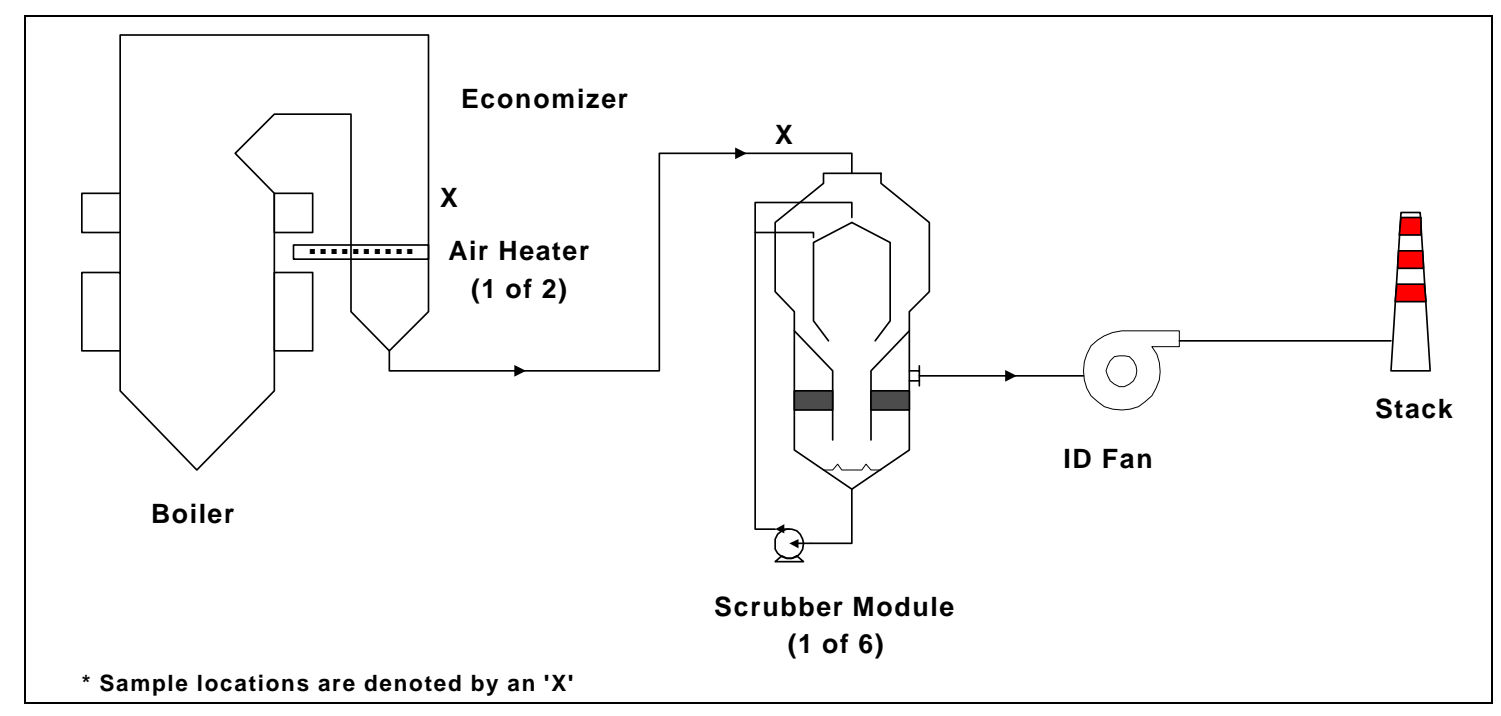

Figure 2-1

Illustration of Flue Gas Path for BMP Unit 2

The concrete stack contains four 19-ft diameter steel flues. Two of the flues are from Unit 1 and two of the flues are from Unit 2. Since the flue gas from two units is combined in one stack, it is difficult to determine if sulfuric acid control measures tested on one unit has had an effect on plume opacity. The flue gas in the stack is saturated at a temperature of about $130^{\circ} \mathrm{F}\left(54^{\circ} \mathrm{C}\right)$. No reheat is used on the stack gas. 
During these tests, the top rows of burners on the front and rear walls of the unit were generally out of service. Injection of dolomite was through the top row of burners on the front wall. This was accomplished by charging the coal storage hoppers that feed these burners with dolomite. The limestone was delivered to the coal feeders, fed to the pulverizer, pulverized and blown through the burners into the furnace.

The flue gas configuration on Unit 2 (or Unit 1) was seen as being potentially advantageous over that of Unit 3 for dolomite injection. On Units 1 and 2, venturi wet scrubbers are used for combined particulate and $\mathrm{SO}_{2}$ control while Unit 3 has a more conventional configuration with an ESP for particulate control followed by a wet scrubber for $\mathrm{SO}_{2}$ control. The Unit 2 configuration was seen as being potentially advantageous for two reasons. First, there were concerns that injecting significant quantities of dolomite into the furnace would adversely affect the performance of an ESP particulate collection device, because of the high bulk resistivity of the calcium oxides and salts that would be formed. This is not an issue for a wet scrubbing particulate control device. Second, it was expected that excess calcium oxide and magnesium oxide formed in the furnace from the injected dolomite would be removed by the wet scrubbers and used as a source of alkalinity in the scrubbers, offsetting a portion of their normal lime slurry reagent makeup. Thus, with the Unit 2 flue gas configuration, not only could an ESP performance issue be avoided, but a portion of the FGD lime slurry reagent could be replaced with less expensive dolomite.

\section{Unit 2 Operating Conditions}

Tests were conducted on April 18 through 21, 2000. Dolomite was injected around the clock from 4:20 p.m. on April 18 through 1:00 p.m. on April 21, with one interruption the morning of April 19. Flue gas characterization tests were only conducted during daytime hours each day. During all flue gas testing, the steam generator was at nearly full load with two burner rows out of service (typically the top row of burners on the front and rear wall). Overnight the boiler load was sometimes reduced (particularly the evening of April 20 through the morning of April 21), but dolomite injection rates were maintained relatively constant due to minimum flow requirements on the mill used to grind the dolomite. Figure 2-2 illustrates the boiler load and dolomite injection rates over the test period.

Also shown in the figure is the effective molar ratio of alkalinity in dolomite injected to sulfur in the coal fired. This molar ratio is thought to be an important parameter in the control of sulfuric acid by furnace injection, as it indirectly affects the ratio of dolomite alkalinity to sulfuric acid in the flue gas. For the figure, the alkalinity in the dolomite includes both calcium carbonate and magnesium carbonate injected, and the coal sulfur is based on the measured coal feed rates and average coal sulfur analyses.

Flue gas testing conducted on April 18 served as a baseline test and was done with no dolomite being fed to the furnace. The testing conducted on April 19, 20, and 21 included dolomite injection at various flow rates. The dolomite was injected into the furnace through the top elevation of burners on the front wall of the furnace (identified as the "A" burner row). Table 2-1 summarizes the operating conditions during the flue gas test periods. 


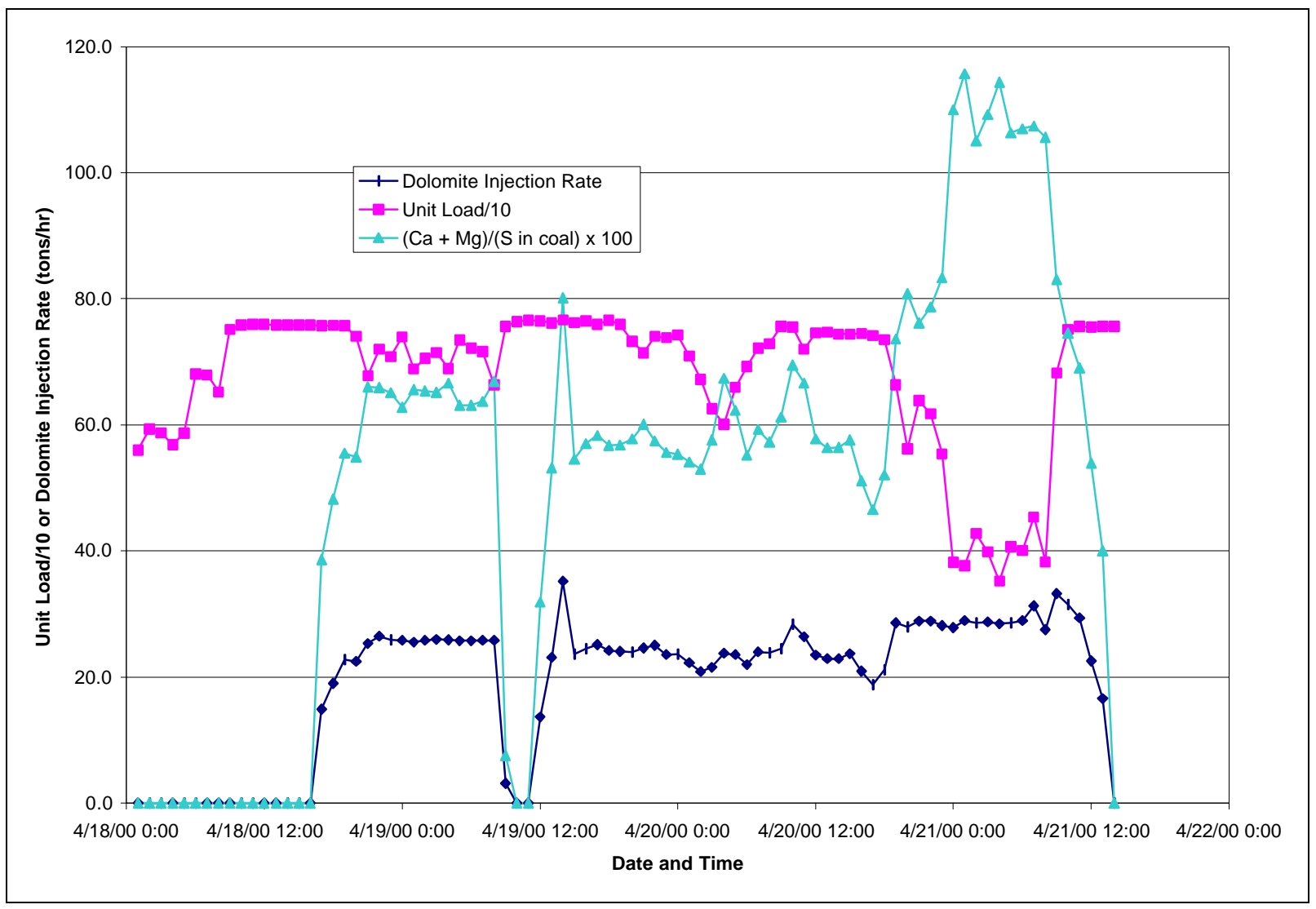

Figure 2-2

Boiler Load and Dolomite Injection Rate during the Test Period

Note: $1 \mathrm{ton} / \mathrm{hr}=909 \mathrm{~kg} / \mathrm{hr}$.

\section{Alkaline Reagent Slurry Injection Tests on BMP Unit 3}

During the second through fourth short-term tests, alkaline slurry sorbents were injected into one half of the BMP Unit 3 boiler for up to two weeks each to assess their effectiveness for flue gas $\mathrm{SO}_{3}$ control.

Various analytical techniques were used to assess the effects of sorbent injection, similar to those used during the dolomite injection test conducted on Unit 2 as described above. These measurements primarily included sampling with the CCS method for determining flue gas $\mathrm{SO}_{3}$ content; other measurement and analytical techniques employed are described later in this section.

\section{Unit 3 Description}

Unit 3 is rated at 800 net MW. It has an opposed-wall fired, supercritical boiler rated at approximately $6,415,000$ pounds of steam per hour $(2,916,00 \mathrm{~kg} / \mathrm{hr})$ at $3785 \mathrm{psig}(26,100 \mathrm{kPa})$ and $1005 / 1005^{\circ} \mathrm{F}\left(541 / 541^{\circ} \mathrm{C}\right)$ superheat and reheat temperatures. Like Unit 2, the boiler has 16 burners each on the front and back walls of the furnace. The burners are arranged in four 
Table 2-1

Summary of Operating Conditions during Dolomite Injection Tests

\begin{tabular}{|c|c|c|c|c|}
\hline Date & $4 / 18 / 2000$ & $4 / 19 / 2000$ & $4 / 20 / 2000$ & $4 / 21 / 2000$ \\
\hline $\begin{array}{l}\text { Generator load, avg. } \\
\text { MW (gross) }\end{array}$ & 758 & 763 & 743 & 754 \\
\hline Steam flow, Klb/hr & 5480 & 5530 & 5400 & 5450 \\
\hline Burners out of service & $\begin{array}{l}\text { Elevations } \\
A \text { and } D\end{array}$ & $\begin{array}{l}\text { Elevations } \\
A \text { and } D\end{array}$ & $\begin{array}{l}\text { Elevations } \\
A \text { and } D\end{array}$ & $\begin{array}{l}\text { Elevations } \\
A \text { and } D\end{array}$ \\
\hline $\begin{array}{l}\text { Economizer outlet flue } \\
\text { gas } \mathrm{O}_{2} \text {, vol. \% (wet) }\end{array}$ & $3.3-4.1$ & 3.1 & 3.1 & 3.0 \\
\hline $\mathrm{NO}_{x}, \mathrm{lb} / \mathrm{MMBtu}$ & 0.34 & 0.31 & 0.33 & 0.35 \\
\hline Fuel flow, avg. Klb/hr & 608 & 634 & 602 & 622 \\
\hline $\begin{array}{l}\text { Dolomite flow, tons } \\
\text { per hour }\end{array}$ & $\begin{array}{l}0-26.5 \text { (dolomite } \\
\text { feed started } \\
\sim 1620 \mathrm{hr} \text { ) }\end{array}$ & $\begin{array}{l}23.1 \text { to } 35.2, \\
\text { avg. } 25.7\end{array}$ & $\begin{array}{l}18.8 \text { to } 28.4, \\
\text { avg. } 23.3\end{array}$ & $\begin{array}{l}16.6 \text { to } 33.2, \\
\text { avg. } 25.0\end{array}$ \\
\hline $\begin{array}{l}\text { Molar ratio, alkalinity } \\
\text { in dolomite injected to } \\
\text { sulfur in coal fired }\end{array}$ & 0.0 to 0.66 & $\begin{array}{l}0.53 \text { to } 0.80, \\
\text { avg. } 0.65\end{array}$ & $\begin{array}{l}0.47 \text { to } 0.69, \\
\text { avg. } 0.62\end{array}$ & $\begin{array}{l}0.40 \text { to } 0.83, \\
\text { avg. } 0.64\end{array}$ \\
\hline
\end{tabular}

Note: $1 \mathrm{Klb} / \mathrm{hr}=454 \mathrm{~kg} / \mathrm{hr} ; 1 \mathrm{lb} / \mathrm{MMBtu}=1.8 \times 10^{-3} \mathrm{~g} / \mathrm{kg}-\mathrm{cal} ; 1 \mathrm{ton} / \mathrm{hr}=909 \mathrm{~kg} / \mathrm{hr}$.

horizontal rows on each wall, with four burners per row. One ball mill pulverizer provides the pulverized fuel for each row. Depending on fuel quality and mill condition, full load can generally be achieved with six of the eight mills in operation (and thus six of eight rows of burners in service).

Unit 3 typically burns a coal blend, predominantly blends of a McElroy coal, similar to that described for Unit 2. The actual coal sulfur can vary over a range from 2.0 to $4.5 \%$. The facility also has permission to burn up to $20 \%$ of the fuel as petroleum coke. During the test periods on Unit 3, a standard coal blend averaging about $4 \%$ sulfur was typically fired, although during the byproduct magnesium hydroxide test a small amount of petroleum coke was reportedly blended with a lower sulfur coal for a portion of that test.

Unit 3 was brought into service in 1980. The 800-net-MW unit operates as a swing unit to meet the load demands of the grid. During most of the short-term tests, Unit 3 operated at 750 to 850 MW gross load during daylight hours and 550 to $650 \mathrm{MW}$ overnight. The boiler is equipped with two air heaters following the economizer section. The average flue gas temperature at the outlet of the air heaters is controlled to about $320^{\circ} \mathrm{F}\left(160^{\circ} \mathrm{C}\right)$ due to acid dew-point considerations.

Figure 2-3 illustrates the flue gas path for Unit 3, and notes the gas sampling locations used during this test. Flue gas from each of the two air heaters splits into two duct runs, each of which goes to an electrostatic precipitator (ESP) followed by an induced draft (ID) fan. There are no 


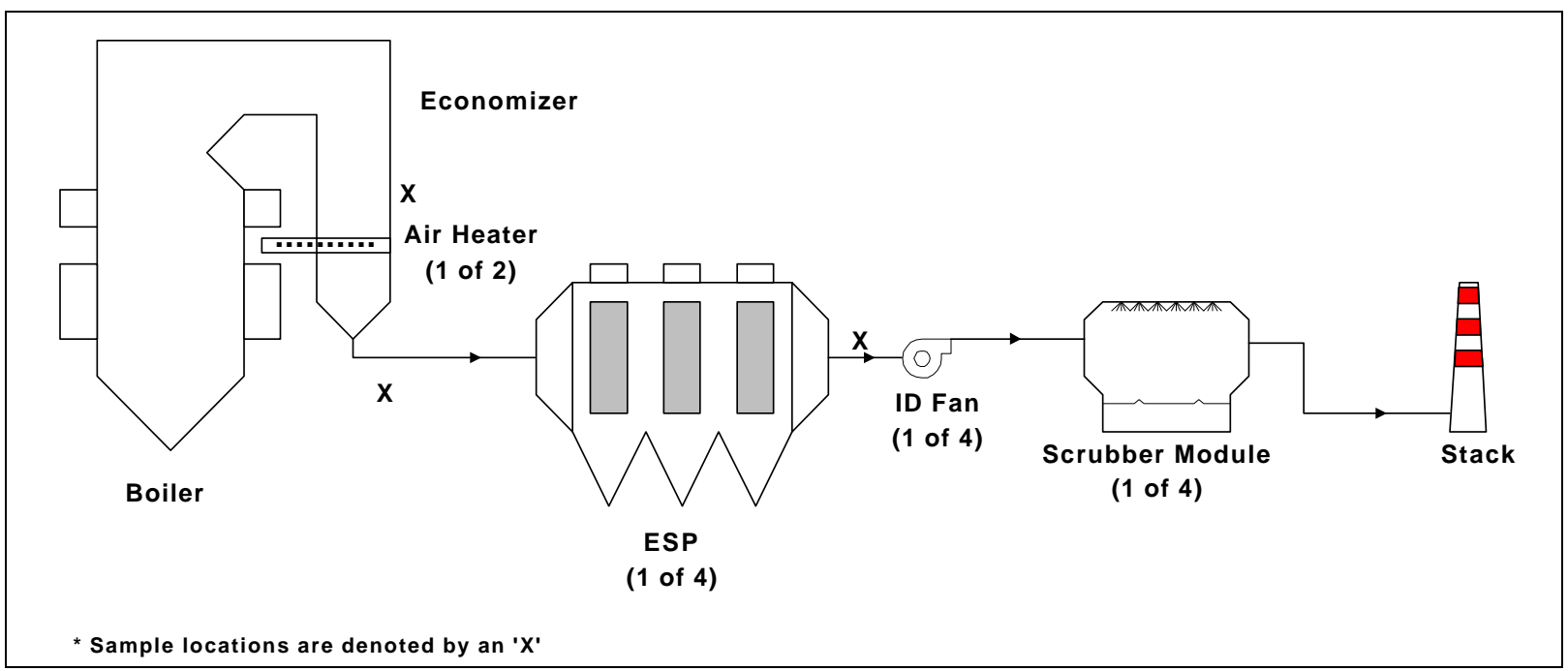

Figure 2-3

Illustration of Flue Gas Path for BMP Unit 3

ties between the four ducts (two per air heater) so when an ID fan is out of service, there is no gas flow through the associated air heater outlet duct and ESP. Correspondingly, the gas flow through the air heater on that side of the boiler is also reduced, although the plant tries to bias the ID fans to equalize the gas flow as much as possible. Downstream of the ID fans, the flue gas flows to a common plenum, then the gas flow splits to up to five horizontal-gas-flow, FGD system absorber modules (four normally operate at full load). The scrubbers use a magnesiumenhanced, Thiosorbic ${ }^{\circledR}$ lime slurry reagent. The flue gas in the stack is saturated at a temperature of about $130^{\circ} \mathrm{F}\left(54^{\circ} \mathrm{C}\right)$; no reheat is employed.

The three sorbent slurries tested included a pressure-hydrated dolomitic lime (PHDL) $\left[\mathrm{Ca}(\mathrm{OH})_{2} \bullet \mathrm{Mg}(\mathrm{OH})_{2}\right]$, a technical-grade magnesium hydroxide slurry from Martin Marietta (commercial $\mathrm{Mg}$ ), and a byproduct magnesium hydroxide produced at Allegheny Energy's Pleasants Station (byproduct Mg). During these tests, injection of the sorbent slurries was accomplished through up to six air-atomizing nozzles inserted through inspection port openings on the front wall of half of the boiler. During the PHDL and commercial Mg test, the slurry was fed through ports located at the $11^{\text {th }}$ floor of the boiler structure, approximately across from the "nose" of the boiler. Midway through the third slurry injection test, the byproduct Mg test, the injection location was elevated to the $14^{\text {th }}$ floor of the boiler structure, across from the pendant secondary superheater tubes. The injection levels are illustrated in Figure 2-4.

At either level, the slurry injection lances were inserted through up to six upper furnace inspection ports on the east half of the boiler. At both the $11^{\text {th }}$ and $14^{\text {th }}$ floor, there are twelve observation ports across the face of the boiler. There is a port adjacent to each corner of the boiler along the front wall, then the remaining ports are situated on either side of five partial division walls that are equally spaced across the upper furnace cavity. Figure 2-5 illustrates the six lance locations on the east half of the boiler. Note that on the $14^{\text {th }}$ floor, lance location No. 5 was blocked by a camera installed at that inspection port. When injecting at the $14^{\text {th }}$ floor, the slurry flow that would normally have been split among six nozzles was instead fed to only five. 


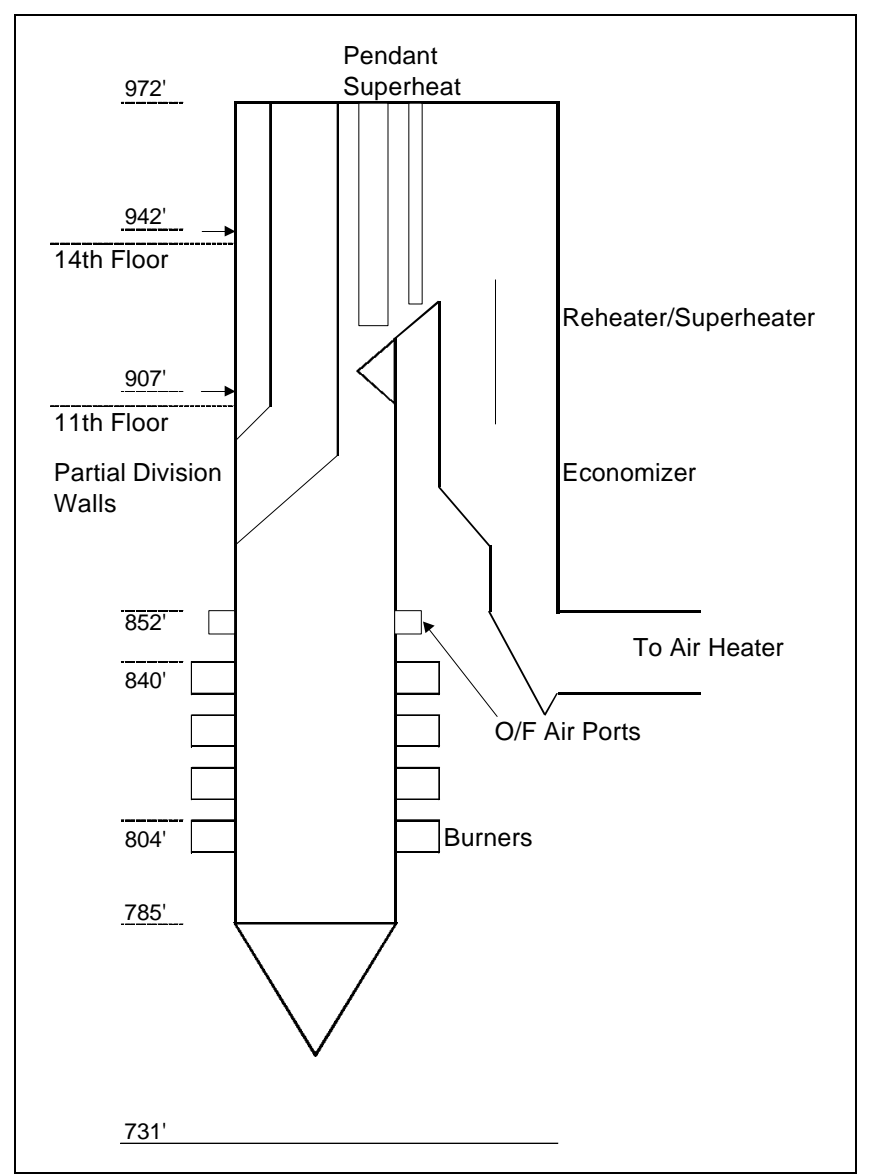

Figure 2-4

Illustration of Slurry Injection Levels

Note: $1 \mathrm{ft}=0.305 \mathrm{~m}$.

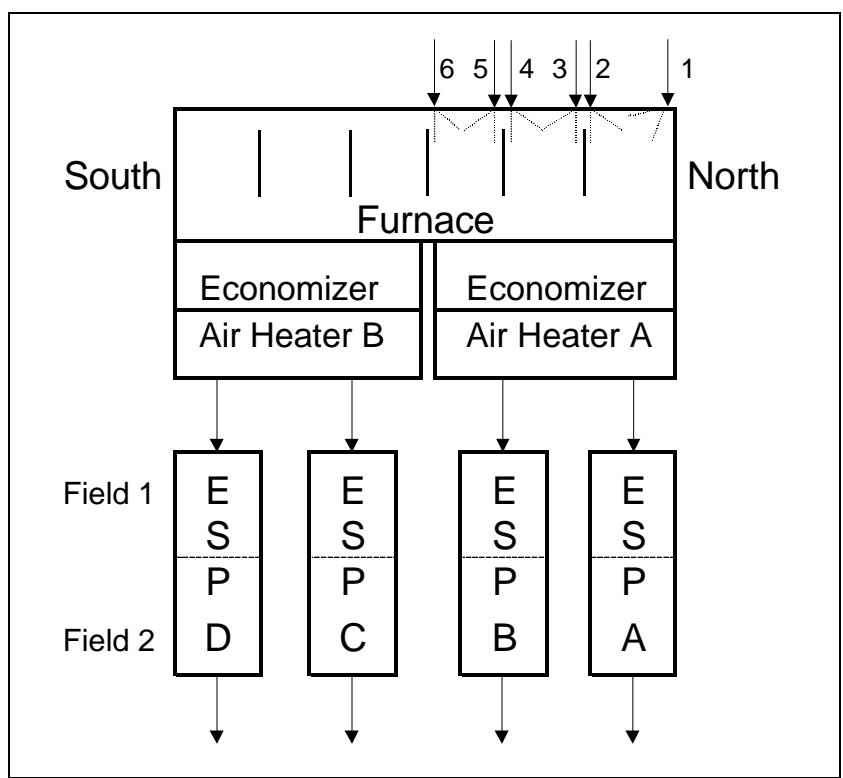

Figure 2-5

Illustration of Slurry Injection Locations - Plan View 
The air-atomizing nozzles were designed by Ashworth Engineering specifically for this application. The proprietary design employs an internal mix configuration, and was designed for relatively low airflow requirements and to achieve a relatively large minimum passage diameter. The air pressure to the nozzles was typically $80 \mathrm{psig}(550 \mathrm{kPa})$, although in some testing the pressure was varied to quantify its effect on $\mathrm{SO}_{3}$ control performance.

The sorbents injected into the furnace were delivered to the site in truckload quantities, as slurries containing 15 to $60 \mathrm{wt} \%$ solids, depending on the reagent. Two 11,000-gallon $\left(41 \mathrm{~m}^{3}\right)$ slurry storage tanks were situated in the basement of Unit 3 . The tanker trucks unloaded into one or both of these tanks. Between the two tanks, approximately four to five truckloads could be stored on site. From the storage tanks, one of two air-driven diaphragm pumps was used to transfer slurry up to a 1000-gallon $\left(3.8 \mathrm{~m}^{3}\right)$ "day" tank located on the $9^{\text {th }}$ floor of the boiler house. The day tank level was controlled by a signal from an ultrasonic level indicator on the day tank. Relays controlled by this signal energized (opened) a solenoid valve on the air supply to the transfer pump on low day tank level, and closed the solenoid valve on high level.

From the day tank, one or two Moyno progressing cavity pumps were used to feed slurry to the injection nozzles. The Moyno pumps were equipped with magnetic flow meters at their discharge, and pump speed was modulated to maintain slurry flow rate at a set point. The slurry flow rate set point was adjusted according to the density and purity of the reagent, the Unit 3 load, the expected Unit 3 coal sulfur content, and the desired reagent-to- $\mathrm{SO}_{3}$ molar ratio. Slurry from the Moyno pumps was fed to a manifold, which in turn distributed slurry to the five or six operating injection nozzles. Plant compressed air was connected to each lance individually, through flexible hoses, to provide the source of atomizing air.

Also illustrated in Figure 2-5 is the arrangement of the four ESPs relative to the two air heaters. Note that, because of the direction of rotation of the regenerative-type air heaters, the flue gas going to the outboard ESPs (labeled "A" and "D" in Figure 2-5) tends to be cooler and have a lower $\mathrm{SO}_{3}$ content than the flue gas going to the inboard ESPs (labeled "B" and "C"). However, no attempt was made to bias the sorbent slurry flow to the nozzles on the inboard side of the east air heater to account for this observed stratification. It was felt that the stratification was caused by the drop in gas temperature across the air heater, and was not reflective of stratification in flue gas $\mathrm{SO}_{3}$ content in the furnace, where the sorbent was injected.

\section{Unit 3 Operating Conditions}

Testing was conducted on Unit 3 during four discrete time periods. Baseline (no sorbent injection) measurements were conducted on October 3 through 6, 2000. PHDL testing was conducted October 17 through November 1, commercial Mg testing was conducted November 28 through December 8, and byproduct Mg testing was conducted February 13 through February 22, 2001. Unit 3 operating conditions during these test periods are summarized in Table 2-2.

The times listed in the table are periods when flue gas characterization testing was conducted on Unit 3. Flue gas $\mathrm{SO}_{3}$ concentrations by the CCS method were the primary measure of sorbent performance. Flue gas characterization tests were typically conducted during daytime hours each test day, although there were periods during the PHDL and commercial Mg tests where sampling 
Table 2-2

Unit 3 Operating Conditions during Baseline and Short-term Slurry Injection Tests

\begin{tabular}{|c|c|c|c|c|c|}
\hline Date & $\begin{array}{l}\text { Time Period } \\
\text { for Testing }\end{array}$ & $\begin{array}{l}\text { Average Unit } \\
\text { Load } \\
\text { (gross MW) }\end{array}$ & $\begin{array}{c}\text { Average } \\
\text { Economizer } \\
\text { Exit } \mathrm{O}_{2}(\%)\end{array}$ & $\begin{array}{l}\text { Coal Mills Out } \\
\text { of Service }\end{array}$ & $\begin{array}{l}\text { ID Fans Out } \\
\text { of Service }\end{array}$ \\
\hline \multicolumn{6}{|c|}{ Baseline Testing } \\
\hline $10 / 3 / 00$ & 15:00-19:00 & 782 & 3.3 & D & $N A^{*}$ \\
\hline $10 / 4 / 00$ & $10: 00-17: 00$ & 788 & 3.3 & D & NA \\
\hline $10 / 5 / 00$ & $10: 00-16: 00$ & 796 & 3.2 & D & NA \\
\hline $10 / 6 / 00$ & 10:00-15:00 & 851 & 3.2 & D & NA \\
\hline \multicolumn{6}{|c|}{ PHDL Testing } \\
\hline $10 / 17 / 00$ & 13:00-18:00 & NA & NA & NA & NA \\
\hline $10 / 18 / 00$ & 09:00-13:00 & 798 & 3.4 & $\mathrm{D}, \mathrm{F}$ & NA \\
\hline 10/20/00 & 10:00-16:00 & 791 & 3.3 & $D, F$ & NA \\
\hline $10 / 23 / 00$ & $11: 00-17: 00$ & NA & NA & NA & NA \\
\hline $10 / 24 / 00$ & 09:00-17:00 & 825 & 3.5 & $\mathrm{D}$ & NA \\
\hline $10 / 25 / 00$ & 09:00-11:00 & 870 & 3.6 & D & NA \\
\hline 10/26/00 & 02:00-05:00 & 560 & 5.0 & $A, D, F$ & NA \\
\hline $11 / 1 / 00$ & 01:00-05:00 & 631 & 4.5 & A, D & NA \\
\hline \multicolumn{6}{|c|}{ Commercial Mg Testing } \\
\hline $11 / 28 / 00$ & 11:00-20:00 & 785 & 3.6 & $G$ & - \\
\hline $11 / 29 / 00$ & $11: 00-13: 00$ & 785 & 3.4 & $D, F$ & - \\
\hline $11 / 30 / 00$ & 01:00-04:00 & 549 & 4.9 & A, C, D & D \\
\hline $12 / 1 / 00$ & $10: 00-17: 00$ & 788 & 3.4 & $\mathrm{D}$ & D \\
\hline $12 / 4 / 00$ & $10: 00-16: 00$ & 757 & 3.7 & - & D \\
\hline $12 / 5 / 00$ & 10:00-16:00 & 826 & 3.7 & $\mathrm{D}$ & - \\
\hline $12 / 6 / 00$ & 09:00-15:00 & 813 & 4.1 & D & - \\
\hline $12 / 7 / 00$ & $11: 00-18: 00$ & 785 & 3.2 & D & - \\
\hline
\end{tabular}


Table 2-2

Unit 3 Operating Conditions during Baseline and Short-term Slurry Injection Tests (continued)

\begin{tabular}{|l|l|l|l|l|l|}
\hline \multicolumn{1}{|c|}{ Date } & \multicolumn{1}{|c|}{$\begin{array}{c}\text { Time Period } \\
\text { for Testing }\end{array}$} & $\begin{array}{c}\text { Average Unit } \\
\text { Load } \\
\text { (gross MW) }\end{array}$ & $\begin{array}{c}\text { Average } \\
\text { Economizer } \\
\text { Exit } \text { O }_{2}(\%)\end{array}$ & $\begin{array}{c}\text { Coal Mills Out } \\
\text { of Service }\end{array}$ & $\begin{array}{c}\text { ID Fans Out } \\
\text { of Service }\end{array}$ \\
\hline $12 / 8 / 00$ & $09: 00-11: 00$ & 816 & 3.1 & H & - \\
\hline Byproduct Mg Testing & $09: 00-15: 00$ & 726 & 4.6 & A, C, D & NA \\
\hline $2 / 13 / 01$ & $07: 00-16: 00$ & 669 & 4.2 & A, D & C, A \\
\hline $2 / 14 / 01$ & $09: 00-15: 00$ & 766 & 4.6 & A, D & A \\
\hline $2 / 15 / 01$ & $09: 00-15: 00$ & 773 & 4.2 & D & A \\
\hline $2 / 16 / 01$ & $09: 00-16: 00$ & 807 & 3.8 & D & - \\
\hline $2 / 19 / 01$ & $09: 00-12: 00$ & 802 & 4.0 & D & - \\
\hline $2 / 20 / 01$ & $09: 00-13: 00$ & 791 & 4.0 & D & - \\
\hline $2 / 21 / 01$ & $09: 00-13: 00$ & 800 & 4.6 & A, D & - \\
\hline $2 / 22 / 01$ & & & & & \\
\hline
\end{tabular}

*NA - data not available.

was conducted very early in the morning, between 1:00 a.m. and 5:00 a.m. These early morning tests were conducted for two reasons: 1). Testing overnight while the unit was at low load allowed testing at higher sorbent-to- $\mathrm{SO}_{3}$ mole ratios than could be achieved at full load, and 2). Testing at low load presumably lowered furnace temperatures at the point where sorbent was injected. This effect is discussed further in Section 4.

During most flue gas testing, the steam generator was at close to full load with one to two pulverizers and burner rows out of service. Most frequently, the " $D$ " pulverizer was out of service, which correspondingly takes the top row of burners on the back side of the furnace out of service. Average loads during daytime test periods were typically in the range of 800 gross $\mathrm{MW} \pm 50 \mathrm{MW}$. One exception was during the first week of the byproduct $\mathrm{Mg}$ test, when coal quality and slagging concerns caused the unit load to be limited to around 700 gross MW \pm 50 MW. Overnight the boiler load was often reduced. In most cases overnight loads were reduced into the range of 550 gross MW to 650 gross MW, although in some instances the load remained above $700 \mathrm{MW}$ overnight due to grid demand. During sorbent injection tests the sorbent injection rate was typically reduced in direct proportion to unit load. An exception was during the overnight flue gas testing periods, when the sorbent injection rates were maintained at maximum rates achievable to allow operation at high sorbent-to- $\mathrm{SO}_{3}$ mole ratios. 


\section{Test Measurement Methods}

This section describes the test methods used to evaluate sorbent injection impacts. The first subsection describes flue gas measurements, and the second describes slurry and solid sample measurements.

\section{Flue Gas Measurements}

\section{$\mathrm{H}_{2} \mathrm{SO}_{4}$ Vapor by Controlled Condensation}

Sulfuric acid vapor concentrations were measured at the economizer outlet using the CCS method. A diagram of this sulfuric acid vapor train is shown in Figure 2-6. Controlled condensation is generally regarded as the most accurate method for measuring sulfuric acid vapor concentrations in flue gas, particularly where the flue gas is above the acid dew point. For these units, this would include flue gas temperatures above about $280^{\circ} \mathrm{F}\left(138^{\circ} \mathrm{C}\right)$, or all locations upstream of the FGD system.

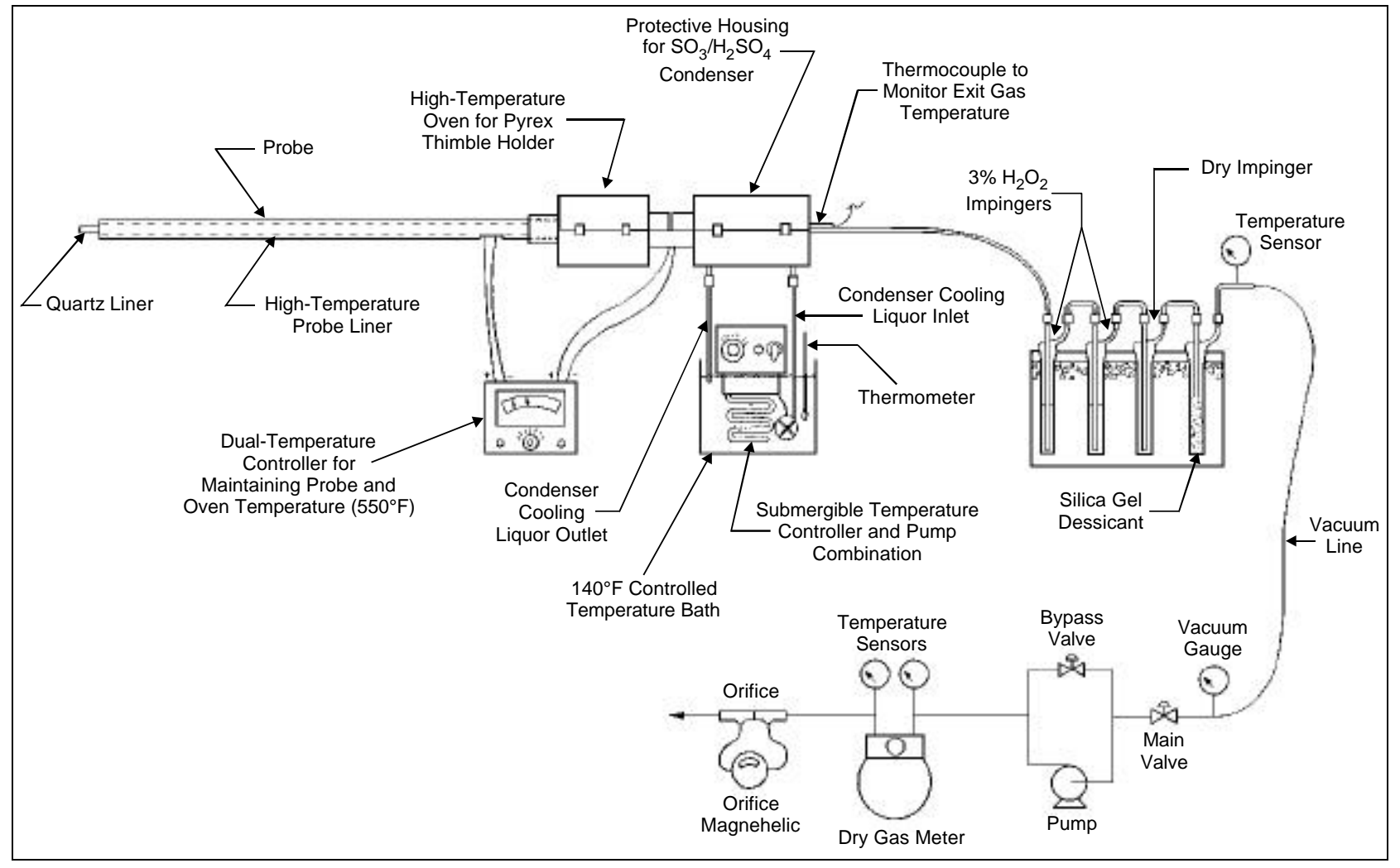

Figure 2-6

Controlled Condensation Sulfuric Acid Vapor Train

Note: $550^{\circ} \mathrm{F}=288^{\circ} \mathrm{C}$. 
In the CCS method, a sample of flue gas is pulled from the duct through a heated, quartz-lined probe. Particulate material is removed from the sample using a quartz thimble filter. Both the probe and the filter are maintained at about $550^{\circ} \mathrm{F}\left(288^{\circ} \mathrm{C}\right)$ to ensure that no sulfuric acid vapor condenses in this part of the sampling system. Next, the filtered flue gas sample passes to a glass condenser that is maintained at a temperature of about $150^{\circ} \mathrm{F}\left(66^{\circ} \mathrm{C}\right)$ by a circulating water bath. This temperature is well below the acid dew point but above the water dew point. The only material in most flue gases that will condense at this temperature is sulfuric acid vapor. Other acid gases have dew points that are much nearer the water dew point. At the completion of a CCS run, the condenser is removed from the sampling system, and a rinse of the condenser is analyzed for sulfate content. By measuring the total volume of flue gas pulled through the system and the amount of sulfate in the condenser, the concentration of $\mathrm{H}_{2} \mathrm{SO}_{4}$ vapor in the flue gas can be calculated.

\section{Acid Dew Point}

During some tests, measurements were made using either an in-situ or a portable acid dew-point meter manufactured by Land Combustion, or both, to determine the acid dew point. These measurements were made at the inlet ducts to the ESPs or wet scrubbers, where the flue gas temperature is in the range of 280 to $340^{\circ} \mathrm{F}\left(138\right.$ to $\left.171^{\circ} \mathrm{C}\right)$. The acid dew-point measurement can be used to estimate the flue gas content of sulfuric acid. There are several relationships correlating acid dew point to flue gas sulfuric acid concentration, such as those by Verhoff and Banchero. ${ }^{1}$ Acid dew-point correlations from different sources are not always in agreement, often yielding results considerably different, especially at high dew points and/or high sulfuric acid concentrations. Acid dew-point measurements were used primarily as an indicator of sorbent effectiveness, but not directly to quantify performance.

\section{Method 26a—Hydrogen Halide and Halogen Emissions (chloride and fluoride)}

Method 26a is the reference EPA test method for determining hydrogen halide and halogen emissions-hydrochloric and hydrofluoric acids, chlorine and fluorine. This method requires isokinetic sample extraction with an apparatus similar to that used in EPA Method 5. An illustration of the Method 26a train is shown in Figure 2-7. Method 26a is different from Method 5 in that it includes an impinger containing sulfuric acid and an impinger containing sodium hydroxide. With the Method 26a sampling train, a flue gas sample is extracted isokinetically, passes through a heated probe and through a particulate filter contained in a heated oven. Following the particulate filter, the gas sample passes through the impinger train where moisture is removed in the first impinger, hydrogen halides $(\mathrm{HCl}$ and $\mathrm{HF})$ are dissolved in the second impinger which contains sulfuric acid, and halogens $\left(\mathrm{Cl}_{2}\right.$ and $\left.\mathrm{F}_{2}\right)$ are dissolved in the third impinger which contains sodium hydroxide. The samples collected are analyzed by ion chromatography (IC) or ion specific electrode.

\footnotetext{
${ }^{1}$ Pierce, Robert R., "Estimating Acid Dewpoints in Stack Gases," Chemical Engineering, April 11, 1977, pp 125128.
} 


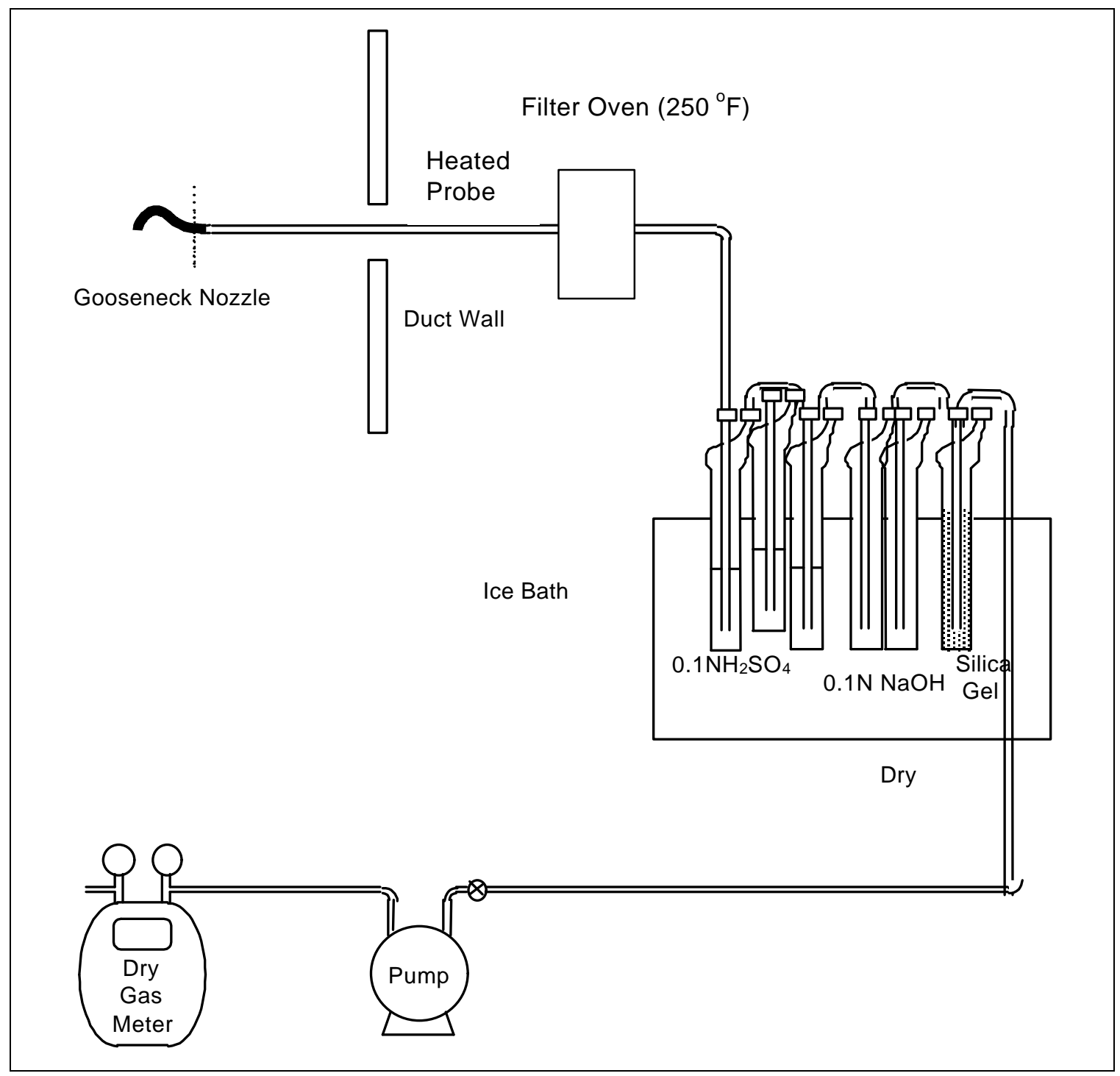

Figure 2-7

EPA Method 5/Method 26a Sampling Train

Note: $250^{\circ} \mathrm{F}=121^{\circ} \mathrm{C}$.

The Method 26a measurements were made only for the dolomite injection test on Unit 2; for the slurry injection tests, it was decided to wait and conduct these measurements during the later long-term tests, if one or more of the slurry sorbents was selected for long-term testing.

\section{Solid and Slurry Sample Analyses}

\section{Economizer Ash}

Economizer ash hopper samples were analyzed by the loss-on-ignition (LOI) method, which is typically used as an indicator of carbon content in the ash. Samples of ash were obtained from the economizer ash hoppers during each test and later analyzed for LOI using American Society 
for Testing and Materials procedures. With the LOI method a sample of ash is weighed then incinerated and weighed again. The loss in weight is intended to provide an indication of the amount of combustible material in the ash. However, the method is not specific in that any compound that dissociates at high temperature could lose weight during this procedure (e.g., calcium hydroxide).

LOI analyses were conducted on economizer ash samples only from the dolomite injection tests conducted on BMP Unit 2. The smaller quantities of slurry sorbents injected into the upper furnace on BMP Unit 3 were not expected to impact ash carbon content.

\section{Fly Ash Samples}

Fly ash samples were collected from the Unit 3 ESP hoppers (fly ash is removed in the wet scrubbers on Unit 2) and analyzed for acid-soluble magnesium content (predominantly magnesium from injected sorbent rather than magnesium in the coal ash). Magnesium analyses were conducted by atomic absorption. Some fly ash samples were also analyzed for acid-soluble sulfate content, by ion chromatography.

The magnesium content analyses were used to determine how uniformly the reagents were distributed among the ESP hoppers, and to conduct cursory material balance calculations to ensure that the amounts of reagents injected could be accounted for in the ESP fly ash catch.

\section{Reagent Slurry Samples}

Reagent slurries were analyzed for specific gravity and weight percent solids content (gravimetric determination), magnesium and/or calcium content (atomic absorption), and total alkalinity (acid-base titration). The results of these analyses were used to determine the amount of alkaline reagent (calcium hydroxide and/or magnesium hydroxide) present in the slurries injected into the furnace. The byproduct magnesium hydroxide also contains about 30 weight percent gypsum $\left(\mathrm{CaSO}_{4} \cdot 2 \mathrm{H}_{2} \mathrm{O}\right)$ as an impurity, so a number of these samples were also analyzed for sulfate content, by ion chromatography.

\section{Unit 2 FGD Recycle Slurry Analyses}

For the dolomite injection test conducted on Unit 2, it was expected that all of the dolomite injected was collected in the FGD system, which is used for combined particulate and $\mathrm{SO}_{2}$ control. Prior to and during the dolomite injection tests, representative samples of FGD recycle slurry and preserved liquors were collected and analyzed for a variety of species, in an attempt to quantify the impacts of the dolomite injected in the furnace on the FGD system. These slurries and liquors were analyzed for weight percent solids (gravimetric determination, on slurry samples only), calcium and magnesium (atomic absorption), chloride and total sulfate (ion chromatography), sulfite (iodometric titration), and carbonate (coulometry). 


\section{3 \\ RESULTS OF DOLOMITE POWDER INJECTION TEST}

The first short-term test investigated the effect of injecting dry dolomite powder $\left(\mathrm{CaCO}_{3} \cdot \mathrm{MgCO}_{3}\right)$, a mineral similar to limestone, into the furnace of Unit 2 . The results of this test are presented and discussed in this section. The other three short-term were conducted on BMP Unit 3, to investigate the effectiveness of alkaline sorbent slurries for sulfuric acid control. Results from the three slurry injection tests are included in Section 4.

Results from the four-day dolomite injection test are presented and discussed below. First, results of fuel analyses are presented, then the impact of dolomite injection on measured sulfuric acid concentrations, as measured by CCS and by the acid dew-point meter, is discussed. Next, the hydrogen halide and halogen emissions, as determined by Method 26a measurements, are discussed, followed by a discussion of the operation of the steam generating unit itself, including ash LOI and observations of slag deposition during the test. Finally, the observed impacts of the injected sorbent on the downstream FGD system are also discussed.

\section{Fuel Analyses}

Fuel samples were collected during each day of testing, and were submitted to Commercial Testing and Engineering for a variety of analyses. The results of the analyses are contained in Table 3-1 and, for the most part, show consistency between the properties of the samples analyzed. The most notable difference in the ultimate constituents between the samples was the sulfur content, which varied by as much as $0.47 \%$ over the four-day period. The higher heating value varied by almost $400 \mathrm{Btu} / \mathrm{lb}(220 \mathrm{~kg}-\mathrm{cal} / \mathrm{kg})$, or by about $3 \%$ among the samples. These differences in ultimate constituents and heating value are not considered significant. The average coal content of the four samples was used for sorbent mole ratio calculations for the test period.

The trace constituents determined were chlorine, fluorine, and arsenic. The fluorine and arsenic contents of the two samples analyzed were fairly consistent. However, chlorine content was analyzed for all four samples, and the content of the April 18 sample was reported as $1050 \mathrm{ppm}$ while the chlorine content of other samples ranged from approximately 600 to $700 \mathrm{ppm}$. This difference is substantial. It should be noted, however, that the authors have previously seen a wide range of variability in results of coal chlorine content analyses conducted by commercial coal laboratories. It is suspected that the chlorine content of the sample from April 18 is erroneously high. 
Table 3-1

Fuel Analyses (as received basis, except as noted)

\begin{tabular}{|c|c|c|c|c|c|}
\hline Sample Date & $4 / 18 / 2000$ & 4/19/2000 & $4 / 20 / 2000$ & $4 / 21 / 2000$ & Average \\
\hline \multicolumn{6}{|l|}{ Ultimate Analysis, wt\% } \\
\hline Carbon & 65.59 & 67.41 & 66.97 & 67.24 & 66.80 \\
\hline Hydrogen & 4.36 & 4.61 & 4.56 & 4.45 & 4.50 \\
\hline Nitrogen & 1.11 & 1.15 & 1.14 & 1.11 & 1.13 \\
\hline Sulfur & 3.97 & 3.92 & 4.39 & 4.28 & 4.14 \\
\hline Oxygen (by difference) & 4.82 & 5.02 & 4.72 & 3.62 & 4.54 \\
\hline Moisture & 6.63 & 4.74 & 5.29 & 5.79 & 5.61 \\
\hline Ash & 13.52 & 13.15 & 12.93 & 13.51 & 13.28 \\
\hline Total & 100.00 & 100.00 & 100.00 & 100.00 & 100.00 \\
\hline \multicolumn{6}{|l|}{ Proximate Analysis, wt\% } \\
\hline Moisture & 6.63 & 4.74 & 5.29 & 5.79 & 5.61 \\
\hline Ash & 13.52 & 13.15 & 12.93 & 13.51 & 13.28 \\
\hline Volatile & 34.41 & 36.46 & 35.75 & 36.24 & 35.72 \\
\hline Fixed carbon & 45.44 & 45.65 & 46.03 & 44.46 & 45.39 \\
\hline Total & 100.00 & 100.00 & 100.00 & 100.00 & 100.00 \\
\hline $\mathrm{HHV}$ (Btu/lb) [kg-cal/kg] & $\begin{array}{l}11602 \\
{[6445]}\end{array}$ & $\begin{array}{l}11870 \\
{[6594]}\end{array}$ & $\begin{array}{l}11861 \\
{[6589]}\end{array}$ & $\begin{array}{l}11984 \\
{[6657]}\end{array}$ & $\begin{array}{l}11829 \\
{[6571]}\end{array}$ \\
\hline Chloride (ppm, dry basis) & 1050 & 571 & 694 & 590 & 726 \\
\hline Fluoride (ppm, dry basis) & 111 & - & - & 104 & 108 \\
\hline Arsenic (ppm, dry basis) & 8 & - & - & 10 & 9 \\
\hline
\end{tabular}

\section{$\mathrm{SO}_{3} /$ Sulfuric Acid Measurements}

Measurements of $\mathrm{SO}_{3}$ were made at the economizer exit in the east duct. During the test program, two CCS sampling systems were utilized: one sampling system being designated "sampling system ' 1 '” the other "sampling system 'a'." Sampling system " 1 " had its probe inserted in the fourth test penetration in the duct (counting east to west) and sampling system "a" had its probe inserted in the sixth test penetration. There are a total of 10 test penetrations across the duct, so both probes were inserted close to the middle of the duct. Sampling system "1" was utilized throughout the entire test program, while sampling system "a" was utilized during the 
final two days of testing. The purpose of using two sampling systems was to confirm the validity of the data by taking additional measurements (typically simultaneously) at an alternate location in the duct.

Acid dew-point measurements were made with a Land Combustion portable acid dew-point monitor. This device was used at the air heater exit/scrubber inlet location.

The flue gas $\mathrm{SO}_{3}$ concentrations calculated from CCS data are reported in Table 3-2. Note that there are two values reported for $\mathrm{SO}_{3}$ concentration by CCS in the table. The first represents the results from on-site titrations of aliquots of the condenser catch from each CCS run, while the second represents the results from off-site ion chromatograph (IC) analyses. The IC results are typically regarded as being more accurate, as the end point for the on-site titration is difficult to see. In most cases, the two values for a given CCS run are very close anyway. Also shown in the table are the results of acid dew-point measurements made by the Land instrument during the corresponding CCS runs, the equivalent sulfuric acid concentrations indicated by the acid dewpoint values, and the dolomite injection rate at the time the CCS run was made. The equivalent sulfuric acid concentration values shown are output values from the Land instrument.

The results of the $\mathrm{SO}_{3}$ and acid dew-point measurements indicate a significant reduction in flue gas $\mathrm{SO}_{3}$ concentration and acid dew point with the introduction of dolomite into the furnace. Based on the CCS measurements, the flue gas $\mathrm{SO}_{3}$ concentration dropped by over $60 \%$ (from approximately $52 \mathrm{ppm}$ to $19 \mathrm{ppm}$ ) within two hours of initiating dolomite injection. On the second day of testing, dolomite injection was interrupted for several hours. Despite this interruption, flue gas $\mathrm{SO}_{3}$ levels remained relatively low (15 ppm to $18 \mathrm{ppm}$ ), indicating a residual effect of previously injected dolomite. As discussed below, this apparent residual effect is most likely the result of dolomite products adhering to heat transfer surfaces and continuing to remove $\mathrm{SO}_{3}$ from the flue gas stream and/or reducing the amount of $\mathrm{SO}_{2}$ oxidized to $\mathrm{SO}_{3}$ in the furnace. As dolomite feed continued, $\mathrm{SO}_{3}$ removal as measured by both CCS and acid dew point improved, with measured concentrations dropping to as low as 2 to $4 \mathrm{ppm}$ at times of higher injection rates.

Figures 3-1 and 3-2 provide plots of the CCS data versus time during the week. The data plots show a downward trend in the CCS measurements over the first two days of dolomite injection. Over the last two test days, the measured $\mathrm{SO}_{3}$ concentrations (by sampling system 1) averaged 7 ppm and ranged from 2 to $12 \mathrm{ppm}$. Relative to the pre-injection average concentration of 52 ppm, this indicates an average of $86 \%$ reduction in economizer outlet $\mathrm{SO}_{3}$ concentrations. Over this period, the dolomite injection rate averaged about $25.7 \mathrm{tons} / \mathrm{hr}(23,400 \mathrm{~kg} / \mathrm{hr})$. At this rate, the dolomite injected represents about $8.8 \%$ of the coal feed rate. The alkalinity in the dolomite $(\mathrm{CaO}$ plus $\mathrm{MgO}$ ) represents about a 0.7:1 mole ratio compared to the sulfur in the coal fired, and about a 40:1 mole ratio compared to the amount of $\mathrm{SO}_{3}$ produced under baseline conditions (about $1.7 \%$ of the coal sulfur oxidized to the $\mathrm{SO}_{3}$ form). Note that on those last two days, during the periods when sulfuric acid concentration data were actually being measured, the dolomite alkalinity molar ratio to the coal sulfur was slightly lower, at about $0.62: 1$, due to the effects of higher unit load during the day. The latter value represents about a 36:1 alkalinity molar ratio compared to the amount of $\mathrm{SO}_{3}$ produced under baseline conditions. 
Results of Dolomite Powder Injection Test

Table 3-2

Results of CCS and Acid Dew-Point Meter Measurements

\begin{tabular}{|c|c|c|c|c|c|c|c|c|}
\hline Date & \multicolumn{8}{|c|}{$4 / 18 / 2000$} \\
\hline Dolomite Rate, Tons/hr & 0 & 0 & 0 & 0 & 0 & 0 & 22.8 & 22.5 \\
\hline Test Run - Sample Train 1 & 1 & 2 & 3 & 4 & 5 & 6 & 7 & 8 \\
\hline Time Start & $9: 41$ & $10: 23$ & 10:57 & $11: 38$ & $12: 14$ & $14: 21$ & 18:15 & $18: 53$ \\
\hline Time End & $10: 16$ & $10: 51$ & 11:29 & 12:09 & $12: 46$ & $14: 51$ & 18:50 & 19:23 \\
\hline $\mathrm{SO}_{3}$ by Titration, ppm & 47.3 & 54.8 & 52.5 & 53.4 & 33.0 & 51.4 & 18.3 & 16.8 \\
\hline $\mathrm{SO}_{3}$ by $\mathrm{IC}, \mathrm{ppm}$ & 50.5 & 58.5 & 55.5 & 57.3 & 34.8 & 55.6 & 19.3 & 17.7 \\
\hline Avg. Acid Dew Point, ${ }^{\circ} \mathrm{F}\left({ }^{\circ} \mathrm{C}\right)$ & $\begin{array}{l}299 \\
(148)\end{array}$ & $\begin{array}{l}300 \\
(149)\end{array}$ & $\begin{array}{l}300 \\
(149)\end{array}$ & $\begin{array}{l}300 \\
(149)\end{array}$ & NA & $\begin{array}{l}300 \\
(149)\end{array}$ & $\begin{array}{l}284 \\
(140)\end{array}$ & $\begin{array}{l}280 \\
(138)\end{array}$ \\
\hline $\mathrm{SO}_{3}$ Equivalent, ppm & 42 & 40 & 42 & 42 & NA & 43 & 18 & 16 \\
\hline Date & \multicolumn{8}{|c|}{$4 / 19 / 2000$} \\
\hline Dolomite Rate, Tons/hr & 0 & 0 & 13.7 & 23.6 & 24.2 & 24.5 & 24.2 & 24.1 \\
\hline Test Run - Sample Train 1 & 1 & 2 & 3 & 4 & 5 & 6 & 7 & 8 \\
\hline Time Start & 9:30 & 10:05 & 10:40 & 14:11 & $14: 50$ & $15: 23$ & 17:14 & $17: 48$ \\
\hline Time End & 10:00 & $10: 35$ & $11: 15$ & $14: 45$ & $15: 20$ & $15: 56$ & $17: 44$ & $18: 18$ \\
\hline $\mathrm{SO}_{3}$ by Titration, ppm & 14.3 & 17.1 & 16.4 & 9.5 & 12.4 & 15.5 & 9.0 & 15.3 \\
\hline $\mathrm{SO}_{3}$ by $\mathrm{IC}, \mathrm{ppm}$ & 15.1 & 18.2 & 17.6 & 10.1 & 13.0 & 16.3 & 9.4 & 15.8 \\
\hline Avg. Acid Dew Point, ${ }^{\circ} \mathrm{F}\left({ }^{\circ} \mathrm{C}\right)$ & $\begin{array}{l}269 \\
(132)\end{array}$ & NA & NA & $\begin{array}{l}271 \\
(133)\end{array}$ & $\begin{array}{l}273 \\
(134)\end{array}$ & NA & NA & NA \\
\hline $\mathrm{SO}_{3}$ Equivalent, ppm & 8 & NA & NA & 8.8 & 9.6 & NA & NA & NA \\
\hline Date & \multicolumn{8}{|c|}{ 4/20/00 } \\
\hline Dolomite Rate, Tons/hr & 27.4 & 26.4 & 23.5 & 22.9 & 22.9 & 23.4 & 21.2 & 21.2 \\
\hline Test Run - Sample Train 1 (or a) & 1 & 2 & 3 & & 4 & 5 & (1a) & $(2 a)$ \\
\hline Time Start & 9:45 & 10:25 & 11:10 & 12:00 & 13:10 & 13:50 & 17:02 & $17: 28$ \\
\hline Time End & 10:15 & 10:55 & 11:40 & 13:00 & $13: 40$ & $14: 20$ & 17:22 & 17:57 \\
\hline $\mathrm{SO}_{3}$ by Titration, ppm & 2.3 & 2.1 & 2.0 & NA & 10.5 & 8.0 & 3.2 & 20.0 \\
\hline $\mathrm{SO}_{3}$ by IC, $\mathrm{ppm}$ & 2.5 & 2.7 & 1.6 & NA & 11.7 & 9.4 & 3.5 & 21.2 \\
\hline
\end{tabular}


Table 3-2

Results of CCS and Acid Dew-Point Meter Measurements (continued)

\begin{tabular}{|c|c|c|c|c|c|c|c|c|}
\hline \multirow{2}{*}{\begin{tabular}{|c|} 
Date \\
Avg. Acid Dew Point, ${ }^{\circ} \mathrm{F}\left({ }^{\circ} \mathrm{C}\right)$
\end{tabular}} & \multicolumn{8}{|c|}{$4 / 18 / 2000$} \\
\hline & $\begin{array}{l}259 \\
(126)\end{array}$ & $\begin{array}{l}261 \\
(127)\end{array}$ & $\begin{array}{l}273 \\
(134)\end{array}$ & $\begin{array}{l}273 \\
(134)\end{array}$ & $\begin{array}{l}276 \\
(136)\end{array}$ & $\begin{array}{l}278 \\
(137)\end{array}$ & NA & NA \\
\hline $\mathrm{SO}_{3}$ Equivalent, ppm & 4.8 & 5.0 & 9.6 & 9.6 & 11 & 12 & NA & NA \\
\hline Date & \multicolumn{8}{|c|}{$4 / 21 / 2000$} \\
\hline Dolomite Rate, Tons/hr & 33.2 & 31.5 & 29.4 & 29.4 & 22.5 & 16.6 & 16.6 & - \\
\hline Test Run Sample Train 1 & 1 & 2 & 3 & 4 & 5 & 6 & 7 & - \\
\hline Time Start & $8: 30$ & $9: 12$ & $9: 55$ & $10: 35$ & $11: 12$ & 11:55 & $12: 35$ & - \\
\hline Time End & 9:00 & $9: 42$ & $10: 25$ & 11:05 & $11: 52$ & $12: 25$ & 13:05 & - \\
\hline $\mathrm{SO}_{3}$ by Titration, ppm & 6.1 & 3.5 & 11.1 & 9.8 & 5.6 & 7.2 & 10.5 & - \\
\hline $\mathrm{SO}_{3}$ by IC, $\mathrm{ppm}$ & 7.0 & 3.7 & 12.3 & 10.7 & 6.2 & 8.2 & 11.7 & - \\
\hline Test Run Sample Train a & $1 a$ & $2 a$ & $3 a$ & $4 a$ & $5 a$ & $6 a$ & $7 a$ & - \\
\hline Time Start & $8: 40$ & $9: 22$ & 10:05 & $10: 45$ & $11: 25$ & 12:05 & $12: 45$ & - \\
\hline Time End & $9: 10$ & $9: 52$ & $10: 35$ & 11:15 & $11: 55$ & $12: 35$ & 13:15 & - \\
\hline $\mathrm{SO}_{3}$ by Titration, ppm & 5.2 & 7.9 & 9.1 & 7.2 & 2.9 & 5.7 & 12.5 & - \\
\hline $\mathrm{SO}_{3}$ by $\mathrm{IC}, \mathrm{ppm}$ & 6.2 & 8.9 & 10.1 & 8.2 & 3.1 & 6.1 & 13.3 & - \\
\hline Avg. Acid Dew Point, ${ }^{\circ} \mathrm{F}\left({ }^{\circ} \mathrm{C}\right)$ & $\begin{array}{l}253 \\
(123)\end{array}$ & $\begin{array}{l}258 \\
(126)\end{array}$ & $\begin{array}{l}259 \\
(126)\end{array}$ & $\begin{array}{l}267 \\
(131)\end{array}$ & $\begin{array}{l}265 \\
(129)\end{array}$ & $\begin{array}{l}271 \\
(133)\end{array}$ & $\begin{array}{l}277 \\
(136)\end{array}$ & - \\
\hline $\mathrm{SO}_{3}$ Equivalent, ppm & 3.5 & 4.4 & 4.5 & 7.5 & 6.3 & 8.7 & 12 & - \\
\hline
\end{tabular}

Note: $1 \mathrm{ton} / \mathrm{hr}=909 \mathrm{~kg} / \mathrm{hr}$. 
Results of Dolomite Powder Injection Test

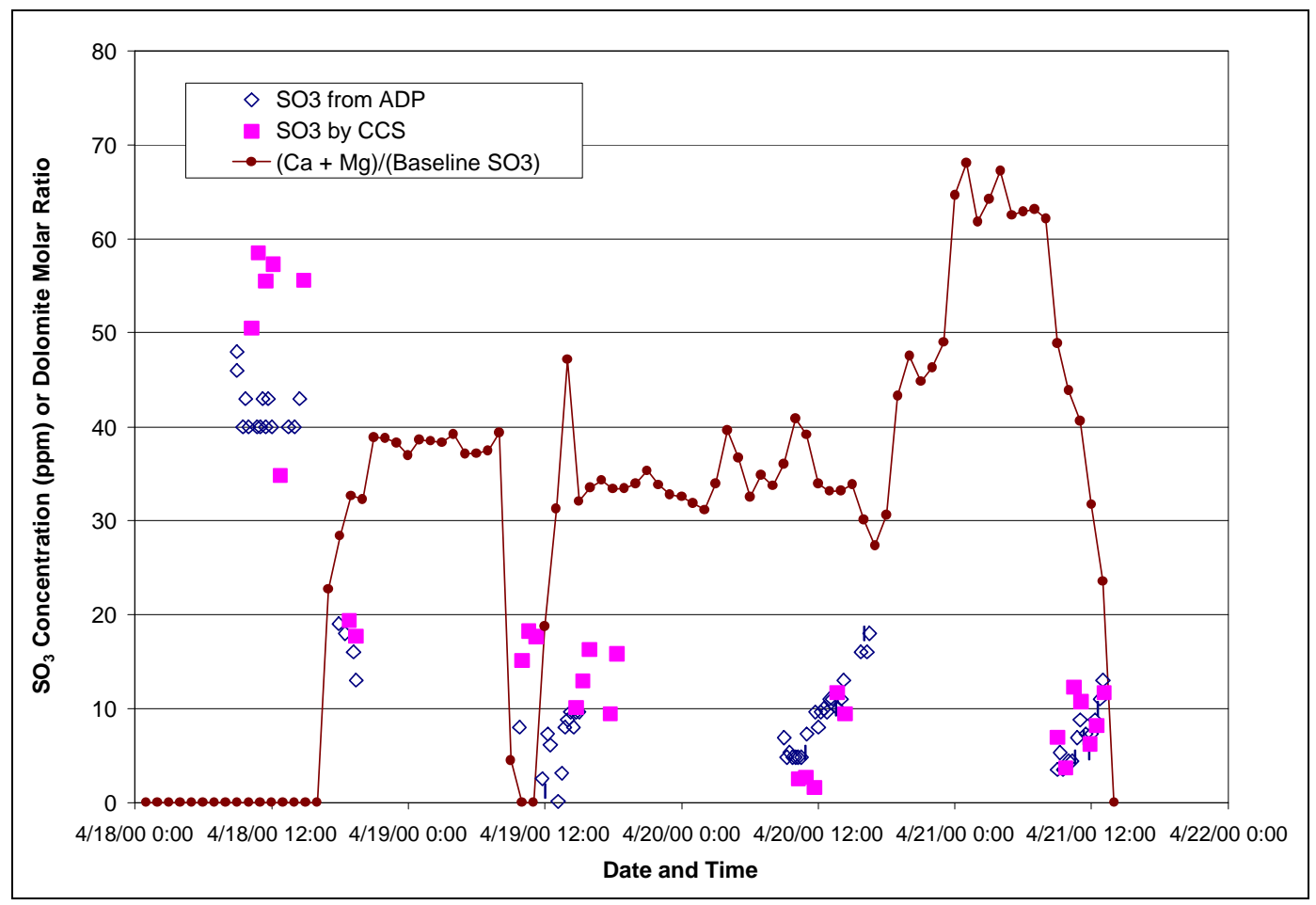

Figure 3-1

$\mathrm{CCS} \mathrm{SO}_{3}$ Measurement Data

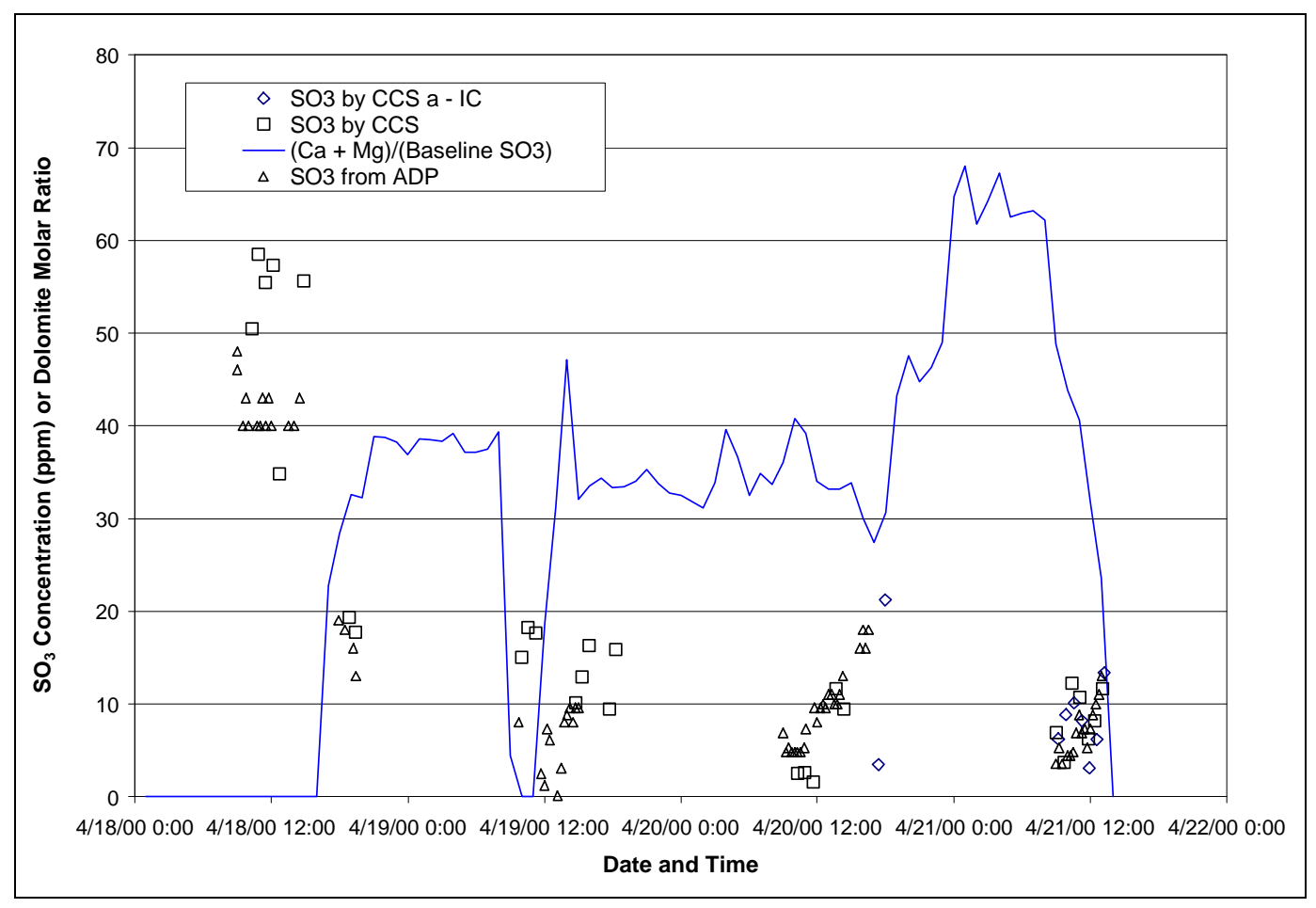

Figure 3-2

$\mathrm{CCS} \mathrm{SO}_{3}$ Measurements Compared to Acid Dew-Point Measurements 
During the test periods, the dolomite feed rate was adjusted several times in an attempt to establish $\mathrm{SO}_{3}$ removal as a function of dolomite feed rate. The dolomite feed rate was varied from approximately 16.6 to 33.2 tons per hour $(15,100$ to $30,200 \mathrm{~kg} / \mathrm{hr})$. However, two effects confounded the ability to establish such a correlation. The dolomite feed rate changes were made relatively frequently, with a stable feed rate often being maintained for just an hour or two at a time. The other effect is that, particularly for the measurements on April 21, low load operation overnight meant that the dolomite was injected at a much higher molar ratio relative to the coal sulfur immediately prior to the testing period (see Figure 3-1).

It is very likely that residual effects of dolomite previously injected into the unit confounded the observed relationship between dolomite feed rate and $\mathrm{SO}_{3}$ removal on April 21. The effects of alkaline materials injected into a furnace for $\mathrm{SO}_{3}$ control are thought to be twofold. One is that the alkali calcines in the furnace (evolves $\mathrm{CO}_{2}$ to form a high-surface-area oxide), and reacts with $\mathrm{SO}_{3}$ in the furnace gas to produce alkaline sulfate salts. The extent of this reaction, which primarily occurs as a gas/solid interaction in the furnace gas, should change almost immediately with changes in dolomite injection rate. The other effect is that a portion of the alkaline material deposits on heat transfer surfaces in the boiler, where it can continue to participate in the gas/solid reactions described above, and/or reduce the conversion of $\mathrm{SO}_{2}$ to $\mathrm{SO}_{3}$ by coating and neutralizing potential catalyst sites. Iron oxide scale on boiler tubes, and iron oxide and vanadium pentoxide in ash deposits are thought to catalyze $\mathrm{SO}_{3}$ formation. The effects of alkaline materials deposited on boiler heat transfer surfaces are less affected by instantaneous alkali injection rates, and may take hours or even days to reach a steady state level of effect after the injection rate changes. However, the relative contribution to $\mathrm{SO}_{3}$ control of gas/solid sorbent reactions versus that of sorbent deposits on boiler surfaces can vary from boiler to boiler.

Evidence of residual effects of alkaline sorbents injected into the Unit 2 furnace was shown in Figure 3-1. The morning of April 19, the dolomite injection was stopped for over two hours, yet both CCS and acid dew-point measurements made during the period of no sorbent injection indicated $\mathrm{SO}_{3}$ concentration reductions of greater than $60 \%$ relative to baseline concentrations from the previous day.

During the short-term variations in dolomite feed rates, particularly during the daytime hours on April 20 and the morning of April 21, there was a clear response of measured $\mathrm{SO}_{3}$ concentrations by CCS and acid dew point to dolomite feed rate. Increased dolomite feed rates resulted in lower measured values, and vice versa. However, in most instances the feed rates were changed too rapidly to establish an $\mathrm{SO}_{3}$ concentration that could be considered steady-state performance at a given dolomite feed rate.

There were two periods where the injection rate was held at a relatively constant value for two or more hours during which CCS runs were made. Late in the afternoon of April 19, the injection rate averaged 24.4 tons per hour $(22,200 \mathrm{~kg} / \mathrm{hr})$, and CCS runs over that period averaged $14 \mathrm{ppm}$ of $\mathrm{SO}_{3}$. This indicates an average removal percentage of about $74 \%$ relative to baseline at a mole ratio of dolomite injected to coal sulfur of $0.57: 1$ (34:1 compared to baseline $\mathrm{SO}_{3}$ ). On the morning of April 20, the dolomite injection rate averaged 27.4 tons per hour $(24,900 \mathrm{~kg} / \mathrm{hr})$ over a two-hour period. CCS runs during that period averaged about $2.6 \mathrm{ppm}$ of $\mathrm{SO}_{3}$, indicating a 
sulfuric acid removal rate of about $95 \%$ relative to baseline. The mole ratio of dolomite injected to coal sulfur during this period was about 0.68:1 (40:1 compared to baseline $\mathrm{SO}_{3}$ ).

It would take longer duration at a given dolomite injection rate and unit load to determine a steady state (or near steady state) $\mathrm{SO}_{3}$ removal level. A full day or more at each injection rate and unit load combination would provide more representative $\mathrm{SO}_{3}$ removal percentages.

The equivalent $\mathrm{SO}_{3}$ concentrations determined from acid dew-point measurements were in fairly good agreement with the CCS results. This comparison can be made from the data in Table 3-2 and is illustrated in Figure 3-1. Before dolomite injection began, the acid dew-point measurements indicated substantially lower $\mathrm{SO}_{3}$ concentrations than did the CCS results, with the two differing by as much as $15 \mathrm{ppm}$. During dolomite injection, though, the two measurement techniques typically differed by 2 to 3 ppm or less. During the last two days of the test, the $\mathrm{SO}_{3}$ concentrations indicated by the acid dew-point measurements were, with few exceptions, bracketed by the CCS results.

The data plotted in Figure 3-2 compare the results from the measurements with the two sampling trains, "1" and "a." The plot shows good comparison between the measurements at two locations in the duct except for relatively low value of $3.5 \mathrm{ppm}$ followed by a much higher value of 21 ppm from the "a" sample train the evening of 4/20. There are no corresponding CCS run data for sampling system " 1 " during the sampling system "a" measurements that day. However, the high value follows a trend for increasing $\mathrm{SO}_{3}$ concentrations previously that afternoon, as indicated by the acid dew-point values, during a period of relatively low dolomite injection rate. From this standpoint, the 21-ppm measurement seems consistent with the other data, while the measurement of $3.5 \mathrm{ppm}$ that immediately preceded the $21-\mathrm{ppm}$ measurement by the "a" sampling train is most likely erroneous.

\section{Method 26a-Hydrogen Halide and Halogen Concentration Results}

The flue gas hydrogen halide and halogen content was determined by conducting the EPA Method 26a test procedure. The samples collected with this sampling train were analyzed for chloride and fluoride content. A summary of these analyses is presented in Table 3-3. The concentrations of each chlorine and fluorine species are shown in the table in units of ppmv on a dry flue gas basis.

The injection of dolomite into the Unit 2 furnace did not appear to have a noticeable affect on the measured concentrations of hydrochloric acid or hydrofluoric acid. The measured hydrochloric acid and hydrofluoric acid concentrations actually averaged about 15 to $20 \%$ higher during dolomite injection than during the baseline period. However, some reduction in the mass emission rate of chlorine and fluorine was seen, with the values measured during dolomite injection averaging about one-third of the baseline average for chlorine and one-fourth of the baseline average for fluorine. Samples of the dolomite were not analyzed for chloride or fluoride, so any contribution to the measured concentrations from the dolomite is unknown. It is assumed that this contribution is negligible, though. 
Table 3-3

Summary of Method 26a Data

\begin{tabular}{|c|c|c|c|c|c|}
\hline \multirow[b]{2}{*}{ Date } & \multirow[b]{2}{*}{ Test } & \multicolumn{2}{|c|}{ Hydrogen Halides } & \multicolumn{2}{|c|}{ Halogens } \\
\hline & & $\begin{array}{l}\mathrm{HCl}, \text { ppmv } \\
\text { (dry basis) }\end{array}$ & $\begin{array}{c}\text { HF, ppmv } \\
\text { (dry basis) }\end{array}$ & $\begin{array}{l}\mathrm{Cl}_{2}, \text { ppmv (dry } \\
\text { basis) }\end{array}$ & $\begin{array}{c}F_{2}, \text { ppmv } \\
\text { (dry basis) }\end{array}$ \\
\hline 4/18/00 (baseline) & 1 & 28.4 & 14.2 & 0.22 & 0.075 \\
\hline 4/18/00 (baseline) & 2 & 30.9 & 13.2 & 0.21 & 0.085 \\
\hline 4/18/00 (baseline) & 3 & 24.9 & 14.0 & 0.58 & 0.062 \\
\hline $4 / 19 / 00$ & 4 & 34.6 & 17.6 & 0.15 & 0.037 \\
\hline $4 / 19 / 00$ & 5 & 34.1 & 18.8 & 0.18 & 0.021 \\
\hline $4 / 19 / 00$ & 6 & 31.9 & 17.3 & 0.18 & 0.027 \\
\hline $4 / 20 / 00$ & 7 & 36.0 & 19.3 & 0.02 & 0.008 \\
\hline $4 / 20 / 00$ & 8 & 33.1 & 18.5 & 0.00 & 0.014 \\
\hline $4 / 20 / 00$ & 9 & 28.3 & 14.6 & 0.07 & 0.010 \\
\hline $4 / 21 / 00$ & 10 & 34.9 & 17.7 & 0.00 & 0.009 \\
\hline $4 / 21 / 00$ & 11 & 23.1 & 11.4 & 0.26 & 0.008 \\
\hline
\end{tabular}

Table 3-4 presents these data in terms of calculated mass rates of hydrogen halides, halogens and total chloride and fluoride as measured by Method 26a. The concentrations of chlorine and fluorine in the fuel samples submitted for analysis were shown in Table 3-1 and are repeated in Table 3-4. Also shown are calculated mass rates of chlorine and fluorine fed into the furnace with the fuel, based on measured coal feed rates and the fuel analyses.

The fuel sample obtained during the first day of testing contained approximately 50 to $80 \%$ greater concentrations of chlorine than the samples from the other three days of testing, while the two fluoride analyses yielded similar concentrations. The flue gas measurement results agree reasonably well with the coal chlorine contents reported for the samples from 4/19 through 4/21. For the sample from 4/18, though, the mass rate of chloride entering the furnace with the coal based on that day's analysis was more than twice what was measured in the flue gas by Method 26a. This makes the coal chloride analysis for 4/18 suspect. The authors' experience has been that coal chlorine analyses for concentrations in the range of $1000 \mathrm{ppm}$ or lower can show quite a bit of variability, so this one suspect analysis out of four is not surprising.

The Method 26a results for total fluoride in the flue gas showed about 20 to $50 \%$ more fluoride accounted for than was indicated in the fuel. This apparent measurement bias was seen for both coal analyses and all four days of flue gas measurements. It is not obvious whether the measurement bias is in the flue gas or the coal, although it is the authors' opinion that the bias is more likely in the coal analyses. 
Table 3-4

Hydrogen Halide and Halogen Mass Rates

\begin{tabular}{|c|c|c|c|c|c|c|c|c|c|c|c|}
\hline \multirow[b]{3}{*}{ Date } & \multirow[b]{3}{*}{ Test } & \multicolumn{6}{|c|}{ Flue Gas Data } & \multicolumn{4}{|c|}{ Fuel Data } \\
\hline & & \multicolumn{2}{|c|}{ Hydrogen Halides } & \multicolumn{2}{|c|}{ Halogens } & \multicolumn{2}{|c|}{ Total } & \multirow[b]{2}{*}{$\begin{array}{c}\text { Fuel } \\
\text { Chlorine } \\
\text { Content, } \\
\mu \mathrm{g} / \mathrm{g}\end{array}$} & \multirow[b]{2}{*}{$\begin{array}{c}\text { Fuel } \\
\text { Fluorine } \\
\text { Content, } \\
\mu \mathrm{g} / \mathrm{g}\end{array}$} & \multirow{2}{*}{$\begin{array}{c}\text { Approximate } \\
\text { Input Rate of } \\
\text { Chlorine from } \\
\text { Fuel, Ib/hr (\% } \\
\text { closure with } \\
\text { flue gas) }\end{array}$} & \multirow{2}{*}{$\begin{array}{l}\text { Approximate } \\
\text { Input Rate of } \\
\text { Fluorine from } \\
\text { Fuel, Ib/hr (\% } \\
\text { closure with } \\
\text { flue gas) }\end{array}$} \\
\hline & & $\begin{array}{c}\mathrm{HCl}, \mathrm{lb} / \mathrm{hr} \\
\text { as } \\
\text { Chloride }\end{array}$ & $\begin{array}{l}\mathrm{HF}, \mathrm{lb} / \mathrm{hr} \\
\text { as } \\
\text { Fluoride }\end{array}$ & $\begin{array}{c}\mathrm{Cl}_{2}, \mathrm{lb} / \mathrm{hr} \\
\text { as } \\
\text { Chloride }\end{array}$ & $\begin{array}{c}\mathrm{F}_{2} \text {, lb/hr } \\
\quad \text { as } \\
\text { Fluoride }\end{array}$ & $\begin{array}{c}\text { Chlorine } \\
\text { Emission, } \\
\text { lb/hr }\end{array}$ & $\begin{array}{c}\text { Fluorine } \\
\text { Emission, } \\
\text { lb/hr }\end{array}$ & & & & \\
\hline $\begin{array}{l}\text { 4/18/00 } \\
\text { (baseline) }\end{array}$ & 1 & 295 & 79 & 4.5 & 0.83 & 300 & 80 & \multirow{3}{*}{1050} & \multirow{3}{*}{111} & \multirow{3}{*}{$638(214 \%)$} & \multirow{3}{*}{67 (86\%) } \\
\hline $\begin{array}{l}4 / 18 / 00 \\
\text { (baseline) }\end{array}$ & 2 & 321 & 73 & 4.3 & 0.95 & 325 & 74 & & & & \\
\hline $\begin{array}{l}4 / 18 / 00 \\
\text { (baseline) }\end{array}$ & 3 & 259 & 78 & 12.0 & 0.69 & 271 & 79 & & & & \\
\hline $4 / 19 / 00$ & 4 & 360 & 98 & 3.2 & 0.42 & 363 & 98 & \multirow{3}{*}{571} & \multirow{3}{*}{$108^{*}$} & \multirow{3}{*}{$362(103 \%)$} & \multirow{3}{*}{$68(68 \%)$} \\
\hline $4 / 19 / 00$ & 5 & 355 & 105 & 3.7 & 0.23 & 358 & 105 & & & & \\
\hline $4 / 19 / 00$ & 6 & 332 & 97 & 3.8 & 0.30 & 336 & 97 & & & & \\
\hline $4 / 20 / 00$ & 7 & 375 & 107 & 0.4 & 0.09 & 375 & 108 & \multirow{3}{*}{694} & \multirow{3}{*}{$108^{*}$} & \multirow{3}{*}{418 (124\%) } & \multirow{3}{*}{$65(67 \%)$} \\
\hline $4 / 20 / 00$ & 8 & 345 & 103 & 0.01 & 0.16 & 344 & 103 & & & & \\
\hline $4 / 20 / 00$ & 9 & 294 & 82 & 1.4 & 0.11 & 295 & 82 & & & & \\
\hline $4 / 21 / 00$ & 10 & 363 & 99 & 0.05 & 0.10 & 363 & 99 & \multirow{2}{*}{590} & \multirow{2}{*}{104} & \multirow{2}{*}{367 (121\%) } & \multirow{2}{*}{65 (80\%) } \\
\hline $4 / 21 / 00$ & 11 & 240 & 63 & 5.3 & 0.09 & 246 & 64 & & & & \\
\hline
\end{tabular}

${ }^{\star}$ Used test average because daily sample results were not available.

Note: $1 \mathrm{lb} / \mathrm{hr}=0.454 \mathrm{~kg} / \mathrm{hr}$. 


\section{Economizer Ash—Loss on Ignition Results}

Two ash samples were obtained from the economizer hoppers, one from each side of the unit (east and west), during each day of testing. Each sample was analyzed in duplicate for apparent combustibles content using the LOI test method. The results of the LOI tests are reported in Table 3-5. The LOI result is indicative of unburned combustible matter in the ash, typically carbon, which is a source of energy loss.

With the injection of dolomite, which adds calcium and magnesium oxides to the ash, it is possible that hydroxides could form as the ash cools in the presence of humid air. Hydroxides in the ash could show up as LOI in the ash sample. However, this effect is expected to have been minimal in the samples collected during this test, as the samples were sealed in plastic bags shortly after they were removed from the economizer hoppers.

During the test program, the only significant operating parameter that changed from day to day was the introduction of dolomite into the furnace. Dolomite or limestone injected into the furnace absorbs heat as it goes through the calcination process (an endothermic reaction). However, the relatively small quantity of dolomite injection into the furnace was not expected to significantly affect the quantity of unburned carbon. It is somewhat surprising, therefore, that the results in Table 3-5 show a considerable variation of LOI: from 0 to $3.4 \mathrm{wt} \%$ on the samples from the east side of the unit and 0.4 to $8.1 \mathrm{wt} \%$ on the west side of the unit.

The baseline samples collected on April 18 showed very low LOI values of 0.0 to $0.4 \mathrm{wt} \%$, on the east and west sides, respectively. These values are lower than would be expected for this unit in the operating mode during the baseline test. The higher values, ranging from 1.4 to $3.4 \mathrm{wt} \%$ on the east side and 3.0 to $8.1 \mathrm{wt} \%$ on the west side, were all collected during dolomite injection.

Boiler CO values were compared to see if they showed any indication of less complete combustion, and hence higher carbon content in the fly ash during dolomite injection. $\mathrm{CO}$ values averaged about 47 ppm during operation at about $750 \mathrm{MW}$ on April 18, and about $24 \mathrm{ppm}$ during operation at $750 \mathrm{MW}$ on April 21 during dolomite injection. These are both relatively low CO concentrations, not typically associated with high LOI in the ash.

It is also noted that the LOI results from the west-side samples were roughly double the magnitude of the east samples. It is not surprising to see side to side differences in fly ash LOI for various reasons. Most fossil fired steam generating units have side to side air and fuel flow imbalances that can result in one side of the unit having less excess air than the other, resulting in higher LOI on one side. It is also common for a single burner to be malfunctioning to the point where its air-to-fuel ratio or air-fuel mixing results in excessive unburned carbon. A single malfunctioning burner can result in excessive LOI results.

It is also possible that the anomalous results for the LOI analyses could be due to the quality of the samples. The economizer ash samples were grab samples collected from economizer hoppers. As such, there are no assurances that the small sample collected each time was 
Table 3-5

Loss on Ignition Data

\begin{tabular}{|c|c|c|c|c|c|c|}
\hline Date & $\begin{array}{c}\text { Sample } \\
\text { Identification }\end{array}$ & $\begin{array}{c}\text { Initial Vessel + } \\
\text { Sample (g) }\end{array}$ & $\begin{array}{c}\text { Final Vessel + } \\
\text { Sample (g) }\end{array}$ & $\begin{array}{l}\text { Mass Lost } \\
\quad(\mathrm{g})\end{array}$ & $\begin{array}{l}\text { Init. Ash } \\
\text { LOI (\%) }\end{array}$ & $\begin{array}{l}\text { LOI Avg. } \\
(\%)\end{array}$ \\
\hline $4 / 18 / 00$ & $4-18 E$ & 13.1926 & 13.1962 & -0.0036 & -0.30 & \multirow{2}{*}{0} \\
\hline $4 / 18 / 00$ & $4-18 E$ & 11.8627 & 11.8641 & -0.0014 & -0.14 & \\
\hline $4 / 18 / 00$ & $4-18 W$ & 13.1480 & 13.1441 & 0.0039 & 0.38 & \multirow{2}{*}{0.37} \\
\hline $4 / 18 / 00$ & $4-18 W$ & 12.6095 & 12.6058 & 0.0037 & 0.36 & \\
\hline $4 / 19 / 00$ & $4-19 E$ & 13.0966 & 13.0610 & 0.0356 & 3.46 & \multirow{2}{*}{3.42} \\
\hline $4 / 19 / 00$ & $4-19 E$ & 12.3881 & 12.3513 & 0.0368 & 3.38 & \\
\hline $4 / 19 / 00$ & $4-19 W$ & 12.0549 & 11.9707 & 0.0842 & 8.14 & \multirow{2}{*}{8.14} \\
\hline $4 / 19 / 00$ & $4-19 W$ & 12.6092 & 12.5229 & 0.0863 & 8.15 & \\
\hline $4 / 20 / 00$ & $4-20 E$ & 13.0504 & 13.0363 & 0.0141 & 1.36 & \multirow{2}{*}{1.38} \\
\hline $4 / 20 / 00$ & $4-20 E$ & 12.8215 & 12.8076 & 0.0139 & 1.40 & \\
\hline $4 / 20 / 00$ & $4-20 \mathrm{~W}$ & 12.5032 & 12.4730 & 0.0302 & 2.98 & \multirow{2}{*}{2.97} \\
\hline $4 / 20 / 00$ & $4-20 \mathrm{~W}$ & 10.7327 & 10.7030 & 0.0297 & 2.96 & \\
\hline $4 / 21 / 00$ & $4-21 E$ & 18.1721 & 18.1380 & 0.0341 & 3.38 & \multirow{2}{*}{3.39} \\
\hline $4 / 21 / 00$ & $4-21 E$ & 17.8907 & 17.8476 & 0.0431 & 3.40 & \\
\hline $4 / 21 / 00$ & $4-21 W$ & 16.7747 & 16.7059 & 0.0688 & 6.70 & \multirow{2}{*}{6.67} \\
\hline $4 / 21 / 00$ & $4-21 W$ & 16.4713 & 16.4034 & 0.0679 & 6.65 & \\
\hline
\end{tabular}

representative of the bulk of the material collecting in the economizer during that period of operation.

For all of these reasons, the LOI data are inconclusive as to the effect of dolomite injection on the amount of unburned carbon in the fly ash.

\section{Unit Performance, General Observations and Slag Formation Observations}

Other than FGD impacts, which are discussed in the following sub-section, there were no remarkable events with respect to unit operation that appeared to have been directly or indirectly related to injection of dolomite into the furnace. There were occurrences of equipment failure but these events were not out of the ordinary and were not related to dolomite injection. 
Observations of slag accumulations were made on a daily basis to assess if slag build-up on heat transfer surfaces was affected by dolomite injection. Observations were made primarily in the upper furnace where the partial-division-wall superheater and pendant superheater sections could be observed. Furnace slag accumulations were not the focus of attention because injection of dolomite was through the top elevation of burners and furnace observation ports are primarily located at or below that elevation. Soot blowing schedules and procedures were not altered from the normal during these tests. The soot blowers on this unit do not have a significant affect on the slag accumulation in the area observed. Prior to injection of dolomite, the upper furnace side walls, partial division walls and pendants had very little slag accumulations, with perhaps $1 / 2$ to 1 inch $(1.3$ to $2.5 \mathrm{~cm})$ of slag build-up. This amount of accumulation is fairly typical in this area of the unit. After three consecutive days of injecting dolomite, the slag accumulations on the side wall varied from 0 to 2 inches $(0$ to $5.1 \mathrm{~cm}$ ) in thickness, accumulations on the partial division walls were between 1 and 2 inches $(2.5$ and $5.1 \mathrm{~cm})$ and the pendant superheaters had between 2 and 4 inches $(5.1$ and $10.2 \mathrm{~cm}$ ) of slag accumulation. There did not appear to be any bridging of flue gas flow passages; however, visibility in the upper furnace was limited by a hazy appearance, presumably caused by injection of the dolomite (the visibility was not as limited when no dolomite was being injected).

Flue gas temperatures at the economizer exit and the air heater exit were examined to determine if solids buildup adversely affected heat transfer in the boiler and back pass. Adverse effects would be seen as temperature increases at these locations. Temperature increases were, in fact, seen over the course of the test. When compared at a gross unit load of approximately $760 \mathrm{MW}$, the average economizer outlet temperature increased from about 706 to $731^{\circ} \mathrm{F}\left(374\right.$ to $\left.388^{\circ} \mathrm{C}\right)$ and the average air heater exit temperature increased from 314 to $322^{\circ} \mathrm{F}\left(157\right.$ to $\left.161^{\circ} \mathrm{C}\right)$, both over the time period April 18 through April 21. These temperature increases suggest that dolomite injection had an adverse effect on unit heat rate. It is difficult to quantify this effect from these short-term test results, though. The best way to quantify such an effect would be to track air heater exit temperature versus time of operation, starting with a clean air heater, for baseline operation versus extended operation with dolomite injection.

If dolomite injection does result in a measurable increase in air heater exit gas temperature, this could represent a substantial operating cost impact. EPRI heat rate documents show an industry average of $2.7 \mathrm{Btu} / \mathrm{kW}-\mathrm{hr}-{ }^{\circ} \mathrm{F}\left(1.2 \mathrm{kcal} / \mathrm{kw}-\mathrm{hr}{ }^{\circ} \mathrm{C}\right)$ increase in exit gas temperature (corrected to zero air inleakage). For a unit the size of Unit 2 , an $8{ }^{\circ} \mathrm{F}\left(4^{\circ} \mathrm{C}\right)$ increase in air heater exit temperature would correspond with about $\$ 200,000$ in fuel cost increase annually.

\section{Scrubber Performance Results}

Results from the analyses of a number of slurry samples collected before and during dolomite injection on Unit 2 are summarized in Tables 3-6 and 3-7. Table 3-6 summarizes slurry solid phase analyses, and Table 3-7 summarizes liquid phase analyses.

Special precautions had to be made in sampling the scrubber slurry. In normal FGD situations, whole slurries can be collected in a sealed bottle and the solid phase analyzed later, as so little material is present in the liquid phase that any dissolution or precipitation would not measurably affect the solid phase composition. However, in this situation, the possibility existed for oxides 
in the solid phase to hydrate over time. Therefore the solids were separated from the liquor in the slurry samples within approximately 30 minutes after the samples were collected, and dried to halt any ongoing hydration reactions.

Based on the results summarized in Table 3-6, the calcium content of the dolomite appears to be highly utilized in the wet scrubber. The analytical results for April 21 suggest that about 96 to $97 \%$ of the $\mathrm{CaO}$ in the calcined dolomite slakes in the scrubber and replaces a portion of the normal slaked lime feed. This calculation is made by comparing the moles of calcium to the moles of sulfite, sulfate, and carbonate in the solid phase, and assuming that none of the latter are present in the solid phase as magnesium salts. Magnesium sulfate and sulfite are much more soluble than the corresponding calcium salts, and would be expected to have been in the liquid rather than the solid phase. At the dolomite injection rate the morning of April 21, 96 to $97 \%$ of the calcium in the dolomite would represent (and offset) about one-third of the normal scrubber lime makeup.

The magnesium content of the dolomite does not appear to be as highly utilized. About half of the magnesium appears to be passing through the scrubber as relatively unreactive $\mathrm{MgO}$, which remains in the scrubber solids. This is seen as an increase in the magnesium content of the scrubber solids, but no corresponding increase in the amount of sulfite, sulfate, and/or carbonate in the solids beyond that which can be accounted for as calcium salts.

Further evidence of the apparently low utilization of the magnesium content of the dolomite is seen in the reagent utilization calculations in Table 3-6. The utilization is calculated in three different manners, using various combinations of the calcium, magnesium, sulfate, sulfite, and carbonate analyses of the scrubber solids. The first two approaches $\left(\mathrm{Ca}\right.$-independent and $\mathrm{SO}_{4}$ independent) assume that all of the calcium and magnesium present in the solids are present either as sulfates, sulfites, or carbonates. These approaches show high apparent calcium and magnesium utilization in all of the samples. The third approach $\left(\mathrm{CO}_{3}\right.$-independent $)$ divides the molar amount of sulfur species in the solids (sulfate and sulfite) by the molar amount of calcium and magnesium present. This approach shows considerably lower utilization than by the other two approaches during dolomite injection (April 21), suggesting that there is additional calcium or magnesium present in a form other than sulfate, sulfite or carbonate (e.g., as an unreactive oxide). As described above, other evidence suggests that the excess alkalinity is more likely to be magnesium oxide than calcium oxide.

Note that the "reagent ratio" values in Table 3-6 are the reciprocals of the utilization values, when expressed as fractions rather than percentages. Correspondingly, the $\mathrm{CO}_{3}$-independent reagent ratio values are considerably higher during dolomite injection than was calculated by the other two methods.

The half of the magnesium in the dolomite that is utilized appears to end up in the liquid phase in the scrubber. On module 2B, the liquid-phase magnesium concentrations doubled from baseline values over the time period April 18 through April 21; the baseline (April 18) magnesium concentration was about $173 \mathrm{mmole} / \mathrm{L}$ (4200 ppm), and the April 21 value was about 325 mmole/L (7900 ppm). The liquid phase magnesium increase also doubled the amount of sulfite and sulfate in the liquid phase, so this magnesium should also go towards offsetting lime 
Table 3-6

Unit 2 FGD Slurry Solids Analyses

\begin{tabular}{|c|c|c|c|c|c|c|c|}
\hline Description & 2B & $2 \mathrm{C}$ & UF & 2B & $2 C$ & $2 E$ & UF \\
\hline Date & 18-Apr-00 & 18-Apr-00 & 18-Apr-00 & 21-Apr-00 & 21-Apr-00 & 21-Apr-00 & 21-Apr-00 \\
\hline Time & $11: 30$ & $11: 30$ & - & - & - & - & - \\
\hline Ca, mmole/g & 4.39 & 4.31 & 4.73 & 3.81 & 3.89 & 3.80 & 4.33 \\
\hline $\mathrm{Mg}, \mathrm{mmole} / \mathrm{g}$ & 0.281 & 0.208 & 0.286 & 0.967 & 0.880 & 0.960 & 1.10 \\
\hline $\mathrm{SO}_{3}, \mathrm{mmole} / \mathrm{g}$ & 3.53 & 3.52 & 3.95 & 3.09 & 2.97 & 2.84 & 3.04 \\
\hline $\mathrm{SO}_{4}, \mathrm{mmole} / \mathrm{g}$ & 0.745 & 0.720 & 0.906 & 0.771 & 1.043 & 0.993 & 1.051 \\
\hline $\mathrm{CO}_{3}, \mathrm{mmole} / \mathrm{g}$ & 0.338 & 0.311 & 0.321 & 0.156 & 0.103 & 0.145 & 0.326 \\
\hline Inerts, wt\% & 33.32 & 38.12 & 30.26 & 33.27 & 36.12 & 37.94 & 30.86 \\
\hline Solids, wt\% & 14.24 & 9.58 & NR & NR & NR & NR & NR \\
\hline $\mathrm{pH}$ & 7.4 & 7.93 & NR & NR & NR & NR & NR \\
\hline Temp, ${ }^{\circ} \mathrm{C}$ & 42.3 & 47.3 & NR & NR & NR & NR & NR \\
\hline \multicolumn{8}{|l|}{ Reagent Util, \% } \\
\hline Ca-Independent & 92.7 & 93.2 & 93.8 & 96.1 & 97.5 & 96.4 & 92.6 \\
\hline $\mathrm{SO}_{4}$ - Independent & 92.8 & 93.1 & 93.6 & 96.7 & 97.8 & 97.0 & 94.0 \\
\hline $\mathrm{CO}_{3}$ - Independent & 91.4 & 93.7 & 96.9 & 80.8 & 84.3 & 80.6 & 75.5 \\
\hline \multicolumn{8}{|l|}{ Reagent Ratio } \\
\hline Ca- Independent & 1.08 & 1.07 & 1.07 & 1.04 & 1.03 & 1.04 & 1.08 \\
\hline $\mathrm{SO}_{4}$ - Independent & 1.08 & 1.07 & 1.07 & 1.03 & 1.02 & 1.03 & 1.06 \\
\hline $\mathrm{CO}_{3}$ - Independent & 1.09 & 1.07 & 1.03 & 1.24 & 1.19 & 1.24 & 1.33 \\
\hline Oxidation, \% & 17.4 & 17.0 & 18.6 & 20.0 & 26.0 & 25.9 & 25.7 \\
\hline Solid solution, wt\% & 54.5 & 54.4 & 61.1 & 47.7 & 46.0 & 43.9 & 47.0 \\
\hline Gypsum, wt\% & 2.1 & 1.7 & 3.6 & 3.9 & 8.9 & 8.5 & 8.8 \\
\hline $\mathrm{CaCO}_{3}, \mathrm{wt} \%$ & 3.4 & 3.1 & 3.2 & 1.6 & 1.0 & 1.5 & 3.3 \\
\hline Inerts, wt\% & 33.3 & 38.1 & 30.3 & 33.3 & 36.1 & 37.9 & 30.9 \\
\hline
\end{tabular}

NR - Not reported. 
Table 3-7

FGD Slurry Liquor Analyses

\begin{tabular}{|c|c|c|c|c|c|}
\hline Description & $2 B$ & $2 B$ & 2B-2 & $2 B$ & $2 B$ \\
\hline Date & 18-Apr-00 & 19-Apr-00 & 19-Apr-00 & 20-Apr-00 & 21-Apr-00 \\
\hline Time & $11: 30$ & $16: 00$ & $17: 30$ & $12: 15$ & $10: 30$ \\
\hline Ca, mmole/L & 2.52 & 3.25 & 1.64 & 2.11 & 2.17 \\
\hline Mg, mmole/L & 172.95 & 257.4 & 287.0 & 269.1 & 324.8 \\
\hline $\mathrm{Na}, \mathrm{mmole} / \mathrm{L}$ & 5.32 & 5.12 & 5.14 & 4.25 & 3.86 \\
\hline $\mathrm{Cl}, \mathrm{mmole} / \mathrm{L}$ & 32.09 & 28.62 & 0.0 & 23.60 & 24.77 \\
\hline $\mathrm{CO}_{3}, \mathrm{mmole} / \mathrm{L}$ & 2.42 & 1.44 & 0.0 & 1.32 & 2.75 \\
\hline $\mathrm{SO}_{3}, \mathrm{mmole} / \mathrm{L}$ & 38.01 & 78.27 & 71.07 & 82.89 & 113.96 \\
\hline $\mathrm{SO}_{4}, \mathrm{mmole} / \mathrm{L}$ & 114.03 & 185.38 & 192.96 & 186.31 & 213.23 \\
\hline $\mathrm{pH}$ & $\sim 7$ & $\sim 7$ & $\sim 7$ & $\sim 7$ & $\sim 7$ \\
\hline Temp, ${ }^{\circ} \mathrm{C}$ & $\sim 50$ & $\sim 50$ & $\sim 50$ & $\sim 50$ & $\sim 50$ \\
\hline \multicolumn{6}{|l|}{ Relative Saturation } \\
\hline Gypsum & 0.12 & - & - & - & 0.09 \\
\hline $\mathrm{CaSO}_{3} \cdot 1 / 2 \mathrm{H}_{2} \mathrm{O}$ & 3.69 & - & . & & 4.63 \\
\hline $\mathrm{CaCO}_{3}$ & 0.16 & - & - & - & 0.09 \\
\hline
\end{tabular}

consumption (i.e., more of the sulfur species removed were leaving the scrubber in the liquid phase). Based on an approximate material balance, $50 \%$ utilization of the magnesium in the dolomite injected should offset another 15 to $20 \%$ of the lime consumption at the dolomite injection rate of April 21 a.m. Thus, the calcium in the dolomite and half of the magnesium in the dolomite should offset a total of about half of the normal (no dolomite injection) lime flow to the scrubbers.

Note that the 15 to $20 \%$ offset by dissolving magnesium would likely diminish with time, as the FGD liquor will eventually become saturated with respect to magnesium sulfite, and limit the amount of dolomite magnesium that can dissolve in the scrubbers. It would take a longer test period to determine what this steady state magnesium dissolution level would be.

The dolomite that is not reactive in the scrubber seems to continue to react over the extended solids residence time in the thickener. This ongoing reaction is seen in measurements of the thickener influent $\mathrm{pH}$, and of thickener overflow and underflow sample $\mathrm{pH}$. The thickener influent $\mathrm{pH}$ values were observed to increase within hours after dolomite injection began during the afternoon of April 18. On April 17 and 18, prior to the onset of dolomite injection, the 
thickener influent $\mathrm{pH}$ ranged from 6.3 to 6.7. By 9:00 p.m. on April 18, this $\mathrm{pH}$ had increased to 7.2, and ranged from 7.2 to 7.9 over the next two days. During the period of low overnight load the morning of April 21, the thickener influent $\mathrm{pH}$ increased further to 8.2. Over this entire period, the $\mathrm{pH}$ values for individual scrubber slurries remained in the normal range of nominally 6.5 to 7.0. The higher $\mathrm{pH}$ of the thickener influent stream appears to indicate that magnesium oxide dissolution and hydration was occurring between the scrubbers and the thickener influent $\mathrm{pH}$ measurement point.

Samples of the thickener overflow and underflow streams showed even further $\mathrm{pH}$ increases over the residence time in the thickener. On April 21, the thickener overflow was at a considerably higher $\mathrm{pH}$ than either the FGD blow down or the thickener influent, at $\mathrm{pH} 8.70$, and the underflow was even higher at 9.33. Fortunately, the thickener overflow $\mathrm{pH}$ was not high enough to precipitate magnesium sulfite, as the overflow solids content was quite low $(0.002 \%)$.

Magnesium sulfite precipitation in the thickener overflow could be a potential problem in longer runs with dolomite injection. The plant water balance (magnesium blowdown in liquor versus magnesium entering scrubber with dolomite and Thiosorbic ${ }^{\circledR}$ lime) will determine if the steadystate magnesium levels will be high enough to precipitate magnesium sulfite.

Plant operators did report an apparent thickener operating problem during the dolomite injection period. The evening of April 19, after more than 24 hours of dolomite injection, thickener bed level measurements indicated that the bed height increased abruptly from $6 \mathrm{ft}(1.8 \mathrm{~m})$ to about 9 $\mathrm{ft}(2.7 \mathrm{~m})$. Over the morning of April 20, this level indication dropped to 7 to $8 \mathrm{ft}$ (2.1 to $2.4 \mathrm{~m})$, and by April 21 the level indication was down to about 5 to $6 \mathrm{ft}(1.5$ to $1.8 \mathrm{~m})$. It is not surprising that the thickener bed properties changed during dolomite injection, as the chemical composition of the scrubber blow down solids clearly changed. An abrupt change in bed height the evening of April 19 might have been a transient effect as the bed solids properties changed from normal operation to the new composition reflecting operation with dolomite injection. Similar transient effects have been seen in other FGD systems when scrubber blow down solids properties change, such as due to changes in sulfite oxidation percentage or due to the addition of performance additives. Since the bed height was restored to normal values as dolomite injection continued, this is not considered to be a long-term issue for dolomite injection on Unit 2.

On first review of the scrubber solids data, the high magnesium levels appeared to have promoted higher sulfite oxidation percentages, which could also change solids settling properties. This apparent oxidation increase could have resulted because so much of the sulfur species remain in the liquid phase at these very high magnesium concentrations, where they can continue to undergo oxidation reactions. The baseline (April 18) samples showed 17 to $19 \%$ oxidation, and the April 21 samples showed 20 to $26 \%$ oxidation. All of these percent oxidation values are above the desired level of less than $15 \%$ oxidation, below which all of the sulfate formed by sulfite oxidation will co-precipitate as a "solid solution" with the normal calcium sulfite hemihydrate $\left(\mathrm{CaSO}_{3} \bullet 1 / 2 \mathrm{H}_{2} \mathrm{O}\right)$ FGD byproduct. In most wet scrubber applications, as the sulfite oxidation increases above $15 \%$, not all of the sulfate can be co-precipitated, and high gypsum relative saturations result in the FGD liquor. As the gypsum relative saturation levels increase, the likelihood of gypsum scaling increases dramatically. At approximately 20 to $25 \%$ oxidation, gypsum scale formation at some locations in the scrubbers is almost a certainty. 
However, the corresponding liquid phase analyses, summarized in Table 3-7, do not show the expected high gypsum relative saturation values. In fact, the samples from both baseline operation (April 18) and at the end of dolomite injection (April 21) show low gypsum relative saturation values of about 0.1 . This means that the FGD liquor would tend to dissolve gypsum rather than precipitate gypsum scale; precipitation requires FGD liquor relative saturation values above 1.0.

In reviewing both the solid and liquid phase results, we identified two technically feasible explanations for the low FGD liquor gypsum relative saturation values on April 21, while the apparent oxidation values are in the range of 20 to $26 \%$. One, if the calcium oxide in the dolomite reacts with $\mathrm{SO}_{2}$ in the flue gas to achieve approximately $10 \% \mathrm{SO}_{2}$ removal as the gas flows from the furnace to the FGD system, about $10 \%$ of the total sulfur "removed" in the scrubber will be in the form of anhydrite $\left(\mathrm{CaSO}_{4}\right)$ solids that are physically scrubbed in the venturi. The anhydrite would be relatively unreactive, not tending to dissolve or hydrate to form gypsum $\left(\mathrm{CaSO}_{4} \cdot 2 \mathrm{H}_{2} \mathrm{O}\right)$ in the scrubber.

Thus, the $\mathrm{SO}_{2}$ removed from the gas phase in the scrubber could be oxidized at less than $15 \%$, meaning that all of the sulfate formed in the scrubber would be coprecipitated with the calcium sulfite hemihydrate, and the gypsum relative saturation would be less than 1.0. The apparent oxidation would be in the range of 20 to $26 \%$ because of the anhydrite also present in the slurry, having been physically scrubbed from the flue gas as particulate matter.

Said another way, the scrubber bulk solids analyses indicate that the sulfite oxidation was in the range of 20 to $26 \%$, which would lead us to believe the sulfur species in the slurry were present both as "solid solution" (a mixture of calcium sulfite hemihydrate and calcium sulfate hemihydrate) and as gypsum. If this were the case, the FGD liquor should be supersaturated with respect to gypsum, which the liquor analyses do not show. However, it is possible that the sulfur species were present as a mixture of solid solution and anhydrite that was formed by gas/solid reactions upstream of the scrubber. In this case, the scrubber liquor could be subsaturated with respect to gypsum, as the liquor analyses indicate.

A second possible explanation is seen in reviewing the unit load profile the day of the April 21 solid sample. The unit load dropped below $400 \mathrm{MW}$ overnight, and had only been increased above $700 \mathrm{MW}$ for a couple of hours when the slurry sample was collected. At low load, the furnace typically operates at higher excess air levels, raising the ratio of oxygen to $\mathrm{SO}_{2}$ in the flue gas entering the scrubber. This, in turn, can raise the sulfite oxidation percentage in the scrubber. The actual economizer oxygen concentrations were about $4.2 \%$ overnight, and $3.0 \%$ the morning of April 21 after the boiler load was increased. While this is not a large change in excess air levels, it is possible that the scrubber solids sample was representative of overnight operation at a higher oxidation. It would take a number of hours to purge these solids from the scrubber, due to the solids residence time in the scrubber recycle loop. The gypsum relative saturation in the liquor would change rapidly with the load increase. Therefore it is possible that the solids were not representative of the liquor conditions at the time the samples were taken.

The latter scenario could also explain why the baseline liquor sample from April 18 appeared to be subsaturated with respect to gypsum in spite of the sulfite oxidation being in the range of 17 
to $19 \%$. On April 18, the overnight hourly-average economizer oxygen concentrations ranged between 3.8 and $4.2 \%$. However, by the time the liquor sample was taken from module $2 \mathrm{~B}$, the economizer oxygen concentration had been lowered to an hourly average of $3.3 \%$. Again, this is not a large change in excess air levels, but this change could help explain the presence of solids showing greater than $15 \%$ sulfite oxidation, yet a liquor that is subsaturated with respect to gypsum.

There is one other concern about gypsum scaling in the scrubbers during dolomite injection. That is the possibility of scale formation at the wet/dry interface in the scrubber, where the flue gas is first contacted with the recycle slurry. As excess calcium oxide in the calcined dolomite solids dissolves into the liquor to hydrate, it is possible that localized gypsum relative saturation values could increase above 1.0, potentially causing gypsum scale formation in this portion of the scrubber. It may require scrubber inspection before and after an extended period of dolomite injection to determine whether or not this occurs. 


\section{4 \\ RESULTS FROM SLURRY INJECTION TESTS}

Results from the three slurry injection tests on BMP Unit 3 are presented and discussed in this section. First, the results of the Unit 3 baseline tests are presented and discussed, then results which quantify the impacts of sorbent injection on Unit 3 sulfuric acid concentrations are discussed for each of the three sorbents. There is a brief discussion of the effects on injection temperature on the sorbents, and finally, balance-of-plant issues are discussed, including impacts of sorbent injection on fly ash resistivity and ESP performance. Because these data were not collected for all three sorbent tests, balance-of-plant issues are discussed separately, for the tests where such data were collected.

\section{Baseline Test Results}

As described earlier, baseline data were collected during four days early in October 2000. The primary objective of these measurements was to measure baseline (no sorbent injection) $\mathrm{SO}_{3}$ concentrations at a variety of measurement locations, but additional sampling was conducted for flue gas $\mathrm{SO}_{2}, \mathrm{HCl}, \mathrm{HF}$ and halogen gas concentrations, and ESP outlet particulate concentrations.

Table 4-1 summarizes the results of CCS measurements made at various locations throughout the flue gas path on Unit 3. Please refer to Figures 2-3 through 2-5 in Section 2 to review how these sample locations are laid out in the gas path. Table 4-1 shows the results of individual measurement runs by date and by location. Figure 4-1 summarizes these same data by location, showing the average of all measurements made at a particular location.

When presented as averages in Figure 4-1, the results show no significant side-to-side variation in $\mathrm{SO}_{3}$ conversion in the furnace and back pass of the boiler, and little or no $\mathrm{SO}_{3}$ removal across the air heaters on their "hot" sides (11\% or less). $\mathrm{SO}_{3}$ does not appear to be removed across the "B" and "C" ESPs at a high percentage either; on average the removal percentage across these two ESPs varies from 11 to $20 \%$. The sampling ports for the outlet of the "cold" side of the air heaters and inlets to the "A" and "D" ESPs are difficult to access on Unit 3, therefore no CCS measurements were made at those locations. However, comparing the economizer outlet values to the concentrations measured at the outlets of the "A" and "D" ESPs, a total of 73 to $79 \%$ reduction in $\mathrm{SO}_{3}$ concentration is seen. Most of this reduction is presumed to occur across the air heater. Note that the measured concentration averages of 6.0 and $7.5 \mathrm{ppm}$ correspond with acid dew-point values of approximately 263 and $267^{\circ} \mathrm{F}\left(128\right.$ and $\left.133^{\circ} \mathrm{C}\right)$, respectively. These acid dew point values are consistent with temperatures that might be expected on the "cold" side of an air heater that is averaging approximately $305^{\circ} \mathrm{F}\left(152^{\circ} \mathrm{C}\right)$ for an outlet gas temperature. Because of the observed stratification of $\mathrm{SO}_{3}$ concentrations between the ESPs, it was decided to conduct 
Table 4-1

Summary of Flue Gas $\mathrm{SO}_{3}$ Concentrations Measured for Unit 3 Baseline Testing

\begin{tabular}{|c|c|c|c|c|c|}
\hline \multirow[b]{2}{*}{ Date } & \multicolumn{5}{|c|}{ Measured $\mathrm{SO}_{3}$ Concentration, ppmv (dry basis) } \\
\hline & Run 1 & Run 2 & Run 3 & Run 4 & Average \\
\hline \multicolumn{6}{|c|}{ Economizer A Outlet } \\
\hline $10 / 3 / 00$ & 27 & 24 & 28 & - & 26 \\
\hline $10 / 4 / 00$ & 25 & 35 & 26 & 30 & 30 \\
\hline \multicolumn{6}{|c|}{ Economizer B Outlet } \\
\hline $10 / 4 / 00$ & 22 & 29 & 28 & 32 & 28 \\
\hline \multicolumn{6}{|c|}{ ESP B Inlet/Air Heater A Outlet (Hot Side) } \\
\hline 10/5/00 & 39 & 29 & 26 & 31 & 31 \\
\hline \multicolumn{6}{|c|}{ ESP C Inlet/Air Heater B Outlet (Hot Side) } \\
\hline 10/5/00 & 24 & 23 & 27 & 24 & 25 \\
\hline \multicolumn{6}{|l|}{ ESP A Outlet } \\
\hline $10 / 3 / 00$ & 5.0 & 5.6 & 5.2 & - & 5.3 \\
\hline $10 / 4 / 00$ & 6.6 & 7.5 & 7.1 & - & 7.0 \\
\hline $10 / 5 / 00$ & 5.6 & 6.0 & 5.7 & 5.0 & 5.6 \\
\hline 10/6/00 & - & 6.6 & 6.6 & - & 6.6 \\
\hline \multicolumn{6}{|l|}{ ESP B Outlet } \\
\hline $10 / 4 / 00$ & 28 & 25 & 27 & 26 & 27 \\
\hline $10 / 5 / 00$ & 25 & 20 & 26 & - & 24 \\
\hline 10/6/00 & 21 & 24 & 24 & - & 23 \\
\hline \multicolumn{6}{|l|}{ ESP C Outlet } \\
\hline 10/6/00 & 22 & 26 & 18 & - & 22 \\
\hline \multicolumn{6}{|l|}{ ESP D Outlet } \\
\hline $10 / 6 / 00$ & 7.9 & 6.3 & 8.4 & - & 7.5 \\
\hline
\end{tabular}




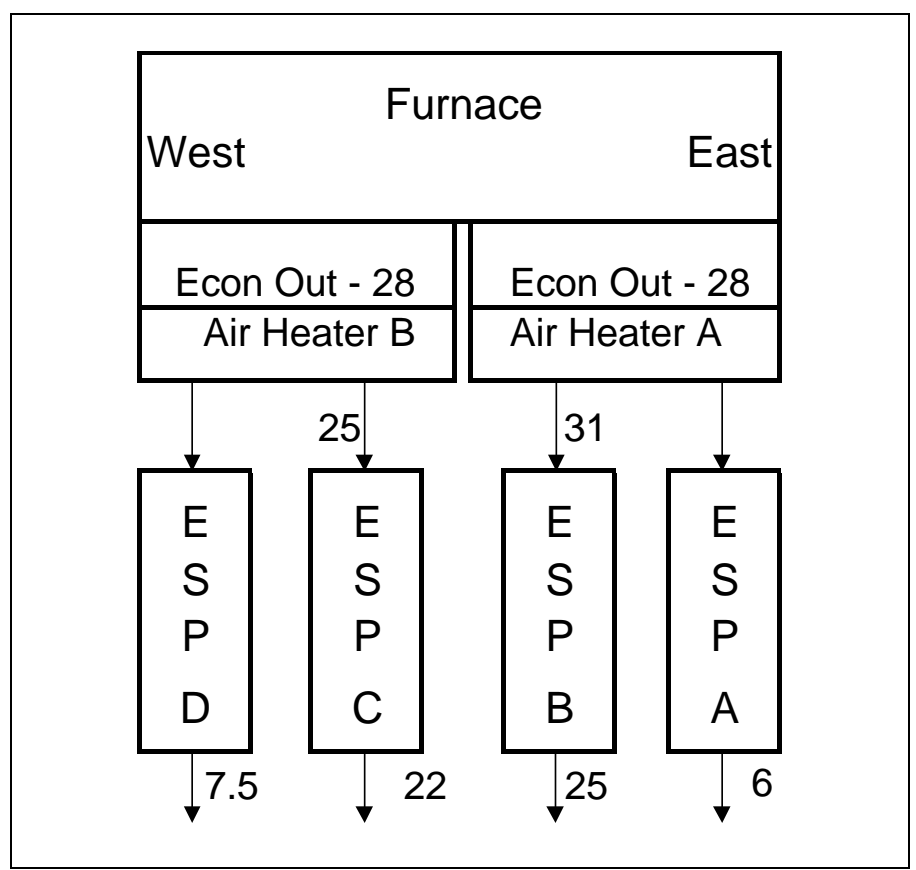

Figure 4-1

Summary of Baseline CCS Measurements at BMP Unit 3

most of the CCS measurements during the sorbent injection tests on the "B" or "C" ESP inlet and outlet, where most of the flue gas $\mathrm{SO}_{3}$ content is seen.

Throughout this report, $\mathrm{SO}_{3}$ removal during sorbent injection is reported as the percent reduction in $\mathrm{SO}_{3}$ concentration as measured at the $\mathrm{B}$ ESP outlet, for injection versus baseline conditions. It would be possible to calculate a higher percentage by comparing baseline economizer outlet values to ESP outlet values during sorbent injection. However, the latter calculation would overstate the effect of reagent injection, because it would also incorporate the removal across the air heater and ESP that is already seen at baseline (no injection) conditions.

The economizer outlet $\mathrm{SO}_{3}$ concentration data in Table 4-1 were used to calculate an average $\mathrm{SO}_{2}$ to $\mathrm{SO}_{3}$ conversion percentage for Unit 3, though, to serve as a basis for setting sorbent injection rates and for reporting sorbent-to- $\mathrm{SO}_{3}$ molar ratios. During the baseline testing, two Unit 3 coal feed samples were collected and analyzed, on October 4 and October 6 . The ultimate analyses of these coal samples are shown in Table 4-2.

These results were used in combustion calculations to calculate the total amount of $\mathrm{SO}_{2}$ that would be produced from the combustion of these coals, then that value was compared to the measured economizer outlet $\mathrm{SO}_{3}$ concentrations. The calculated conversion percentage was $0.9 \%$, which is near the middle of the expected range for bituminous coals in pulverized-coalfired boilers (approximately 0.5 to $1.5 \%$ ). This conversion percentage can be affected by many variables, including excess air levels in the furnace, slag accumulations on heat transfer surfaces, etc. Consequently, it was decided to use a "round number" of $1 \%$ as the average value for conversion of $\mathrm{SO}_{2}$ to $\mathrm{SO}_{3}$ in the Unit 3 boiler for calculating sorbent-to- $\mathrm{SO}_{3}$ mole ratios for the 
Table 4-2

Ultimate Analyses of Coal Samples from the Unit 3 Baseline Test

\begin{tabular}{|l|l|l|}
\hline \multirow{2}{*}{ Parameter } & \multicolumn{2}{c|}{ Composition, wt\% (except as noted) } \\
\cline { 2 - 3 } & \multicolumn{1}{|c|}{ Sample from 10/4/00 } & \multicolumn{1}{c|}{ Sample from 10/6/00 } \\
\hline Carbon & 66.69 & 68.72 \\
\hline Hydrogen & 4.56 & 4.67 \\
\hline Nitrogen & 1.18 & 1.21 \\
\hline Sulfur & 4.10 & 4.01 \\
\hline Chlorine (ppm) & 534 & 616 \\
\hline Oxygen & 4.43 & 4.40 \\
\hline Moisture & 5.77 & 5.50 \\
\hline Ash & 13.22 & 11.43 \\
\hline Total & 100.00 & 100.00 \\
\hline $\begin{array}{l}\text { HHV (Btu/lb) } \\
{[\mathrm{kg} \text {-cal/kg] }}\end{array}$ & 12,495 & $\begin{array}{l}12,195 \\
{[6947]}\end{array}$ \\
\hline
\end{tabular}

short-term slurry injection tests. However, it is recognized that the actual percentage at any given time could vary because of the influences of excess air levels and other factors.

\section{PHDL Sorbent Injection Test Results}

The PHDL slurry tests were conducted the last two weeks in October 2000. The PHDL slurry was purchased from Clear $_{2} \mathrm{O}$ Technologies. They purchase PHDL powder from Gen Lime in central Ohio and prepare it as a $60-\mathrm{wt} \%$ aqueous slurry for use in water treating applications. The 60-wt $\%$ slurry proved to be more viscous than the temporary slurry injection equipment on Unit 3 could handle, so for this testing $\mathrm{Clear}_{2} \mathrm{O}$ produced a more dilute slurry at $35 \mathrm{wt} \%$. This material was injected as a slurry rather than as a powder for several reasons. First, the other sorbents tested were available only as slurries, so testing the PHDL as a slurry allowed the same equipment to be used. The other reason is that the momentum transfer available when injecting relatively dense slurry droplets into a large furnace, including the mass associated with the water, can lead to better sorbent particle penetration into the furnace than if the material was injected as a dry powder.

The PHDL slurry solids were measured to have a mass mean particle diameter in the range of 7 to 8 microns and a specific surface area (by BET analysis) of $19 \mathrm{~m}^{2} / \mathrm{g}$. Both of these values are similar to what might be measured for a high-calcium, atmospheric-hydrated lime. 
Table 4-3 summarizes the data collected during the PHDL testing. The calcium plus magnesium alkali-to- $\mathrm{SO}_{3}$ molar ratio is calculated from the sulfur content of the coal samples collected during these tests, one-half of the coal feed rate (due to testing only one-half of the boiler), and an assumed $1 \%$ conversion of $\mathrm{SO}_{2}$ to $\mathrm{SO}_{3}$. The determination of this factor was described above. It is speculated that the magnesium hydroxide content of the PHDL is more reactive with flue gas $\mathrm{SO}_{3}$ than the calcium hydroxide content, so perhaps the $\mathrm{Mg}: \mathrm{SO}_{3}$ molar ratio is a better metric for performance. The values in the table for $(\mathrm{Ca}+\mathrm{Mg}): \mathrm{SO}_{3}$ ratio can be divided by two to get the $\mathrm{Mg}: \mathrm{SO}_{3}$ mole ratio. The slurry flow rate in the table is the total to all six nozzles; the flow rate to each individual nozzle was nominally one-sixth the value shown.

Table 4-3

Flue Gas $\mathrm{SO}_{3}$ Concentration and Slurry Injection Rate Data for the PHDL Test

\begin{tabular}{|c|c|c|c|c|c|c|}
\hline \multirow[b]{2}{*}{ Date/Time } & \multirow[b]{2}{*}{$\begin{array}{l}\text { Unit Load, } \\
\text { gross MW }\end{array}$} & \multirow[b]{2}{*}{$\begin{array}{l}\text { Injection } \\
\text { Rate, gpm } \\
\text { total }\end{array}$} & \multirow[b]{2}{*}{$\begin{array}{c}(\mathrm{Ca}+\mathrm{Mg}): \\
\mathrm{SO}_{3} \text { Mole } \\
\text { Ratio }\end{array}$} & \multicolumn{3}{|c|}{$\begin{array}{c}\text { Measured } \mathrm{SO}_{3} \text { Concentration } \\
\text { (ppmv, dry basis) }\end{array}$} \\
\hline & & & & $\begin{array}{c}\text { Air Heater } \\
\text { Outlet/ESP } \\
\text { B Inlet }\end{array}$ & $\begin{array}{l}\text { ESP B } \\
\text { Outlet }\end{array}$ & $\begin{array}{l}\text { ESP C } \\
\text { Outlet }\end{array}$ \\
\hline $10 / 17 / 0013: 50$ & $N A^{*}$ & 0 & 0 & - & 19 & - \\
\hline 10/17/00 14:47 & NA & 0 & 0 & - & 20 & 26 \\
\hline 10/17/00 15:10 & NA & 0 & 0 & - & 18 & 24 \\
\hline 10/17/00 15:52 & NA & 0 & 0 & - & - & 26 \\
\hline \multicolumn{5}{|l|}{ Average } & 19 & 25 \\
\hline 10/18/00 9:38 & 807 & 0 & 0 & 42 & - & - \\
\hline 10/18/00 9:52 & 807 & 0 & 0 & 44 & 24 & - \\
\hline 10/18/00 10:30 & 820 & 0 & 0 & 35 & 21 & - \\
\hline 10/18/00 11:03 & 820 & 0 & 0 & - & 25 & 28 \\
\hline 10/18/00 11:45 & 791 & 0 & 0 & - & - & 32 \\
\hline 10/18/00 12:23 & 774 & 0 & 0 & - & - & 38 \\
\hline \multicolumn{4}{|l|}{ Average } & 40 & 24 & 32 \\
\hline 10/20/00 13:55 & 801 & 10.2 & 4.6 & 28 & 11 & 15 \\
\hline 10/20/00 14:12 & 801 & 10.2 & 4.6 & 43 & - & 13 \\
\hline 10/20/00 15:00 & 788 & 10.2 & 4.7 & 53 & 11 & 13 \\
\hline \multicolumn{4}{|l|}{ Average } & 41 & 11 & 14 \\
\hline
\end{tabular}


Results from Slurry Injection Tests

Table 4-3

Flue Gas $\mathrm{SO}_{3}$ Concentration and Slurry Injection Rate Data for the PHDL Test (continued)

\begin{tabular}{|c|c|c|c|c|c|c|}
\hline \multirow[b]{2}{*}{ Date/Time } & \multirow[b]{2}{*}{$\begin{array}{l}\text { Unit Load, } \\
\text { gross MW }\end{array}$} & \multirow[b]{2}{*}{$\begin{array}{l}\text { Injection } \\
\text { Rate, gpm } \\
\text { total }\end{array}$} & \multirow[b]{2}{*}{$\begin{array}{c}(\mathrm{Ca}+\mathrm{Mg}): \\
\mathrm{SO}_{3} \text { Mole } \\
\text { Ratio }\end{array}$} & \multicolumn{3}{|c|}{$\begin{array}{l}\text { Measured } \mathrm{SO}_{3} \text { Concentration } \\
\text { (ppmv, dry basis) }\end{array}$} \\
\hline & & & & $\begin{array}{c}\text { Air Heater } \\
\text { Outlet/ ESP } \\
\text { B Inlet }\end{array}$ & $\begin{array}{l}\text { ESP B } \\
\text { Outlet }\end{array}$ & $\begin{array}{l}\text { ESP C } \\
\text { Outlet }\end{array}$ \\
\hline 10/23/00 11:57 & NA & 0 & 0 & 29 & 27 & 13 \\
\hline $10 / 23 / 0013: 14$ & NA & 0 & 0 & 30 & 29 & 14 \\
\hline 10/23/00 13:52 & NA & 0 & 0 & 34 & 25 & 23 \\
\hline 10/23/00 14:28 & NA & 0 & 0 & 29 & 22 & - \\
\hline \multicolumn{4}{|l|}{ Average } & 30 & 25.7 & 17 \\
\hline 10/24/00 9:57 & 807 & 10.2 & 4.2 & 24 & - & 22 \\
\hline $10 / 24 / 0010: 30$ & 857 & 10.2 & 4.2 & 26 & - & 24 \\
\hline 10/24/00 10:47 & 857 & 10.2 & 4.2 & 28 & 12 & 30 \\
\hline 10/24/00 11:54 & 852 & 10.2 & 4.2 & 25 & 18 & - \\
\hline 10/24/00 12:42 & 861 & 10.2 & 4.2 & - & 20 & - \\
\hline $10 / 24 / 0013: 42$ & 842 & 10.2 & 4.2 & - & 23 & - \\
\hline 10/24/00 14:33 & 766 & 10.2 & 4.2 & - & 19 & - \\
\hline 10/24/00 15:22 & 789 & 10.2 & 4.2 & - & 22 & - \\
\hline \multicolumn{4}{|l|}{ Average } & 26 & 19 & 25 \\
\hline 10/25/00 9:00 & 867 & 10.2 & 4.1 & 35 & 19 & 46 \\
\hline 10/25/00 9:42 & 874 & 10.2 & 4.1 & 37 & - & 29 \\
\hline \multicolumn{4}{|l|}{ Average } & 36 & 19 & 37 \\
\hline 10/26/00 2:04 & 560 & 8.0 & 4.9 & 27 & 16 & 26 \\
\hline 10/26/00 2:38 & 560 & $0^{* *}$ & $0^{* *}$ & 28 & 15 & 24 \\
\hline 10/26/00 3:10 & 560 & 4.4 & 2.7 & 23 & 14 & 28 \\
\hline 10/26/00 3:45 & 559 & 13.3 & 8.2 & 6.4 & 14 & 26 \\
\hline $10 / 26 / 004: 45$ & 585 & 13.3 & 8.2 & 21 & 40 & - \\
\hline
\end{tabular}


Table 4-3

Flue Gas $\mathrm{SO}_{3}$ Concentration and Slurry Injection Rate Data for the PHDL Test (continued)

\begin{tabular}{|c|c|c|c|c|c|c|}
\hline \multirow[b]{2}{*}{ Date/Time } & \multirow[b]{2}{*}{$\begin{array}{l}\text { Unit Load, } \\
\text { gross MW }\end{array}$} & \multirow[b]{2}{*}{$\begin{array}{l}\text { Injection } \\
\text { Rate, gpm } \\
\text { total }\end{array}$} & \multirow[b]{2}{*}{$\begin{array}{c}(\mathrm{Ca}+\mathrm{Mg}): \\
\mathrm{SO}_{3} \text { Mole } \\
\text { Ratio }\end{array}$} & \multicolumn{3}{|c|}{$\begin{array}{l}\text { Measured } \mathrm{SO}_{3} \text { Concentration } \\
\text { (ppmv, dry basis) }\end{array}$} \\
\hline & & & & $\begin{array}{c}\text { Air Heater } \\
\text { Outlet/ ESP } \\
\text { B Inlet }\end{array}$ & $\begin{array}{l}\text { ESP B } \\
\text { Outlet }\end{array}$ & $\begin{array}{l}\text { ESP C } \\
\text { Outlet }\end{array}$ \\
\hline 11/1/00 1:48 & 560 & 16 & 9.8 & 23.6 & 18 & 17 \\
\hline 11/1/00 2:27 & 561 & 20 & 12 & 24.1 & 17 & 17 \\
\hline 11/1/00 3:09 & 561 & 12 & 7.3 & 24.6 & 17 & 19 \\
\hline 11/1/00 4:00 & 561 & 12 & 7.3 & 27.5 & 20 & 19 \\
\hline 11/1/00 4:46 & 606 & 12 & 6.6 & 27.2 & 20 & 21 \\
\hline
\end{tabular}

*NA - data not available

**Temporary interruption in the slurry injection.

Note: $1 \mathrm{gpm}=3.79 \mathrm{l} / \mathrm{min}$.

These same data are plotted versus time in Figure 4-2 for the first week, and Figure 4-3 for the second week of testing. The reader is referred to both the tabulated and graphical presentations of data in the following discussions.

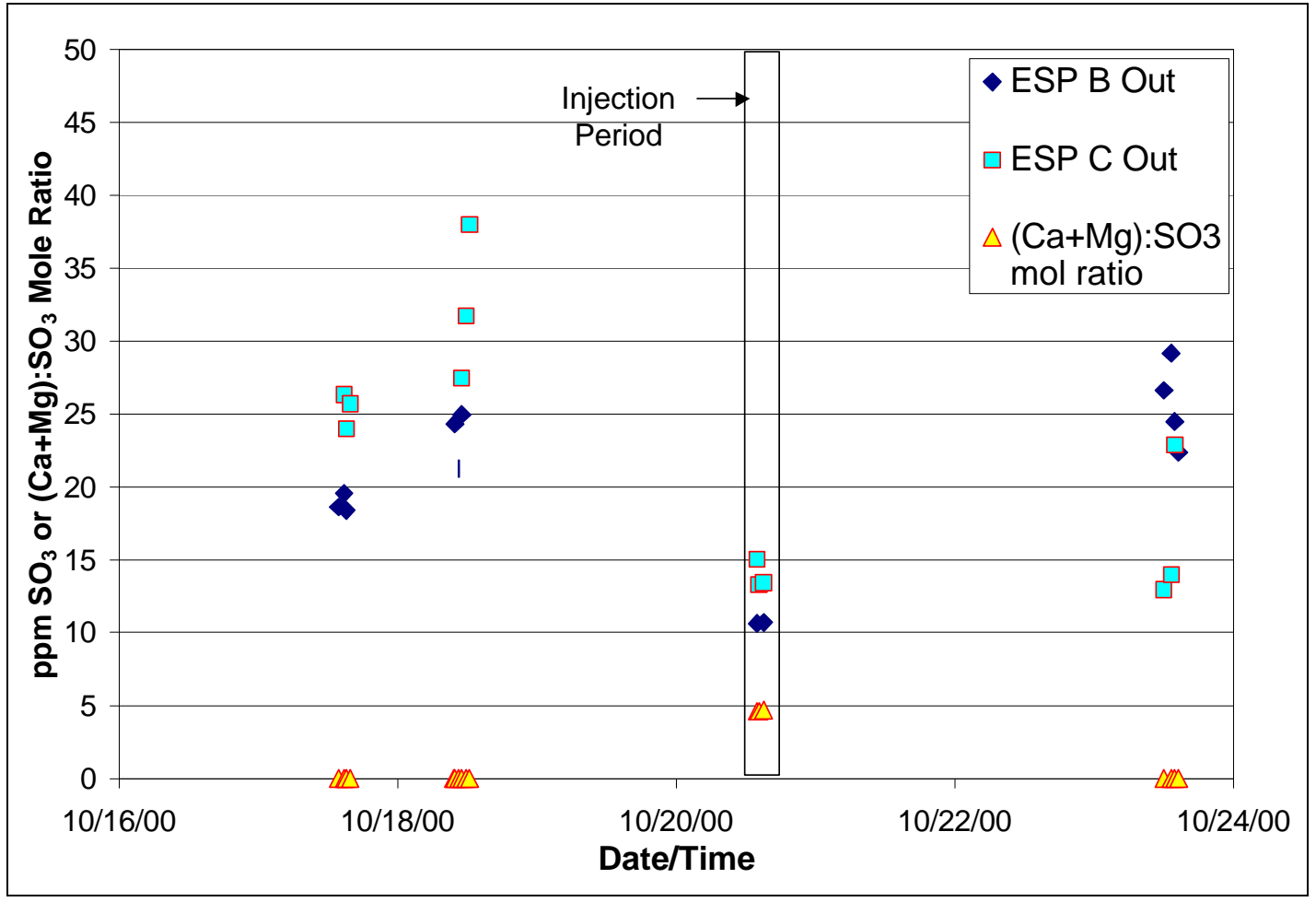

Figure 4-2

Results from the First Week of the PHDL Test 


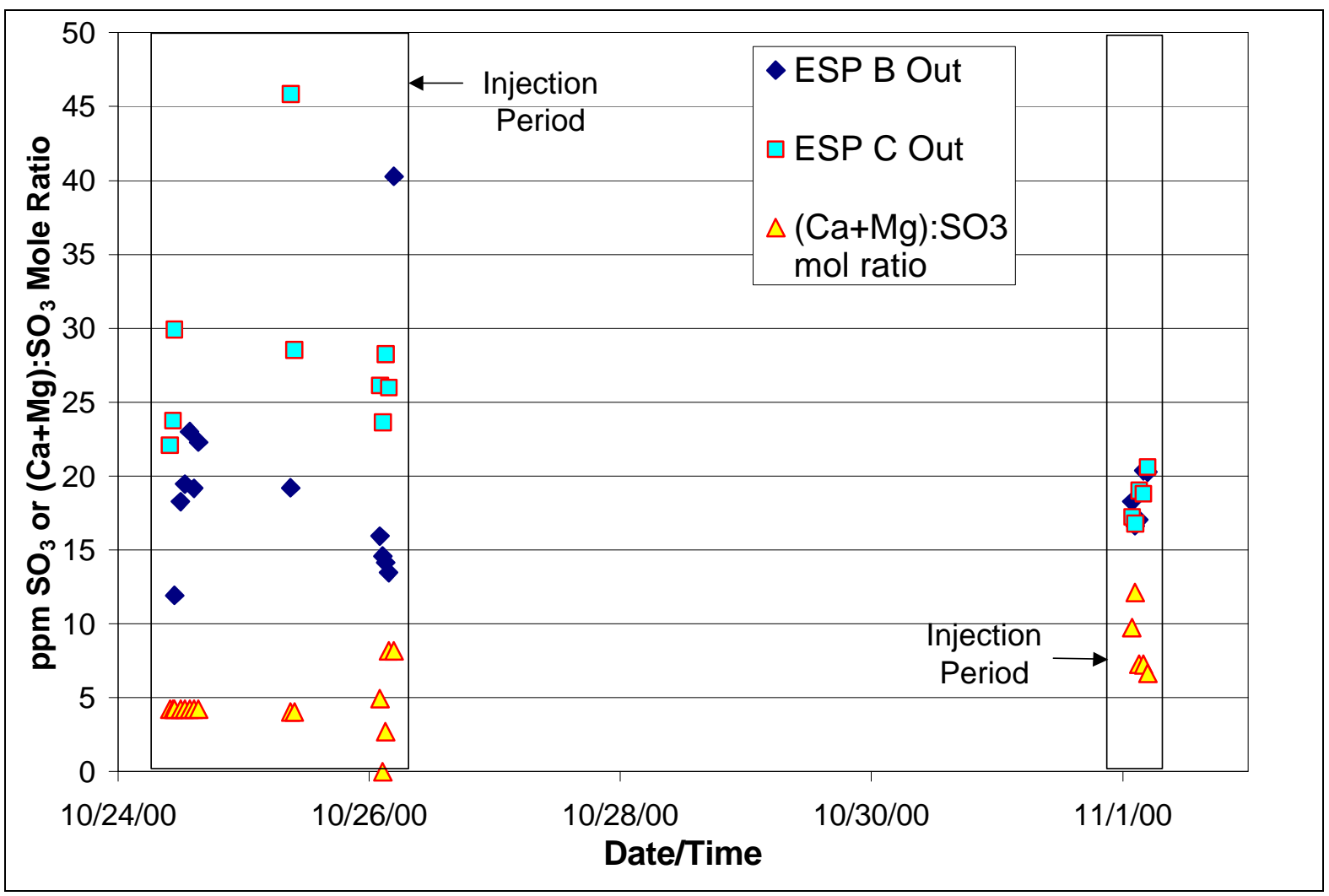

Figure 4-3

Results from the Second Week of the PHDL Test

Note that the ESP C outlet concentration data shown in the table and in the figures is on the side of the boiler not being injected, so this was assumed to represent an "uncontrolled" $\mathrm{SO}_{3}$ concentration. However, as will be discussed later in this technical note, there is evidence that the alkaline slurries being injected on the east side of the furnace were migrating to the west side and influencing $\mathrm{SO}_{3}$ concentrations being measured on the ESP C outlet. This effect was particularly evident when only three of the four ID fans and ESPs were operating, most notably when the " $\mathrm{D}$ " fan was out of service.

The data in Table 4-3 for calcium plus magnesium alkali-to- $\mathrm{SO}_{3}$ molar ratios are based on the amount of alkali in the sorbent slurry injected compared to one-half of the coal feed rate times the coal sulfur content, using the $1 \%$ factor for $\mathrm{SO}_{2}$ to $\mathrm{SO}_{3}$ conversion. Ultimate analysis data for coal samples collected during the PHDL test, which were used in these calculations, are shown in Table 4-4.

Table 4-3 does not show percentage $\mathrm{SO}_{3}$ removals for the PHDL injection periods, primarily because there is some question as to what the uncontrolled concentrations might have been at the ESP B outlet. It was hoped that the ESP C outlet concentrations would provide a good comparison for uncontrolled concentrations, but as discussed below, this did not turn out to be a good assumption due to carryover of injected material to the other side of the boiler. As can be seen in Table 4-4, the coal sulfur content varied somewhat over the test period, with most samples ranging from about 4 to $4.5 \%$ sulfur. 
Table 4-4

Ultimate Analyses of Coal Samples from the Unit 3 PHDL Test

\begin{tabular}{|c|c|c|c|c|c|c|c|c|}
\hline \multirow[b]{2}{*}{ Parameter } & \multicolumn{8}{|c|}{ Composition, wt\% (except as noted) } \\
\hline & $10 / 17$ & $10 / 18$ & $10 / 20$ & $10 / 23$ & $10 / 25$ & $10 / 26$ & $10 / 30$ & $11 / 1$ \\
\hline Carbon & 68.87 & 68.89 & 66.80 & 68.66 & 65.79 & 67.00 & 64.66 & 65.89 \\
\hline Hydrogen & 4.39 & 4.44 & 4.22 & 4.19 & 3.97 & 4.01 & 3.77 & 3.92 \\
\hline Nitrogen & 1.27 & 1.22 & 1.22 & 1.26 & 1.17 & 1.22 & 1.19 & 1.24 \\
\hline Sulfur & 3.57 & 3.99 & 4.04 & 4.37 & 4.56 & 4.03 & 4.07 & 4.18 \\
\hline Chlorine (ppm) & 466 & 527 & 684 & 549 & 477 & 610 & 547 & 540 \\
\hline Oxygen & 4.67 & 4.57 & 5.06 & 4.84 & 4.90 & 4.77 & 4.76 & 4.94 \\
\hline Moisture & 4.19 & 5.43 & 5.84 & 4.53 & 5.57 & 5.86 & 7.05 & 6.01 \\
\hline Ash & 12.99 & 11.41 & 12.75 & 12.10 & 13.99 & 13.05 & 14.45 & 13.77 \\
\hline Total & 100.00 & 100.00 & 100.00 & 100.00 & 100.00 & 100.00 & 100.00 & 100.00 \\
\hline $\begin{array}{l}\text { HHV (Btu/lb) } \\
\text { [kg-cal/kg] }\end{array}$ & $\begin{array}{l}12,301 \\
{[6833]}\end{array}$ & $\begin{array}{l}12,347 \\
{[6859]}\end{array}$ & $\begin{array}{l}12,049 \\
{[6693]}\end{array}$ & $\begin{array}{l}12,364 \\
{[6868]}\end{array}$ & $\begin{array}{l}11,866 \\
{[6592]}\end{array}$ & $\begin{array}{l}11,766 \\
{[6536]}\end{array}$ & $\begin{array}{l}11,662 \\
{[6478]}\end{array}$ & $\begin{array}{l}11,854 \\
{[6585]}\end{array}$ \\
\hline
\end{tabular}

Because the PHDL test was the first slurry injection test conducted, the sorbent injection equipment was also being started up and undergoing shake-down testing. As such, sorbent injection started and stopped a couple of times during the test. This allowed additional opportunities to collect baseline (no injection) $\mathrm{SO}_{3}$ concentration data.

Comparing the baseline data for October 18 with injection data from October 20, it appears that up to $54 \% \mathrm{SO}_{3}$ removal was realized at the ESP B outlet, for slurry injection at a $(\mathrm{Ca}+\mathrm{Mg}): \mathrm{SO}_{3}$ molar ratio of about 4.6:1. However, this level of performance was not seen again in subsequent testing. Comparing baseline values for October 23 to injection results for the next two days, it appears that only $26 \%$ removal was achieved at an only slightly lower $(\mathrm{Ca}+\mathrm{Mg}): \mathrm{SO}_{3}$ ratio of 4.2:1.

For the next two days of data in the table, the tests were conducted in the early morning hours, while the unit was at low load. Daily averages are not shown in the table because of the varied injection rates on those days. The data from the morning of October 26 showed that only about $47 \%$ removal was achieved (assuming at 25 to $26 \mathrm{ppm}$ baseline) when injecting PHDL at a relatively high $(\mathrm{Ca}+\mathrm{Mg}): \mathrm{SO}_{3}$ ratio of $8.2: 1$. This ignores a suspected bad data point $(40 \mathrm{ppm})$ for ESP B outlet concentration in the second measurement at the $13.3 \mathrm{gpm}(50 \mathrm{l} / \mathrm{min})$ slurry injection rate.

At this point, the observed $\mathrm{SO}_{3}$ removal was nowhere near the target value of $90 \%$ or higher when injecting PHDL at the then-current flow rate limit of the injection system, even at lower 
unit load. There was some expectation that $\mathrm{SO}_{3}$ removal would improve with time, due to "boiler conditioning" with the buildup of alkali solids on heat transfer surfaces, but it was presumed that this effect would not improve $\mathrm{SO}_{3}$ removal from less than $50 \%$ to more than $90 \%$. Consequently, it was decided to shut down over the weekend to increase the slurry injection rate capability with some minor piping changes to the system.

The testing on November 1 represented a last attempt to achieve higher $\mathrm{SO}_{3}$ removal percentages with the injection of PHDL. The maximum slurry flow rate achievable was about $20 \mathrm{gpm}$, but this was only for a relatively short period, as $20 \mathrm{gpm}$ exceeded the ability of the air-driven slurry transfer pumps to maintain level in the day tank. The unit load was as low overnight on November 1 as it had been on October 26. A short-term test (about one hour) at a $(\mathrm{Ca}+\mathrm{Mg}): \mathrm{SO}_{3}$ ratio of about $12: 1$ saw only about $35 \% \mathrm{SO}_{3}$ removal, based on an assumed baseline value of $25-$ $26 \mathrm{ppm}$ at the ESP B outlet. Although the test at this injection rate lasted less than one hour, slurry injection had been running at a relatively high rate for about 12 hours prior to these measurements. Continued operation at a $(\mathrm{Ca}+\mathrm{Mg}): \mathrm{SO}_{3}$ ratio of about 7:1 saw only about $25 \%$ $\mathrm{SO}_{3}$ removal based on the assumed baseline value.

This overnight test also provided the first evidence of significant solids crossover to the west side of the boiler under some injection conditions. The ESP C outlet values were measured to be almost equal to those at the ESP B outlet, and appeared to track with the slurry injection rate.

Although the true baseline $\mathrm{SO}_{3}$ concentrations for these low load tests are not known and the removal percentages are approximate, it is clear that PHDL slurry injection at the rates tested was not able to lower ESP B outlet $\mathrm{SO}_{3}$ concentrations to the desired range of less than $5 \mathrm{ppm}$. At this point it was decided to suspend PHDL testing. There were a few remaining issues associated with the PHDL tests, such as whether good slurry distribution into the boiler was being achieved, and whether or not the furnace gas temperature was too high at the $11^{\text {th }}$ floor location. However, based on the $\mathrm{SO}_{3}$ removal percentages generally being at $50 \%$ or less, and the measured ESP B outlet $\mathrm{SO}_{3}$ concentrations remaining above $10 \mathrm{ppm}$, it was decided to test another reagent to see if higher percentages could be achieved with the current injection configuration.

There was concern that the furnace gas temperature at the point of sorbent injection was too high, and was causing sorbent dead burning. If the sorbent is injected at an ideal calcining temperature, the water represented by the hydroxides evolves from the particles, leaving porous, high-surface area calcium and magnesium oxides available to react with furnace gas $\mathrm{SO}_{3}$. If the temperature is too high, though, these oxides sinter, or nearly melt, producing dense, non-porous particles that are relatively unreactive.

There are only two locations where sorbents could be injected into the upper furnace or even the back pass without extensive waterwall modifications, the $11^{\text {th }}$ floor or $14^{\text {th }}$ floor inspection ports. It was estimated that the furnace gas temperature at the $14^{\text {th }}$ floor location was about the same at full load as at the $11^{\text {th }}$ floor at reduced load. If a sorbent was not effective when injected at the $11^{\text {th }}$ floor at reduced load (e.g., $560 \mathrm{MW}$ as on October 26 and November 1), it could not be expected to be effective at full unit load even if the injection location were moved to the $14^{\text {th }}$ floor. 
To provide more data to support these discussions, FirstEnergy conducted furnace gas temperature measurements with high velocity thermocouple (HVT) probes at these locations. The results of these measurements are summarized in Table 4-5.

Table 4-5

Furnace Gas Temperature Measurements on Unit 3 Boiler at Full and Reduced Load

\begin{tabular}{|l|l|l|l|l|}
\hline \multirow{2}{*}{$\begin{array}{c}\text { Inspection } \\
\text { Port Level }\end{array}$} & \multirow{2}{*}{$\begin{array}{c}\text { Unit Load } \\
(\text { net MW) }\end{array}$} & \multicolumn{3}{|c|}{ Furnace Gas Temperature, ${ }^{\circ} \mathrm{F}\left({ }^{\circ} \mathbf{C}\right)$} \\
\cline { 3 - 5 } & & Inspection Port $\mathbf{1}^{*}$ & Inspection Port 3 & Inspection Port 4* \\
\hline $11^{\text {th }}$ Floor & 780 & $2233[1223]$ & $2338[1281]$ & $2074[1134]$ \\
\hline $11^{\text {th }}$ Floor & 500 & $2089[1143]$ & $2157[1181]$ & $1987[1086]$ \\
\hline $14^{\text {th }}$ Floor & 780 & $1935[1057]$ & $1864[1018]$ & $1875[1024]$ \\
\hline
\end{tabular}

*Refer to Figure 4-2 for inspection port numbering; all measurements made $15 \mathrm{ft}$ (4.6 m) into the 40-ft (12.2 m) furnace depth.

The results in Table 4-5 showed several things about the furnace gas temperature at the $11^{\text {th }}$ floor injection location. First, at full load, the temperatures were a bit higher than was assumed to be ideal based on furnace sorbent injection research for $\mathrm{SO}_{2}$ control 15 to 20 years ago. That research generally showed a temperature in the range of 2000 to $2200^{\circ} \mathrm{F}$ (1090 to $1200^{\circ} \mathrm{C}$ ) to be ideal to provide adequate mixing and reaction time, but minimize sintering. At low load, the temperatures were observed to be lowered into a more acceptable range, though. The second observation is that the $14^{\text {th }}$ floor temperatures were 100 to $300^{\circ} \mathrm{F}$ (60 to $160^{\circ} \mathrm{C}$ ) lower at full load than the $11^{\text {th }}$ floor temperatures at low load. If temperature were critical to sorbent reactivity in this range of furnace gas temperatures, these data show that the $14^{\text {th }}$ floor location might provide more favorable results.

\section{Commercial Mg Sorbent Injection Test Results}

The second short-term slurry injection test was originally planned to be a high-calcium (Thiosorbic ${ }^{\circledR}$ ) slaked lime, which is prepared on site as a $15 \mathrm{wt} \%$ slurry for the FGD reagent. This was seen as being a relatively low-cost reagent that was already available on site, and hence a potentially attractive option for furnace injection for $\mathrm{SO}_{3}$ control. However, based on the relatively poor performance of the PHDL in the first test, it was decided to test more of a "known quantity" for in-furnace $\mathrm{SO}_{3}$ control, commercially available magnesium hydroxide. Magnesium hydroxide and magnesium oxide have been widely used as fuel or furnace additives to control $\mathrm{SO}_{3}$ formation in oil-fired applications, and to a lesser extent have been used to control $\mathrm{SO}_{3}$ in coal-fired applications. The literature does not report any previous application of magnesium hydroxide injection on a coal-fired boiler to achieve the target $\mathrm{SO}_{3}$ removal for this project (greater than $90 \%$ removal), though.

The magnesium hydroxide selected for this test is produced by Martin Marietta Magnesia Specialties in their Manistee, Michigan plant. That material is precipitated from magnesium chloride, which reportedly produces a finer particle size than the other common route to 
producing magnesium hydroxide - pressure slaking magnesium oxide. The precipitated material is produced as a $60 \mathrm{wt} \%$ aqueous slurry. The mass mean diameter of the particles in the precipitated material is in the range of 5 to 6 microns, and the BET surface area is in the range of 11 to $16 \mathrm{~m}^{2} / \mathrm{g}$. As was the PHDL, the viscosity and density of this material at $60 \mathrm{wt} \%$ solids was too high to be handled at the anticipated injection rates by the existing temporary injection system. Consequently, this material was diluted to $30 \mathrm{wt} \%$ solids with plant service water as it was unloaded into the 11,000-gallon $\left(41 \mathrm{~m}^{3}\right)$ slurry storage tanks, and injected at $30 \mathrm{wt} \%$.

The commercial Mg test was conducted in the first part of December 2000. The results of this test are summarized in Table 4-6, and illustrated in Figures 4-4 (week one) and 4-5 (week two). The $\mathrm{Mg}: \mathrm{SO}_{3}$ ratios shown in the table and figures are based on the magnesium hydroxide content of the slurry injected compared to one-half of the coal feed rate times the coal sulfur content, using the $1 \%$ factor for $\mathrm{SO}_{2}$ to $\mathrm{SO}_{3}$ conversion. Ultimate analysis data for coal samples collected during the commercial $\mathrm{Mg}$ test, which were used in these calculations, are shown in Table 4-7.

Baseline $\mathrm{SO}_{3}$ sampling was conducted on November 28, and commercial Mg injection began that afternoon. The coal sample for that day showed an abnormally high sulfur content of $4.7 \%$, but the flue gas $\mathrm{SO}_{3}$ measurements prior to sorbent injection did not correspondingly indicate higher than normal $\mathrm{SO}_{3}$ concentrations. The baseline measurements showed a side to side $\mathrm{SO}_{3}$ stratification at the ESP outlet that was not seen in the original baseline measurements in early October. The November 28 data showed only 19 ppm of $\mathrm{SO}_{3}$ at the ESP B outlet and $30 \mathrm{ppm}$ at the ESP C outlet. Immediately after injection began, at a $\mathrm{Mg}: \mathrm{SO}_{3}$ ratio of about 5:1, two sets of $\mathrm{SO}_{3}$ measurements showed only about $10 \% \mathrm{SO}_{3}$ removal at the ESP B outlet. The next day, after almost 24 hours of sorbent injection at nominally the same rate, the indicated $\mathrm{SO}_{3}$ removal percentage at the ESP B outlet had increased to between 40 and $45 \%$.

The next set of measurements were part of an overnight test, conducted November 30, with the unit load reduced to about 550 gross MW and the injection rate increased to $10 \mathrm{gpm}$, then 17 . At the 10-gpm injection rate, corresponding to a $\mathrm{Mg}: \mathrm{SO}_{3}$ molar ratio of 11:1, the ESP B outlet $\mathrm{SO}_{3}$ was observed to drop below $10 \mathrm{ppm}$, representing about 50\% removal. At the 17 -gpm injection rate, corresponding to a $\mathrm{Mg}: \mathrm{SO}_{3}$ ratio of almost 19:1, the ESP B outlet $\mathrm{SO}_{3}$ concentration was observed to drop below 5 ppm, representing 80 to $85 \%$ removal relative to the most recent baseline value.

This test on November 30 provided clear evidence of sorbent migration to the west side of the boiler. The ESP C outlet $\mathrm{SO}_{3}$ concentrations were observed to lower from the previous day's baseline value of 28 to $30 \mathrm{ppm}$ to about $17 \mathrm{ppm}$ at the $11: 1 \mathrm{Mg}: \mathrm{SO}_{3}$ ratio, then to about $12 \mathrm{ppm}$ at the higher ratio. It was observed that the " $D$ " ID fan was out of service for this low load test. It was decided to conduct future testing with all four fans in service, to minimize side-to-side flue gas mixing that appeared to be caused by having one fan out of service (particularly the " $\mathrm{D}$ " fan).

On December 1, a series of tests was conducted to screen the effects of air pressure to the slurry atomizing nozzles on $\mathrm{SO}_{3}$ removal. Air pressure values of $80 \mathrm{psig}(550 \mathrm{kPa}), 40 \mathrm{psig}(280 \mathrm{kPa})$, and $20 \mathrm{psig}(140 \mathrm{kPa})$ were tested. It was thought that higher air pressure would lead to smaller slurry droplets, and hence greater surface area in the dried solids, which should lead to improved $\mathrm{SO}_{3}$ removal. However, lower air pressure would make bigger droplets, which would take longer 
Table 4-6

Flue Gas $\mathrm{SO}_{3}$ Concentration and Slurry Injection Rate Data for the Commercial Mg Test

\begin{tabular}{|c|c|c|c|c|c|c|}
\hline \multirow[b]{2}{*}{ Date/Time } & \multirow[b]{2}{*}{$\begin{array}{l}\text { Unit } \\
\text { Load, } \\
\text { gross } \\
\text { MW }\end{array}$} & \multirow[b]{2}{*}{$\begin{array}{c}\text { Injection } \\
\text { Rate, gpm } \\
\text { total }\end{array}$} & \multirow[b]{2}{*}{$\begin{array}{c}\mathrm{Mg}: \mathrm{SO}_{3} \text { Molar } \\
\text { Ratio }\end{array}$} & \multicolumn{3}{|c|}{$\begin{array}{c}\text { Measured } \mathrm{SO}_{3} \text { Concentration, ppmv dry } \\
\text { basis }\end{array}$} \\
\hline & & & & $\begin{array}{c}\text { Air Heater } \\
\text { Outlet/ESP B } \\
\text { Inlet }\end{array}$ & $\begin{array}{l}\text { ESP B } \\
\text { Outlet }\end{array}$ & $\begin{array}{l}\text { ESP C } \\
\text { Outlet }\end{array}$ \\
\hline 11/28/00 11:46 & 834 & 0 & 0 & 23 & 21 & 29 \\
\hline 11/28/00 12:40 & 779 & 0 & 0 & 23 & 18 & 30 \\
\hline 11/28/00 14:14 & 791 & 0 & 0 & 22 & 18 & 30 \\
\hline \multicolumn{4}{|l|}{ Average } & 22 & 19 & 30 \\
\hline 11/28/00 18:56 & 775 & 6.3 & 4.8 & - & 17 & 22 \\
\hline 11/28/00 19:29 & 775 & 6.3 & 4.9 & - & 18 & - \\
\hline \multicolumn{5}{|l|}{ Average } & 17 & \\
\hline 11/29/00 10:58 & 780 & 6.3 & 5.5 & 15 & 11 & 29 \\
\hline 11/29/00 11:39 & 790 & 6.3 & 5.4 & 17 & 11 & 30 \\
\hline \multicolumn{4}{|l|}{ Average } & 16 & 11 & 30 \\
\hline 11/29/00 12:32 & 790 & 0 & 0 & 28 & 20 & 28 \\
\hline 11/30/00 1:18 & 548 & 10 & 11 & 18 & 10 & 18 \\
\hline $11 / 30 / 00$ 2:05 & 548 & 10 & 11 & 17 & 9.3 & 17 \\
\hline $11 / 30 / 002: 56$ & 549 & 17 & 19 & 14 & 5.0 & 12 \\
\hline $11 / 30 / 003: 51$ & 549 & 17 & 19 & 11 & 3.6 & 12 \\
\hline 12/1/00 10:20 & 780 & 6.3 & 5.3 & 24 & 17 & 23 \\
\hline $12 / 1 / 0010: 57$ & 780 & 6.3 & 5.3 & 27 & 18 & 22 \\
\hline 12/1/00 12:37 & 773 & 6.3 & 5.4 & 28 & $19^{* *}$ & 21 \\
\hline \multirow[t]{2}{*}{ 12/1/00 13:12 } & 773 & 6.3 & 5.4 & 29 & $20^{* *}$ & 26 \\
\hline & & $0^{*}$ & & - & & \\
\hline 12/1/00 15:38 & 777 & 6.3 & 5.3 & 31 & $20^{* \star *}$ & 23 \\
\hline $12 / 1 / 0016: 13$ & 777 & 6.3 & 5.3 & 38 & $21^{\star \star *}$ & 25 \\
\hline
\end{tabular}


Results from Slurry Injection Tests

Table 4-6

Flue Gas $\mathrm{SO}_{3}$ Concentration and Slurry Injection Rate Data for the Commercial Mg Test (continued)

\begin{tabular}{|c|c|c|c|c|c|c|}
\hline \multirow[b]{2}{*}{ Date/Time } & \multirow[b]{2}{*}{$\begin{array}{c}\text { Unit } \\
\text { Load, } \\
\text { gross } \\
\text { MW }\end{array}$} & \multirow[b]{2}{*}{$\begin{array}{l}\text { Injection } \\
\text { Rate, gpm } \\
\text { total }\end{array}$} & \multirow[b]{2}{*}{$\begin{array}{c}\mathrm{Mg}: \mathrm{SO}_{3} \text { Molar } \\
\text { Ratio }\end{array}$} & \multicolumn{3}{|c|}{$\begin{array}{c}\text { Measured } \mathrm{SO}_{3} \text { Concentration, ppmv dry } \\
\text { basis }\end{array}$} \\
\hline & & & & $\begin{array}{c}\text { Air Heater } \\
\text { Outlet/ESP B } \\
\text { Inlet }\end{array}$ & $\begin{array}{l}\text { ESP B } \\
\text { Outlet }\end{array}$ & $\begin{array}{l}\text { ESP C } \\
\text { Outlet }\end{array}$ \\
\hline 12/4/00 9:59 & 768 & 6.3 & 5.4 & 21 & 15 & 23 \\
\hline $12 / 4 / 0010: 54$ & 767 & 6.3 & 5.4 & 28 & 19 & 22 \\
\hline 12/4/00 12:18 & 762 & 10 & 8.6 & 22 & 15 & 21 \\
\hline $12 / 4 / 0012: 53$ & 753 & 10 & 8.7 & 25 & 14 & 19 \\
\hline 12/4/00 14:32 & 775 & 17 & 14 & 22 & 10 & 19 \\
\hline $12 / 4 / 00$ 15:10 & 775 & 17 & 14 & 21 & 9.4 & 20 \\
\hline 12/5/00 10:03 & 824 & 6.3 & 4.7 & 18 & 7.1 & 31 \\
\hline 12/5/00 10:36 & 824 & 6.3 & 4.8 & 15 & 9.3 & 31 \\
\hline 12/5/00 12:24 & 822 & 6.3 & 4.8 & 17 & $12^{\star \star}$ & 31 \\
\hline 12/5/00 12:58 & 828 & 6.3 & 4.7 & 22 & $13^{\star *}$ & 35 \\
\hline 12/5/00 14:36 & 836 & 6.3 & 4.7 & 20 & $13^{\star * \star}$ & 35 \\
\hline $12 / 5 / 0015: 11$ & 836 & 6.3 & 4.7 & 25 & $14^{* * *}$ & 36 \\
\hline 12/6/00 9:35 & 817 & 6.3 & 5.0 & 14 & 13 & 31 \\
\hline 12/6/00 10:08 & 817 & 6.3 & 5.0 & 18 & 12 & 34 \\
\hline 12/6/00 12:06 & 822 & 10 & 8.1 & 15 & 9.0 & 29 \\
\hline 12/6/00 12:41 & 828 & 10 & 7.9 & 14 & 8.5 & 32 \\
\hline 12/6/00 14:22 & 825 & 17 & 14 & 6.2 & 3.6 & 30 \\
\hline 12/6/00 14:56 & 836 & 17 & 13 & 8.6 & 3.8 & 28 \\
\hline 12/7/00 11:05 & 791 & 14 & 12 & 2.5 & 2.4 & 28 \\
\hline 12/7/00 11:40 & 784 & 14 & 12 & 2.3 & 2.3 & 24 \\
\hline 12/7/00 13:42 & 785 & 17 & 14 & 3.0 & 2.1 & 25 \\
\hline
\end{tabular}


Table 4-6

Flue Gas $\mathrm{SO}_{3}$ Concentration and Slurry Injection Rate Data for the Commercial Mg Test (continued)

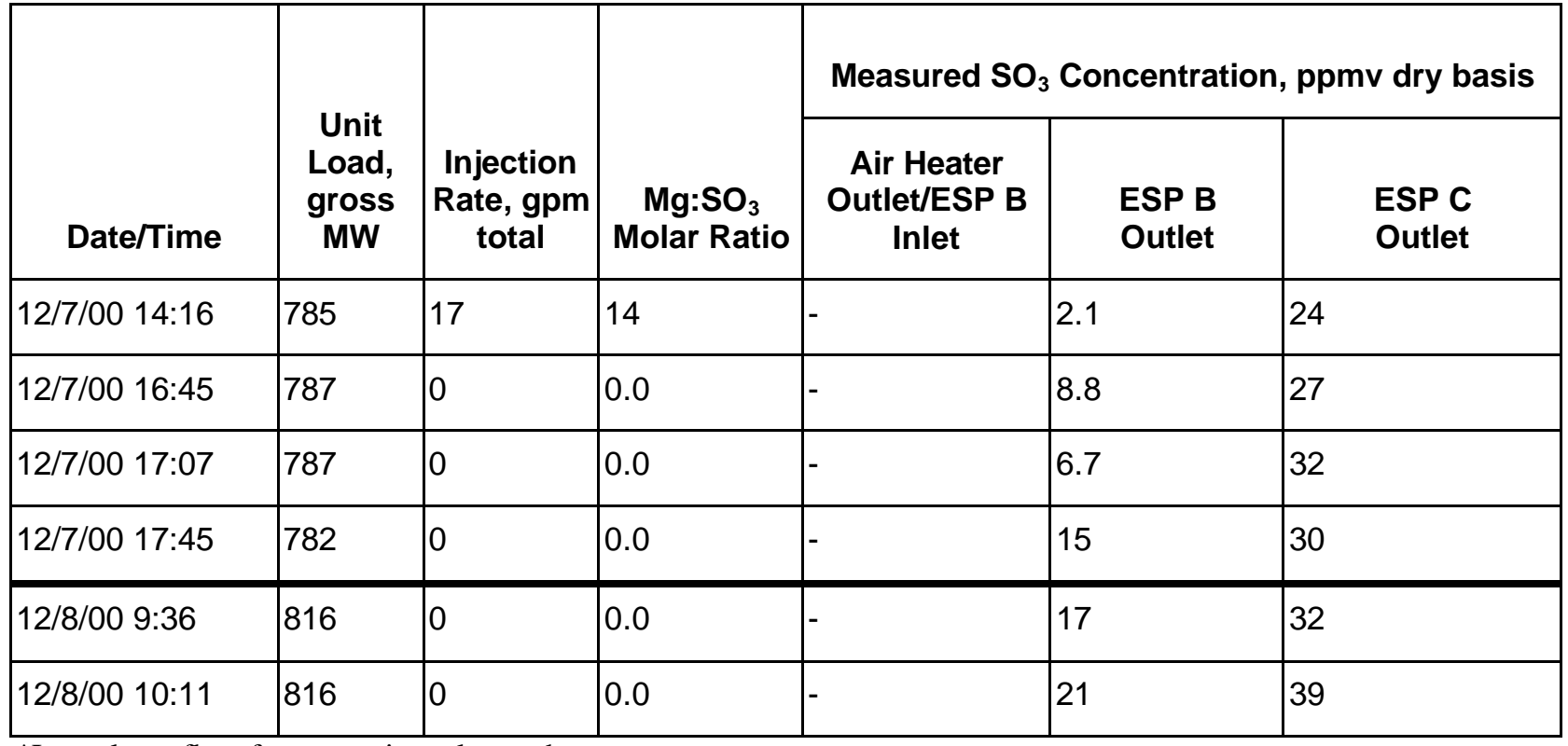

*Lost slurry flow for approximately one hour.

**Low pressure test, 40 psig air pressure to lances.

***Low pressure test, 20 psig air pressure to lances.

Note: $1 \mathrm{gpm}=3.79 \mathrm{l} / \mathrm{min}$.

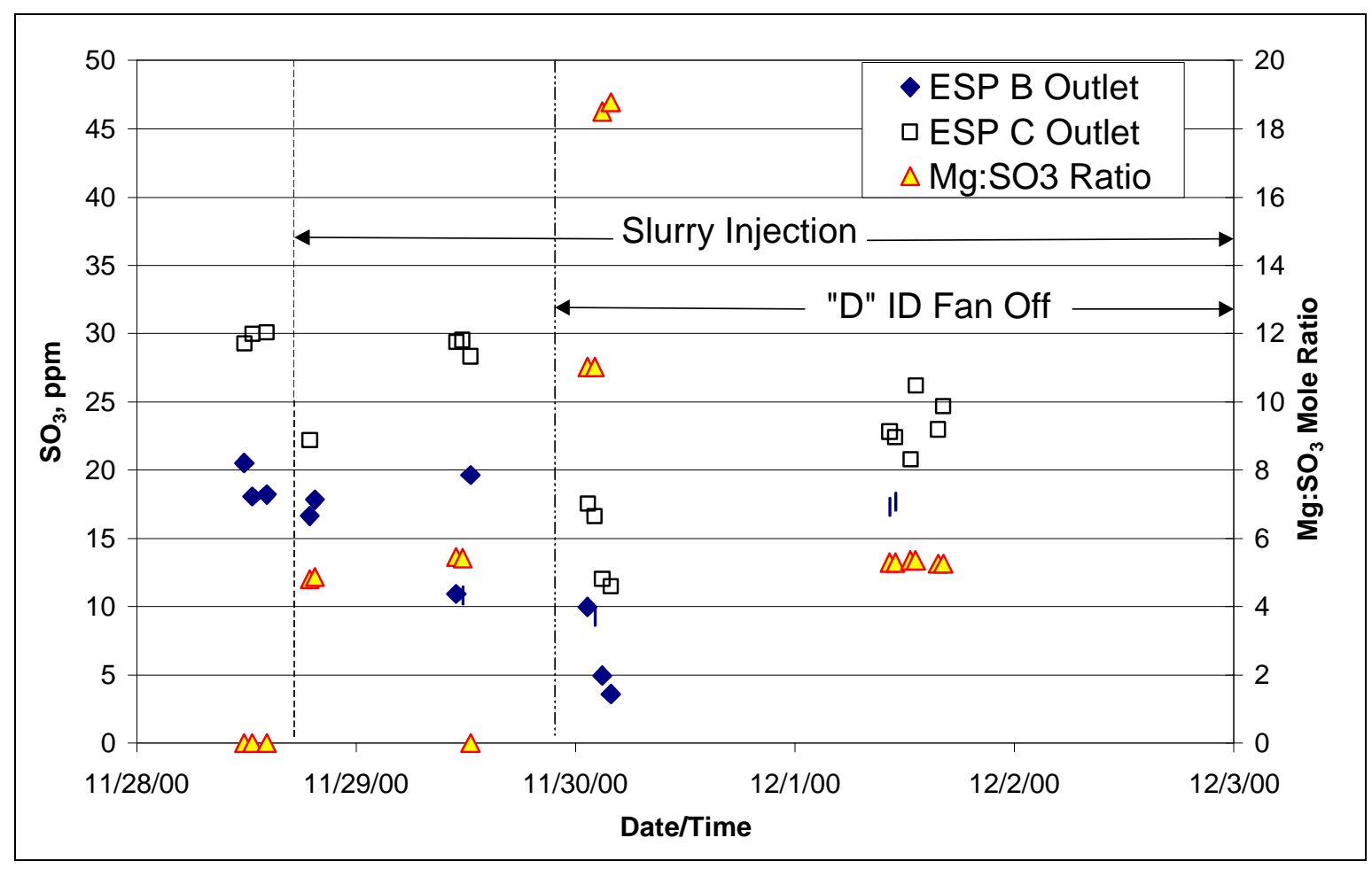

Figure 4-4

Results from the First Week of the Commercial Mg Test 


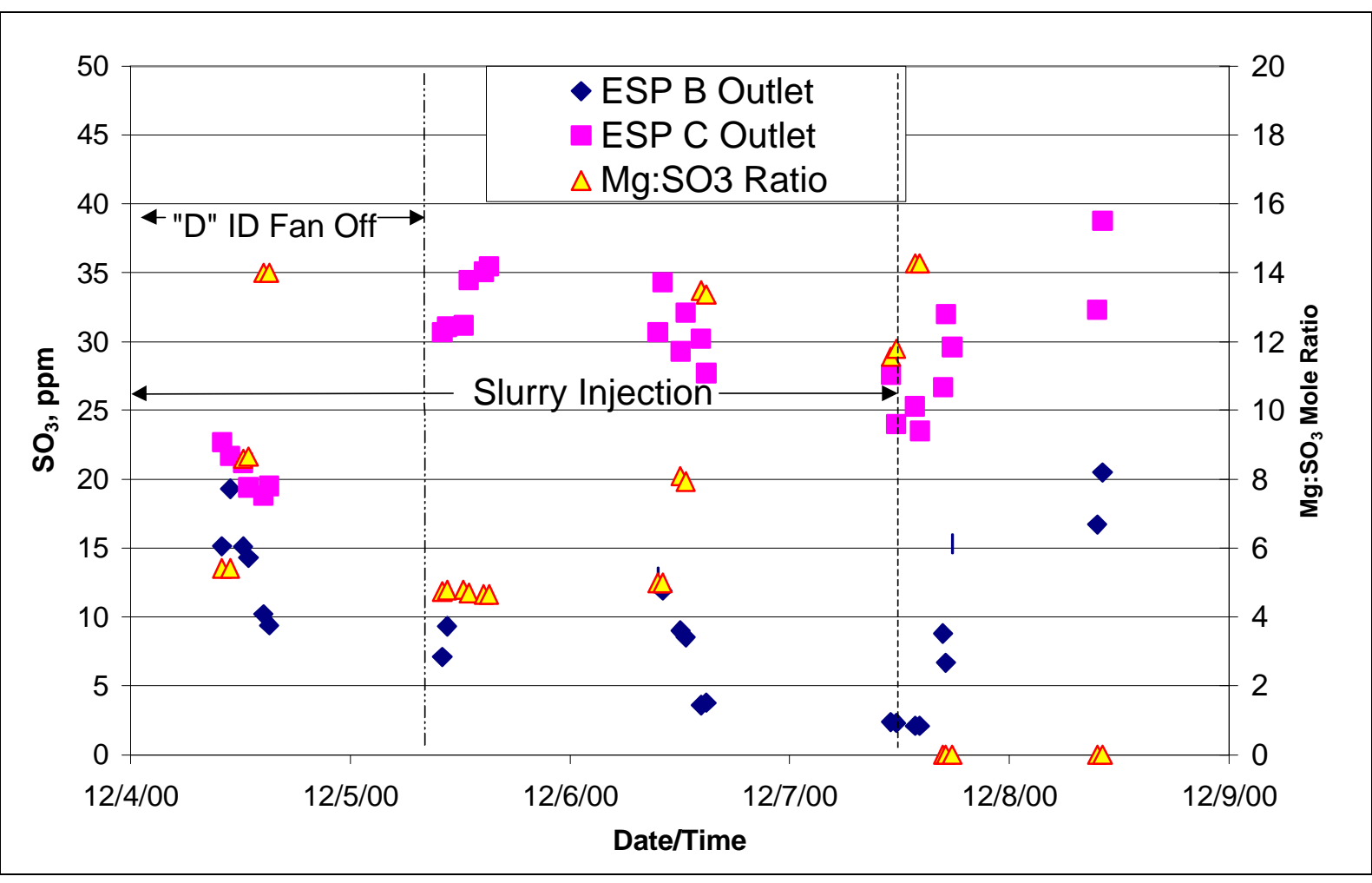

Figure 4-5

Results from the Second Week of the Commercial Mg Test

to evaporate. This could better protect the dried solids from sintering (they would likely reach a lower maximum temperature) and the bigger droplets were also expected to better penetrate the 40-ft (12.2-m) depth of the furnace cavity. These effects might improve $\mathrm{SO}_{3}$ removal when the air pressure is reduced.

The results for December 1 show that the highest pressure produced the lowest ESP B outlet $\mathrm{SO}_{3}$ concentrations. However, the overall $\mathrm{SO}_{3}$ removal levels observed were relatively low. These tests were conducted with the "D" ID fan still off-line, and evidence of minor sorbent migration to the west side was seen in the ESP C outlet $\mathrm{SO}_{3}$ concentrations. The $\mathrm{C}$ outlet concentrations were measured to be in range of 21 to $26 \mathrm{ppm}$, whereas they had ranged from 29 to $30 \mathrm{ppm}$ on November 29 at the same injection rate but all four fans in service. Consequently, the nozzle air pressure screening was conducted again later in the test period. Those results, from testing on December 5, showed the same effect of air pressure, with the highest pressure being the best in terms of lowering ESP B outlet $\mathrm{SO}_{3}$ concentrations. Due to limitations on the supply and pressure of plant compressed air at the $14^{\text {th }}$ floor location, it was not possible to test higher air pressures than 80 psig $(550 \mathrm{kPa})$. It is possible that better $\mathrm{SO}_{3}$ removal performance could be achieved if 100-psig (690-kPa) air were available.

Perhaps the most noteworthy results from the commercial $\mathrm{Mg}$ test came in the last two days of operation, December 6 and 7. By this time, the commercial $\mathrm{Mg}$ sorbent had been injected continuously for over a week, at injection rates corresponding to about a 5:1 $\mathrm{Mg}: \mathrm{SO}_{3}$ ratio or better. It was expected that over the period of a week or more, the boiler would be "conditioned" 
Table 4-7

Ultimate Analyses of Coal Samples from the Commercial Mg Test

\begin{tabular}{|c|c|c|c|c|c|}
\hline \multirow[b]{2}{*}{ Parameter } & \multicolumn{5}{|c|}{ Composition, wt\% (except as noted) } \\
\hline & $11 / 28$ & $11 / 29$ & $12 / 1$ & $12 / 6$ & $12 / 8$ \\
\hline Carbon & 64.76 & 66.41 & 66.42 & 65.85 & 62.94 \\
\hline Hydrogen & 4.30 & 4.57 & 4.48 & 4.48 & 4.27 \\
\hline Nitrogen & 1.14 & 1.15 & 1.13 & 1.11 & 1.04 \\
\hline Sulfur & 4.74 & 4.05 & 4.19 & 4.08 & 3.86 \\
\hline Chlorine (ppm) & NA & NA & NA & NA & NA \\
\hline Oxygen & 4.66 & 4.94 & 4.10 & 4.67 & 5.00 \\
\hline Moisture & 6.36 & 5.48 & 5.30 & 5.25 & 7.57 \\
\hline Ash & 14.04 & 13.40 & 14.38 & 14.56 & 15.32 \\
\hline Total & 100.00 & 100.00 & 100.00 & 100.00 & 100.00 \\
\hline $\begin{array}{l}\operatorname{HHV}(\mathrm{Btu} / \mathrm{lb}) \\
{[\mathrm{kg}-\mathrm{cal} / \mathrm{kg}]}\end{array}$ & $\begin{array}{l}11,548 \\
{[6415]}\end{array}$ & $\begin{array}{l}12,062 \\
{[6700]}\end{array}$ & $\begin{array}{l}11,903 \\
{[6612]}\end{array}$ & $\begin{array}{l}11,955 \\
{[6641]}\end{array}$ & $\begin{array}{l}11,446 \\
{[6358]}\end{array}$ \\
\hline
\end{tabular}

*NA - Not analyzed.

by reaching a steady state buildup of $\mathrm{MgO}$ on heat transfer surfaces, and that $\mathrm{SO}_{3}$ removal performance would continually improve over time. However, after a week of continuous injection it became apparent that the $\mathrm{SO}_{3}$ removal percentage desired at the ESP B outlet would not be achieved without increasing the injection rate to achieve $\mathrm{Mg}: \mathrm{SO}_{3}$ ratios well above 5:1. From the afternoon of December 6 through the afternoon of December 7, the commercial Mg sorbent was injected at a flow rate corresponding to a $\mathrm{Mg}: \mathrm{SO}_{3}$ molar ratio of 12:1 to 14:1. After about 24 hours of injection at this rate, the observed ESP B outlet $\mathrm{SO}_{3}$ concentrations were measured at about $2.3 \mathrm{ppm}$ at a $12: 1$ mole ratio, and $2.1 \mathrm{ppm}$ at a 14:1 mole ratio. These values represent approximately $90 \% \mathrm{SO}_{3}$ removal, the target for this project.

The data from December 7 were collected with all four Unit 3 ID fans in service. The observed migration of sorbent over to the west side of the boiler was greatly reduced with all four fans in service, with the ESP C outlet $\mathrm{SO}_{3}$ concentrations measured to be near baseline at 24 to $28 \mathrm{ppm}$. Figure 4-6 illustrates magnesium concentration values measured for fly ash samples collected from the hoppers on the "B" and "C" ESPs during the commercial Mg test. The results show that the magnesium content of the hopper ash samples from ESP C increased to about one-third those in ESP B while the "D" ID fan was out of service. This is indicative of considerable sorbent migration to the west side of the boiler. After the "D" ID fan was placed back in service, the ESP $\mathrm{C}$ magnesium levels decreased, although they remained somewhat higher than the baseline (no sorbent injection) levels. 


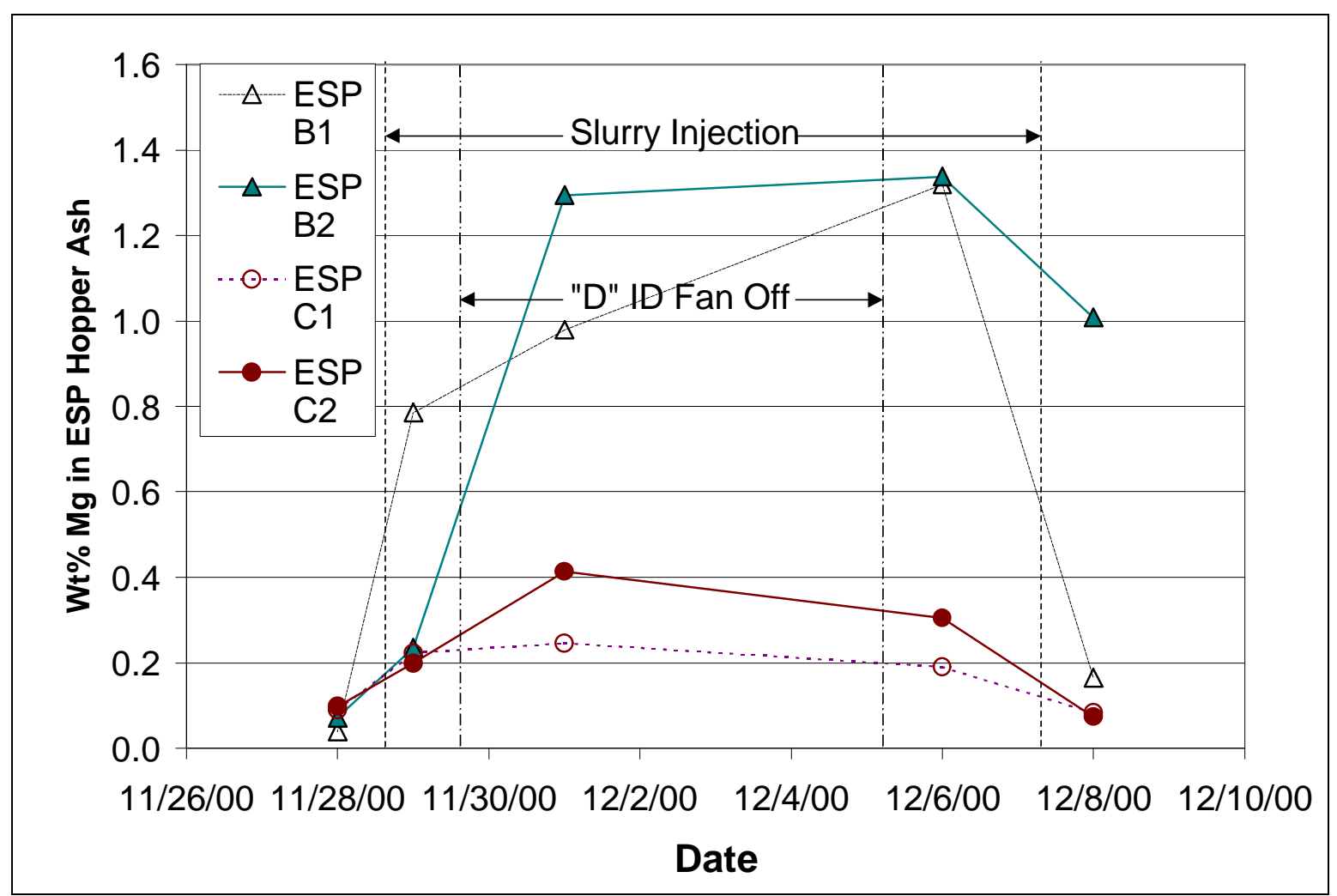

Figure 4-6

Illustration of Magnesium Concentrations in ESP Hopper Ash Samples

In Table 4-6, the data from the evening of December 7 and the morning of December 8 show how rapidly the ESP B outlet $\mathrm{SO}_{3}$ concentrations return to baseline levels after continued sorbent injection at a high rate. Within one to two hours of ceasing sorbent injection, the ESP B outlet $\mathrm{SO}_{3}$ concentrations increased to a level corresponding to about 55 to $65 \%$ removal, and by the next morning, the $\mathrm{SO}_{3}$ concentrations had returned to essentially baseline values. The magnesium concentration data in Figure 4-6 similarly show that the ESP hopper samples had returned to essentially baseline magnesium levels.

\section{Byproduct Mg Test}

The third short-term slurry injection test was conducted the weeks of February 12 and February 19, 2001, using a byproduct magnesium hydroxide produced at Allegheny Energy's Pleasants Station. The Pleasants Station has a modified Dravo Thiosorbic ${ }^{\circledR}$ lime FGD process that employs external forced oxidation to produce a gypsum byproduct. The remaining liquor after the gypsum is produced can be further processed by lime addition to precipitate a mixture of magnesium hydroxide and gypsum particles. This stream is purified to recover most of the gypsum, and a second byproduct is a slurry that contains a mixture of magnesium hydroxide (about $65 \%$ of the solids) and gypsum fines (most of the remaining solids). With the current equipment configuration at the Pleasants Station, this byproduct slurry is produced at about 15 to $20 \mathrm{wt} \%$ total suspended solids. 
The solids in this slurry average about 4 to 5 microns for a mass mean particle diameter, and have a specific surface area of about 49 to $63 \mathrm{~m}^{2} / \mathrm{g}$. The gypsum solids in this slurry most likely have a low specific surface area (less than $5 \mathrm{~m}^{2} / \mathrm{g}$ ) and contribute very little to the average, so the specific surface area of the magnesium hydroxide in this slurry is probably in the range of 70 to $100 \mathrm{~m}^{2} / \mathrm{g}$.

For the short-term byproduct $\mathrm{Mg}$ slurry injection test, the byproduct slurry was trucked from the Pleasants Station and unloaded into the 11,000-gallon $\left(41 \mathrm{~m}^{3}\right)$ storage tanks at BMP Unit 3. Several truckloads per day were required at the slurry injection rates tested.

The results from the byproduct $\mathrm{Mg}$ test are summarized in Table 4-8, and plotted in Figures 4-7 (first week) and 4-8 (second week). The $\mathrm{Mg}: \mathrm{SO}_{3}$ molar ratios in the table are based on the amount of $\mathrm{Mg}$ in the byproduct slurry, one-half the Unit 3 coal feed rate, and ultimate analyses of coal samples for this time period. The coal ultimate analyses are summarized in Table 4-9. The results in Table 4-9 show that the coal quality was quite variable during the two-week test period, and that coal sulfur levels were generally lower than they had been during the previous weeklong baseline period and the two previous short-term slurry injection tests. The coal sulfur averaged about $3.5 \mathrm{wt} \%$ for this test versus about $4 \%$ for the previous tests. Unfortunately, this test was conducted during a time period that the supply of high-sulfur bituminous coal was tight in that part of the country, so the typical coal blend fired at BMP was not available.

In spite of the coal sulfur analyses showing lower sulfur content, the baseline $\mathrm{SO}_{3}$ concentrations measured on February 13 are as high as previous measurements with the higher-sulfur coals. Given that normal flue gas $\mathrm{SO}_{3}$ concentrations were seen, the $\mathrm{Mg}: \mathrm{SO}_{3}$ ratios shown in the table and figures may be biased high by 10 to $15 \%$ because of the lower coal sulfur values used for the calculations.

Note in the table that most of the baseline samples for this short-term test were taken with an ID fan out of service ("A" or "C"). Since the ID fans in service affect the flow rates through the air heaters, they can also affect the downstream $\mathrm{SO}_{3}$ concentrations. This may explain why the baseline values for the ESP B outlet location were initially measured to be higher than they had been for the previous commercial Mg test. After the "C" fan was put back in service and the "A" fan was taken out of service around 10:00 a.m. on February 14, the ESP B outlet concentration was measured to drop to about $20 \mathrm{ppm}$ (one measurement), which is consistent with what it had measured during the commercial $\mathrm{Mg}$ test.

Unit 3 continued to operate on three ID fans ("A" fan out of service) through Friday afternoon of the first week of the test. Most of the testing was conducted with $\mathrm{Mg}: \mathrm{SO}_{3}$ molar ratios of about 5:1 to 6:1, and ESP B outlet $\mathrm{SO}_{3}$ concentrations were typically measured at about 10 to $12 \mathrm{ppm}$. This represents about 40 to $50 \% \mathrm{SO}_{3}$ removal based on $20 \mathrm{ppm}$ as a baseline value, 60 to $70 \%$ removal if the baseline values were actually around $30 \mathrm{ppm}$ as they had been earlier in the week.

The late in the afternoon of Friday, February 16, the slurry injection rate was raised to the maximum achievable value, which corresponded to a $\mathrm{Mg}: \mathrm{SO}_{3}$ molar ratio of almost 9:1. Midway through the afternoon, the boiler operators placed the "A" ID fan back in service, meaning all 
Results from Slurry Injection Tests

Table 4-8

Summary of Results from Short-term Byproduct Mg Test on Unit 3

\begin{tabular}{|c|c|c|c|c|c|}
\hline \multirow[b]{2}{*}{ Date/Time } & \multirow[b]{2}{*}{$\begin{array}{l}\text { Unit Load, } \\
\text { gross MW }\end{array}$} & \multirow[b]{2}{*}{$\begin{array}{c}\mathrm{Mg}: \mathrm{SO}_{3} \text { Molar } \\
\text { Ratio }\end{array}$} & \multicolumn{3}{|c|}{$\mathrm{SO}_{3}$ Concentration, ppmv } \\
\hline & & & $\begin{array}{c}\text { Air Heater } \\
\text { Outlet/ESP B } \\
\text { Inlet }\end{array}$ & $\begin{array}{l}\text { ESP B } \\
\text { Outlet }\end{array}$ & $\begin{array}{l}\text { ESP C } \\
\text { Outlet }\end{array}$ \\
\hline 2/13/01 9:48 & 771 & 0.0 & 36 & - & 35 \\
\hline 2/13/01 10:35 & 716 & 0.0 & 32 & - & 31 \\
\hline 2/13/01 13:04 & 715 & 0.0 & 38 & 24 & 31 \\
\hline 2/13/01 13:53 & 716 & 0.0 & - & 33 & - \\
\hline 2/13/01 14:28 & 716 & 0.0 & - & 30 & - \\
\hline \multicolumn{3}{|l|}{ Average } & 36 & 29 & 32 \\
\hline 2/14/01 7:42 & 654 & 0.0 & $41^{*}$ & $31^{*}$ & $-*$ \\
\hline 2/14/01 8:20 & 653 & 0.0 & $43^{*}$ & $35^{\star}$ & $-^{*}$ \\
\hline 2/14/01 8:58 & 658 & 0.0 & $42^{*}$ & $33^{*}$ & -* \\
\hline 2/14/01 9:34 & 658 & 0.0 & $28^{*}$ & $26^{*}$ & $-*$ \\
\hline 2/14/01 10:09 & 680 & 0.0 & $17^{\star \star}$ & $20^{* *}$ & $29^{\star \star}$ \\
\hline 2/14/01 12:21 & 678 & 4.4 & $18^{* \star}$ & $14^{* *}$ & $27^{\star \star}$ \\
\hline 2/14/01 12:55 & 677 & 4.7 & $14^{\star \star}$ & $13^{* *}$ & $29^{\star \star}$ \\
\hline $2 / 14 / 01$ 13:51 & 638 & 5.4 & $14^{\star *}$ & $11^{* *}$ & $25^{\star \star}$ \\
\hline 2/14/01 15:20 & 611 & 5.7 & - & $10^{* *}$ & $25^{\star *}$ \\
\hline 2/15/01 9:50 & 782 & 6.1 & $18^{* \star}$ & $12^{* *}$ & $28^{* *}$ \\
\hline 2/15/01 10:30 & 782 & 6.1 & $14^{* *}$ & $10^{* *}$ & $28^{* *}$ \\
\hline $2 / 15 / 0111: 24$ & 755 & 6.4 & $17^{* *}$ & - & $27^{* *}$ \\
\hline 2/15/01 13:31 & 755 & 6.4 & $17^{\star \star}$ & $11^{* *}$ & $30^{* *}$ \\
\hline 2/15/01 14:04 & 755 & 5.6 & $17^{\star \star}$ & $12^{* *}$ & $28^{* *}$ \\
\hline 2/15/01 14:37 & 755 & 5.6 & $14^{\star *}$ & $11^{* *}$ & $27^{\star *}$ \\
\hline \multicolumn{3}{|l|}{ Average } & $16^{* *}$ & $11^{* *}$ & $28^{* *}$ \\
\hline 2/16/01 9:39 & 777 & 3.9 & $8.0^{* *}$ & $11^{* *}$ & $36^{* *}$ \\
\hline
\end{tabular}


Table 4-8

Summary of Results from Short-term Byproduct Mg Test on Unit 3 (continued)

\begin{tabular}{|c|c|c|c|c|c|}
\hline \multirow[b]{2}{*}{ Date/Time } & \multirow[b]{2}{*}{$\begin{array}{l}\text { Unit Load, } \\
\text { gross MW }\end{array}$} & \multirow[b]{2}{*}{$\begin{array}{c}\mathrm{Mg}: \mathrm{SO}_{3} \text { Molar } \\
\text { Ratio }\end{array}$} & \multicolumn{3}{|c|}{$\mathrm{SO}_{3}$ Concentration, ppmv } \\
\hline & & & $\begin{array}{c}\text { Air Heater } \\
\text { Outlet/ESP B } \\
\text { Inlet }\end{array}$ & $\begin{array}{l}\text { ESP B } \\
\text { Outlet }\end{array}$ & $\begin{array}{l}\text { ESP C } \\
\text { Outlet }\end{array}$ \\
\hline 2/16/01 10:36 & 769 & 0.4 & $20^{\star *}$ & $17^{\star *}$ & $28^{* *}$ \\
\hline 2/16/01 11:12 & 774 & 4.5 & $20^{\star *}$ & $12^{* *}$ & $26^{\star *}$ \\
\hline 2/16/01 11:39 & 774 & 6.4 & $37^{\star *}$ & - & - \\
\hline 2/16/01 13:13 & 771 & 8.8 & $20^{\star *}$ & $15^{\star *}$ & $28^{* *}$ \\
\hline 2/16/01 14:20 & 772 & 8.8 & 26 & 17 & 32 \\
\hline 2/16/01 15:06 & 772 & 8.8 & 19 & 17 & 31 \\
\hline 2/19/01 9:20 & 808 & 0.0 & 31 & 29 & 38 \\
\hline 2/19/01 9:49 & 807 & 0.0 & 36 & 29 & 33 \\
\hline 2/19/01 10:23 & 807 & 0.0 & 38 & 26 & 34 \\
\hline 2/19/01 14:42 & 804 & 3.2 & 20 & 17 & 34 \\
\hline 2/19/01 15:17 & 807 & 3.3 & 21 & 15 & 30 \\
\hline 2/19/01 15:52 & 806 & 3.3 & 21 & 13 & 31 \\
\hline 2/20/01 9:29 & 787 & 3.9 & 13 & 12 & 35 \\
\hline 2/20/01 10:05 & 810 & 3.8 & 21 & 11 & 35 \\
\hline 2/20/01 10:39 & 810 & 3.8 & 23 & 11 & 35 \\
\hline 2/20/01 11:14 & 815 & 3.8 & - & 11 & 35 \\
\hline 2/20/01 11:50 & 811 & 3.8 & 17 & 10 & 34 \\
\hline 2/21/01 9:49 & 800 & 5.4 & 8.3 & 7.3 & 30 \\
\hline 2/21/01 10:24 & 802 & 7.2 & 5.1 & 3.9 & 24 \\
\hline 2/21/01 11:19 & 794 & 7.3 & 4.5 & 2.0 & 24 \\
\hline 2/21/01 12:10 & 770 & 7.0 & 3.7 & 1.7 & 20 \\
\hline 2/21/01 13:03 & 807 & 7.1 & 3.8 & 2.4 & 25 \\
\hline
\end{tabular}


Table 4-8

Summary of Results from Short-term Byproduct Mg Test on Unit 3 (continued)

\begin{tabular}{|c|c|c|c|c|c|}
\hline \multirow[b]{2}{*}{ Date/Time } & \multirow[b]{2}{*}{$\begin{array}{l}\text { Unit Load, } \\
\text { gross MW }\end{array}$} & \multirow[b]{2}{*}{$\begin{array}{c}\mathrm{Mg}: \mathrm{SO}_{3} \text { Molar } \\
\text { Ratio }\end{array}$} & \multicolumn{3}{|c|}{$\mathrm{SO}_{3}$ Concentration, ppmv } \\
\hline & & & $\begin{array}{c}\text { Air Heater } \\
\text { Outlet/ ESP B } \\
\text { Inlet }\end{array}$ & $\begin{array}{l}\text { ESP B } \\
\text { Outlet }\end{array}$ & $\begin{array}{l}\text { ESP C } \\
\text { Outlet }\end{array}$ \\
\hline 2/22/01 9:23 & 814 & 6.9 & 36 & 8.9 & 38 \\
\hline 2/22/01 10:00 & 811 & 4.1 & 32 & 14 & 39 \\
\hline 2/22/01 11:47 & 769 & 4.4 & 27 & 23 & 40 \\
\hline 2/22/01 12:21 & 807 & 4.1 & 45 & 28 & 40 \\
\hline 2/22/01 12:58 & 748 & 4.5 & 32 & 18 & 39 \\
\hline
\end{tabular}

*“C" ID fan out of service.

**“A" ID fan out of service.

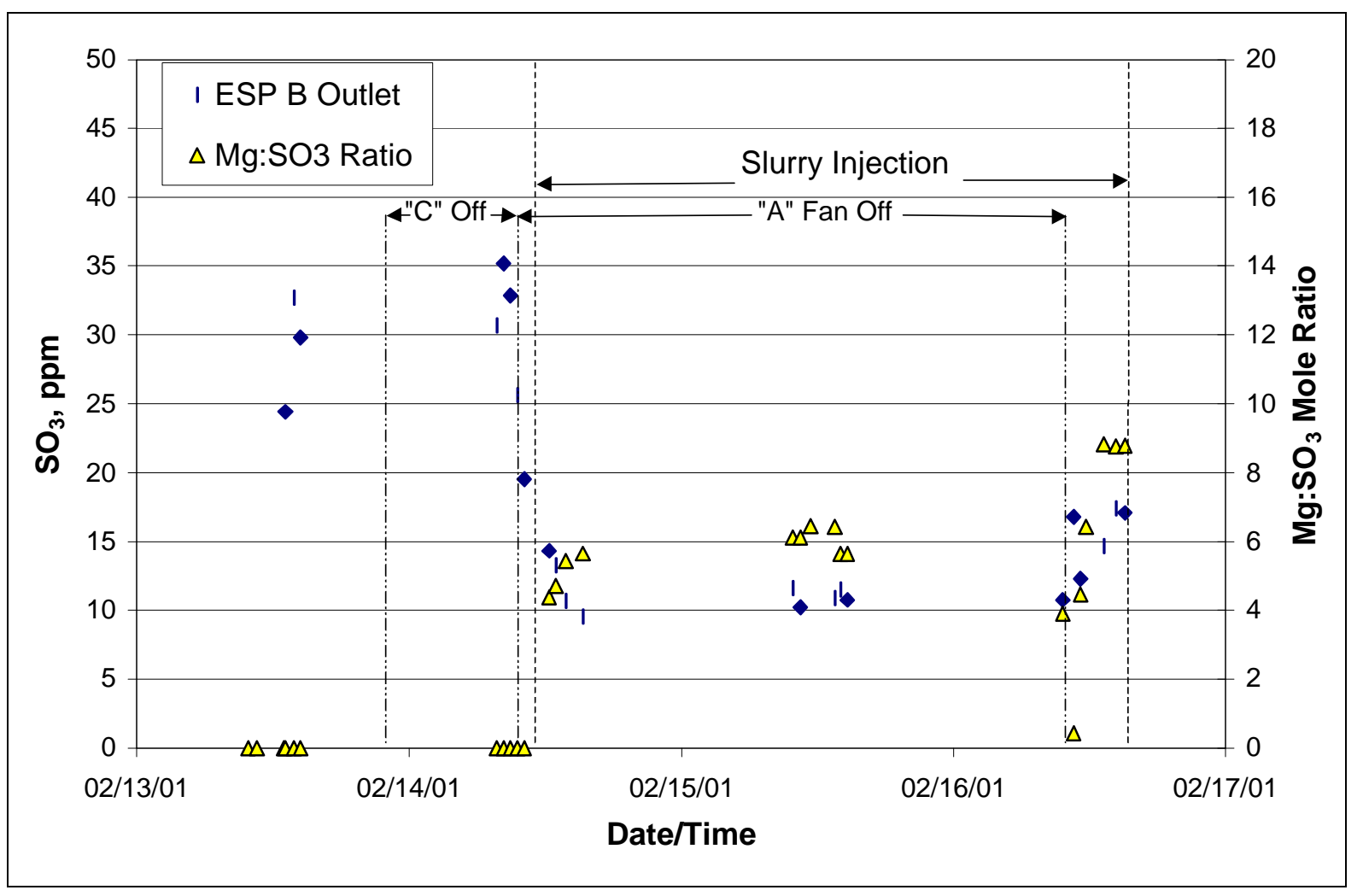

Figure 4-7

Results from the First Week of the Byproduct Mg Test (11 ${ }^{\text {th }}$ Floor Injection) 


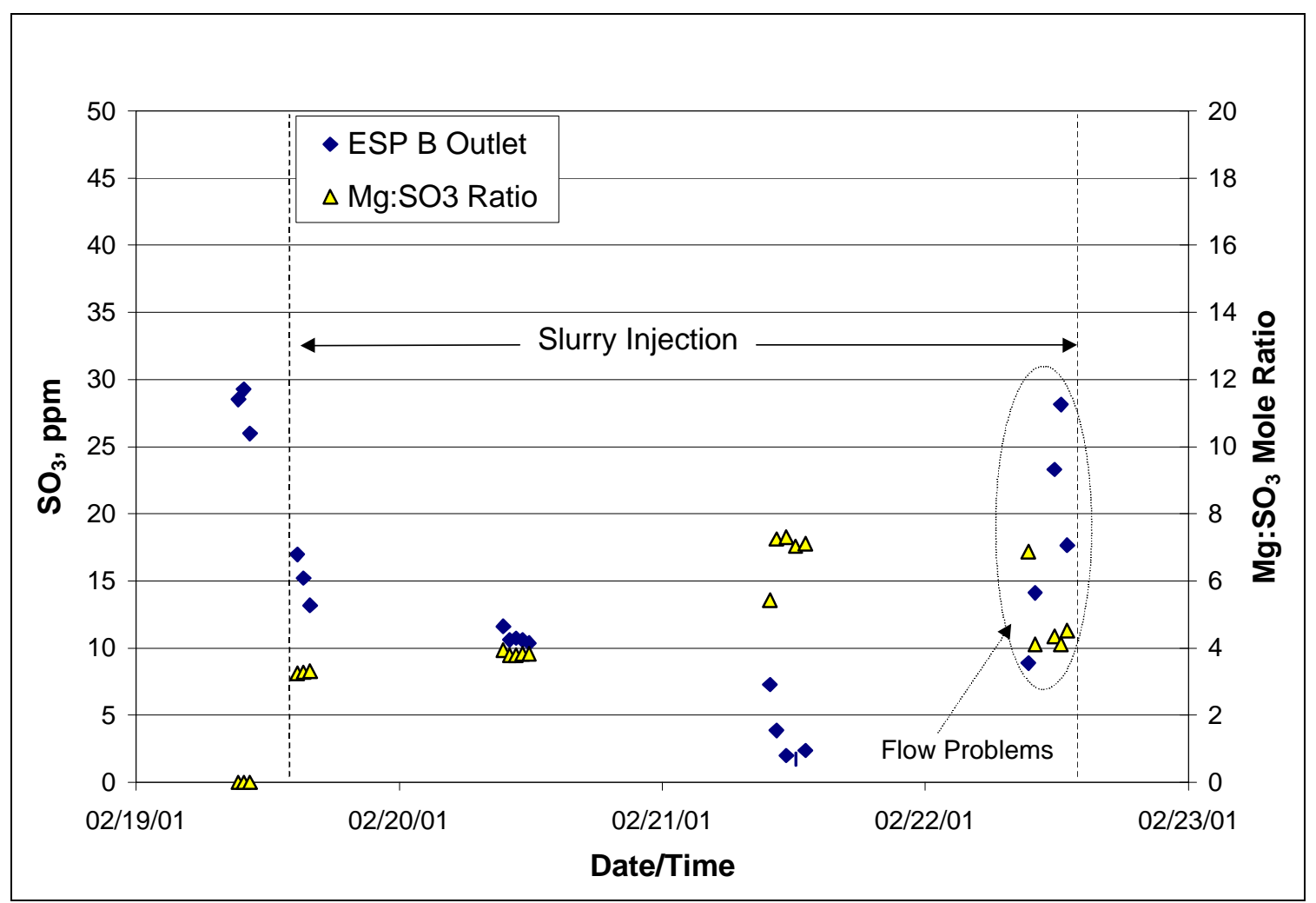

Figure 4-8

Results from the Second Week of the Byproduct Mg Test ( $14^{\text {th }}$ Floor Injection)

four ID fans were operating. The ESP B outlet $\mathrm{SO}_{3}$ concentrations measured at this high injection rate were disappointingly high, ranging from 15 to $17 \mathrm{ppm}$.

Because it had not proven to be possible to control the ESP B outlet $\mathrm{SO}_{3}$ concentrations down below 5 ppm as desired, it was decided to move the injection location up higher in the furnace, injecting through the inspection ports at the $14^{\text {th }}$ floor of the boiler structure. The injection system was shut down over the weekend while the injection system was repositioned, and testing resumed on Monday, February 19.

During the second week of testing, Unit 3 operated with all four ID fans in service the entire week. The baseline $\mathrm{SO}_{3}$ concentrations measured for the ESP B outlet were relatively high, averaging $28 \mathrm{ppm}$. Injection began in the early afternoon, at an effective $\mathrm{Mg}: \mathrm{SO}_{3}$ molar ratio of about 3:1, and by later in the afternoon the measured ESP B outlet $\mathrm{SO}_{3}$ concentration was down to $13 \mathrm{ppm}$, representing over 50\% removal. Injection continued through the next day at a rate corresponding to a $\mathrm{Mg}: \mathrm{SO}_{3}$ ratio of nearly 4:1, and ESP B outlet $\mathrm{SO}_{3}$ concentrations dropped to about 10 to $11 \mathrm{ppm}$, representing just over $60 \% \mathrm{SO}_{3}$ removal compared to the previous day's baseline.

However, the desire was still to lower the ESP B outlet $\mathrm{SO}_{3}$ concentration to below 5 ppm, so overnight the injection rate was increase to a $\mathrm{Mg}: \mathrm{SO}_{3}$ molar ratio of about 5:1 to 6:1. The first measurement the morning of February 21 showed the ESP B outlet had dropped to about 7 ppm, 
Table 4-9

Ultimate Analyses of Coal Samples from the Byproduct Mg Test

\begin{tabular}{|c|c|c|c|c|c|}
\hline \multirow[b]{2}{*}{ Parameter } & \multicolumn{5}{|c|}{ Composition, wt\% (except as noted) } \\
\hline & $2 / 14$ & $2 / 15$ & $2 / 19$ & $2 / 20$ & $2 / 23$ \\
\hline Carbon & 66.05 & 67.51 & 65.31 & 61.76 & 69.09 \\
\hline Hydrogen & 4.28 & 4.44 & 4.23 & 3.74 & 4.13 \\
\hline Nitrogen & 1.22 & 1.24 & 1.17 & 1.16 & 1.30 \\
\hline Sulfur & 3.39 & 3.56 & 3.69 & 3.35 & 3.48 \\
\hline Chlorine (ppm) & NA & NA & NA & NA & NA \\
\hline Oxygen & 4.69 & 4.55 & 4.92 & 3.90 & 3.81 \\
\hline Moisture & 7.49 & 5.92 & 7.05 & 8.50 & 7.00 \\
\hline Ash & 12.88 & 12.78 & 13.63 & 17.59 & 11.19 \\
\hline Total & 100.00 & 100.00 & 100.00 & 100.00 & 100.00 \\
\hline $\begin{array}{l}\mathrm{HHV}(\mathrm{Btu} / \mathrm{lb}) \\
{[\mathrm{kg}-\mathrm{cal} / \mathrm{kg}]}\end{array}$ & $\begin{array}{l}11,995 \\
{[6663]}\end{array}$ & $\begin{array}{l}11,938 \\
{[6632]}\end{array}$ & $\begin{array}{l}11,504 \\
{[6390]}\end{array}$ & $\begin{array}{l}10,991 \\
{[6106]}\end{array}$ & $\begin{array}{l}12,317 \\
{[6842]}\end{array}$ \\
\hline $\mathrm{lb} \mathrm{SO} / \mathrm{MM} \mathrm{Btu}$ & 5.65 & 5.96 & 6.42 & 6.10 & 5.65 \\
\hline
\end{tabular}

*NA - Not analyzed.

representing over $70 \%$ removal. A further increase in injection rate during the day, to a $\mathrm{Mg}: \mathrm{SO}_{3}$ ratio of about 7:1, lowered the ESP B outlet $\mathrm{SO}_{3}$ concentrations to an average of $2 \mathrm{ppm}$. This represents over $90 \% \mathrm{SO}_{3}$ removal compared to the baseline values from Monday, February 19.

The ESP C outlet showed evidence of sorbent crossover to the west side of the furnace when injecting at this higher rate. The ESP C outlet values dropped from about $35 \mathrm{ppm}$ the day before to about 20 to $25 \mathrm{ppm}$ when injecting at a 7:1 $\mathrm{Mg}: \mathrm{SO}_{3}$ ratio. ESP hopper ash samples were not taken on this day, so it is not possible to determine how high the magnesium levels were in the ESP C hoppers resulting from this apparent sorbent crossover.

It was desired to continue injecting at an intermediate rate overnight, midway between a 4:1 and 7:1 Mg: $\mathrm{SO}_{3}$ molar ratio. The sorbent injection test was scheduled to end the next afternoon, February 22, after $\mathrm{SO}_{3}$ concentrations were measured for the intermediate rate. Since the completion of the test was nearing, the 11,000 -gallon $\left(41-\mathrm{m}^{3}\right)$ storage tanks were depleted of inventory during the day on February 22. Although the injection system ran smoothly overnight, as the tank inventories began to deplete the morning of February 22, the injection rate became unstable due to continued pump suction line plugging. The result of the intermittent injection during the day of February 22 is that the ESP B outlet $\mathrm{SO}_{3}$ concentrations measured were much higher than were expected based on the results of the previous day. Also, the ESP C outlet data 
from February 22 suggest a higher than normal baseline $\mathrm{SO}_{3}$ for that day, with the ESP C outlet values averaging almost $40 \mathrm{ppm}$.

Thus, the objective of the project of achieving greater than $90 \% \mathrm{SO}_{3}$ removal, as measured at the ESP B outlet location, was achieved with the byproduct Mg slurry after the injection location was raised to the $14^{\text {th }}$ floor elevation. Due to the slurry injection flow problems on February 22, it was not possible to get more information about removal versus injection rate for a "conditioned" boiler.

\section{Effects of Temperature on Sorbent-Specific Surface Area}

During the short-term slurry injection tests, there was evidence that the temperature of the flue gas at the point of slurry injection had an impact on sorbent effectiveness. The most convincing evidence of this effect was seen in the previous subsection, where the performance of the byproduct $\mathrm{Mg}$ was improved by injecting it at the $14^{\text {th }}$ floor rather than at the $11^{\text {th }}$ floor of the boiler structure. Previous furnace gas temperature measurements, summarized in Table 4-5, showed that at full load, the furnace gas temperature ranged from about 2070 to $2230^{\circ} \mathrm{F}$ ( 1130 to $\left.1220^{\circ} \mathrm{C}\right)$ at the $11^{\text {th }}$ floor location, but only 1860 to $1940^{\circ} \mathrm{F}\left(1020\right.$ to $\left.1060^{\circ} \mathrm{C}\right)$ at the $14^{\text {th }}$ floor location. The temperatures at the $14^{\text {th }}$ floor location were about 200 to $300^{\circ} \mathrm{F}\left(110\right.$ to $\left.160^{\circ} \mathrm{C}\right)$ lower than at the $11^{\text {th }}$ floor level in the furnace.

Based on prior experience with furnace sorbent injection for $\mathrm{SO}_{2}$ control, it was expected that the specific surface area of the dried sorbent after it calcines (evolves $\mathrm{CO}_{2}$ and/or $\mathrm{H}_{2} \mathrm{O}$ ) in the furnace significantly impacts its effectiveness as an $\mathrm{SO}_{3}$ control reagent. In the case of the slurries injected in these three short-term tests, the calcining would occur after all of the water evaporated from the slurry droplets, and the sorbent particles were heated to a temperature sufficient to evolve the water of hydration associated with the hydroxides. In the case of magnesium hydroxide, the water of hydration is evolved to produce magnesium oxide at about $660^{\circ} \mathrm{F}\left(350^{\circ} \mathrm{C}\right)$. The calcium hydroxide component of the PHDL would lose its water of hydration at about $1080^{\circ} \mathrm{F}\left(580^{\circ} \mathrm{C}\right)$. For the dolomite reagent tested on Unit 2, it would calcine by evolving $\mathrm{CO}_{2}$ at about 1350 to $1400^{\circ} \mathrm{F}\left(730\right.$ to $\left.760^{\circ} \mathrm{C}\right)$.

In an attempt to quantify how the furnace gas temperature at the point of slurry (or powder) injection might impact the specific surface area of the calcined sorbents, samples of each sorbent were calcined in a laboratory oven at various temperatures. The resulting calcines were analyzed for specific surface area in a BET analyzer. The results of these laboratory measurements are summarized in Table 4-10.

It is not clear why the two byproduct $\mathrm{Mg}$ samples showed markedly different surface areas when calcined at the highest temperature of $2010^{\circ} \mathrm{F}\left(1100^{\circ} \mathrm{C}\right)$, which was the upper limit of the laboratory oven. In spite of this one discrepancy, the results show that all of the sorbents tested lost surface area as the calcination temperature increased. These laboratory results directly support the observation that the byproduct $\mathrm{Mg}$ sorbent was more effective when injected at the $14^{\text {th }}$ floor $\left(1860\right.$ to $1940^{\circ} \mathrm{F}\left[1020\right.$ to $\left.\left.1060^{\circ} \mathrm{C}\right]\right)$ and less effective when injected at the $11^{\text {th }}$ floor (2070 to $2230^{\circ} \mathrm{F}$ [1130 to $1220^{\circ} \mathrm{C}$ ]). These results also suggest that the commercial $\mathrm{Mg}$ and 
Table 4-10

Results of Laboratory Investigation of the Effect of Temperature on the Specific Surface Area of Calcined Sorbents

\begin{tabular}{|c|c|c|c|}
\hline \multirow[b]{2}{*}{ Sample } & \multicolumn{3}{|c|}{ Specific Surface Area $\left(\mathrm{m}^{2} / \mathrm{g}\right)$ vs. Calcination Temperature } \\
\hline & $1470^{\circ} \mathrm{F}\left(800^{\circ} \mathrm{C}\right)$ & $1740^{\circ} \mathrm{F}\left(950^{\circ} \mathrm{C}\right)$ & $2010^{\circ} \mathrm{F}\left(1100^{\circ} \mathrm{C}\right)$ \\
\hline Byproduct Mg, Sample 1 & 48.4 & 25.2 & 15.1 \\
\hline Byproduct Mg, Sample 2 & 56.7 & 27.0 & 2.2 \\
\hline Commercial Mg & 32.4 & 16.8 & 7.3 \\
\hline PHDL & 25.2 & 19.5 & 5.4 \\
\hline Dolomite & 23.5 & 10.5 & 3.0 \\
\hline
\end{tabular}

PHDL reagents would have been more effective, perhaps approaching the performance of the byproduct $\mathrm{Mg}$, had they been tested with injection at the $14^{\text {th }}$ floor.

These results also suggest why it is that extremely large quantities of dolomite had to be injected through the out-of-service burners to achieve $90 \% \mathrm{SO}_{3}$ capture (see Section 3). At the upper burner level, furnace gas temperatures probably approach $2500^{\circ} \mathrm{F}\left(1370^{\circ} \mathrm{C}\right)$. This is considerably higher than the measured furnace gas temperature at the $11^{\text {th }}$ floor, and considerably higher than the laboratory oven could operate. However, based on the observed effect of temperature on specific surface area in these laboratory samples, we can surmise that the dolomite injected through out-of-service burners would have had a very low specific surface area, greatly reducing its effectiveness for $\mathrm{SO}_{3}$ control.

\section{Balance of Plant Effects}

Balance of plant effects measured were primarily focused on the impacts of sorbent injection and $\mathrm{SO}_{3}$ removal on ESP performance during the short-term slurry injection tests. However, baseline measurements were also made of halogen species concentrations in the Unit 3 flue gas, and particulate loadings in the ESP outlet flue gas. It was decided not to evaluate these additional parameters for each short-term test. Instead, effects of sorbent injection on flue gas halogen species concentrations and on ESP outlet particulate loadings were to be made during the upcoming long-term test.

\section{Impacts of Sorbent Injection and $\mathrm{SO}_{3}$ Removal on ESP Operation}

During the short-term sorbent injection tests on Unit 3, the impacts of sorbent injection and $\mathrm{SO}_{3}$ removal were measured in two different manners. First, the ESP electrical properties were measured, by recording ESP electrical operating conditions (secondary current and voltage) and V-I (secondary voltage vs. secondary current) curves, for each electrical section several times each test. Second, the outputs from the unit's ESP outlet opacity monitors were retrieved from the plant's data archive for these time periods and reviewed. 
Note that the impacts from sorbent injection may be different than the impacts from any resulting $\mathrm{SO}_{3}$ removal. Sorbent injection could have adverse effects if the sorbent has a higher bulk particle resistivity than the fly ash particles. If the resistivity increases into an undesirable range, the corona current in the ESP fields could be limited to low levels by the onset of sparking, and the ability to charge and collect the particles could be severely limited. Also, the addition of the fine particles represented by the injected sorbent can lead to space charge effects that would lower the resulting corona current at a given applied voltage. On the other hand, removal of $\mathrm{SO}_{3}$ upstream of the ESP could have an adverse effect on the resistivity of the fly ash particles themselves. If the $\mathrm{SO}_{3}$ is removed by the sorbent before it has a chance to be adsorbed onto fly ash particles, it could result in greatly increased fly ash resistivity. Thus, the net result of either the sorbent injection or $\mathrm{SO}_{3}$ removal on ESP operation might be similar, just the mechanism would differ.

The following describes the data collected during the three short-term slurry injection tests, and what those data indicate about ESP impacts.

\section{PHDL Injection Test}

The PHDL injection test saw moderately high slurry injection rates (up to $20 \mathrm{gpm}$ at $35 \mathrm{wt} \%$ solids) but never saw high $\mathrm{SO}_{3}$ removal percentages. The lowest $\mathrm{SO}_{3}$ concentration measured at the ESP B outlet was still greater than $10 \mathrm{ppm}$, which should be adequate for fly ash conditioning at the $300^{\circ} \mathrm{F}$ flue gas temperature in ESP B. The ESP B inlet concentrations were even higher, so no effect of $\mathrm{SO}_{3}$ removal on fly ash resistivity would be expected.

Figure 4-9 illustrates the effects of sorbent injection and $\mathrm{SO}_{3}$ removal on the ESP secondary current values. The secondary current values for all four electrical fields of ESP B are shown, as are data for two fields of ESP C. Also shown in the figure are PHDL slurry injection rates and ESP B outlet $\mathrm{SO}_{3}$ concentrations. The data show no effect of sorbent injection on secondary currents. Although the secondary current in the second field of ESP B (BB) dropped with the beginning of sorbent injection, this drop appears to be coincidental and not related to PHDL injection, for two reasons. First, there was no observed effect of the PHDL on the upstream field (BA), and it seems logical that the first field would also be effected. Second, the drop in secondary current persisted after several days with no sorbent injection (see the data point on October 30).

From the data plotted in Figure 4-9, it can be concluded that the PHDL itself did not measurably affect the ESP electrical conditions, nor did the moderate amount of $\mathrm{SO}_{3}$ removal achieved when injecting this sorbent. 


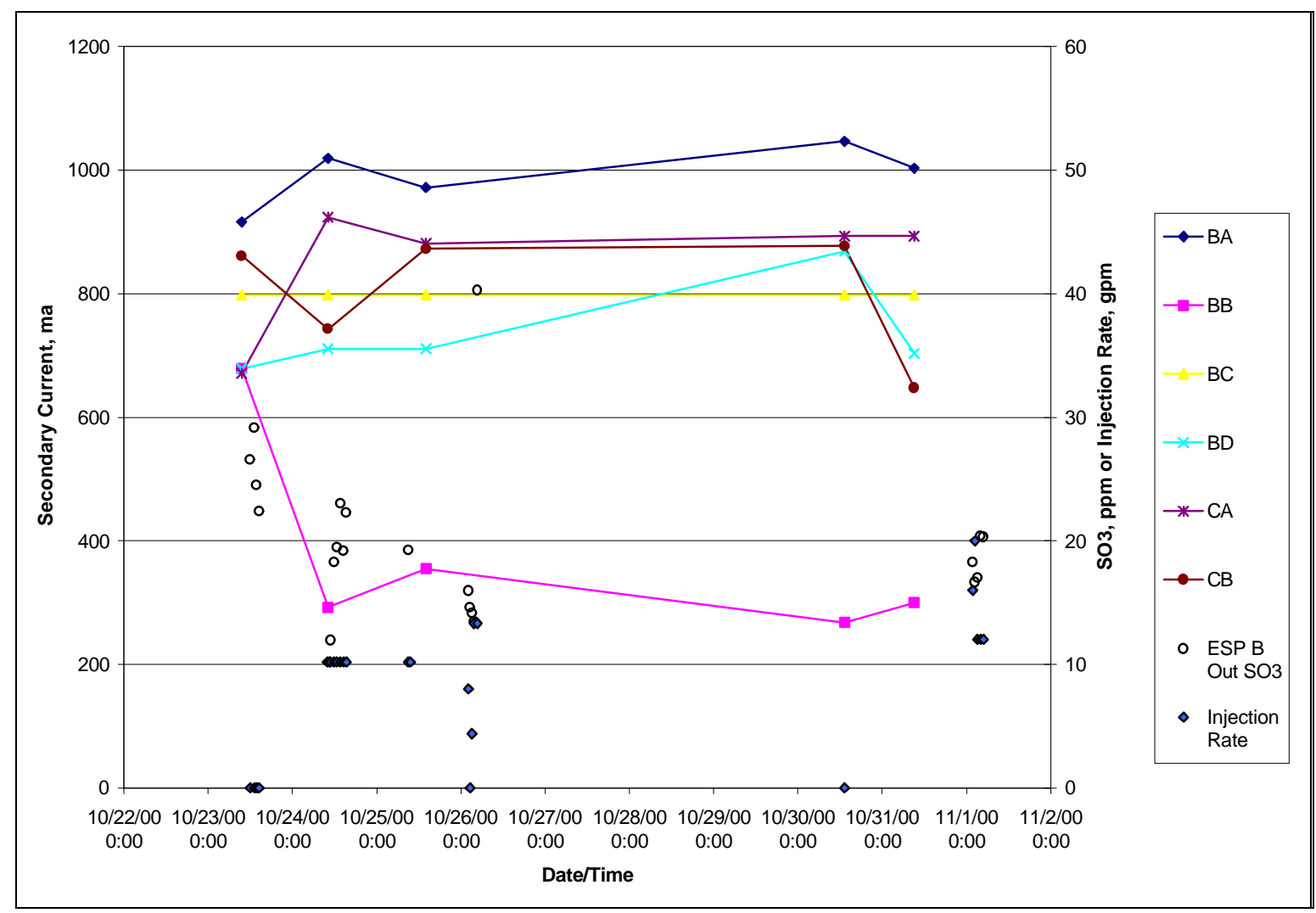

\section{Figure 4-9 \\ Observed Effect of PHDL Injection on ESP B and C Secondary Currents}

\section{Commercial Mg Injection Test}

The commercial $\mathrm{Mg}$ was the first slurry injection test that was successful at achieving approximately $90 \% \mathrm{SO}_{3}$ removal as measured at the ESP B outlet, lowering the ESP B outlet $\mathrm{SO}_{3}$ concentrations to $2 \mathrm{ppm}$. ESP B inlet $\mathrm{SO}_{3}$ concentrations were measured to have been lowered into the range of 2 to $3 \mathrm{ppm}$. Figure 4-10 illustrates secondary current values for all four electrical sections of ESP B, and for a first field of ESP C (CA) during the test period. Also shown are the ESP B outlet $\mathrm{SO}_{3}$ concentrations measured, and the ESP B outlet particulate loading as indicated by the plant's opacity monitor (second week of the test only). The data in Figure 4-10 show an immediate drop in the secondary current at the first fields of ESP B (BA and $\mathrm{BC}$ ) as soon as sorbent injection begins, with the values dropping from about 500 ma to approximately 200 to 250 ma. Effects on the downstream fields (BB and BD) are relatively insignificant, with one field increasing and one decreasing slightly after sorbent injection begins. We would expect initial effects of sorbent injection to be most pronounced for the first fields of the B ESP, most likely due to a space charge effect from the additional small particles added to the flue gas by the sorbent.was only for a few hours. Continued operation on the entire furnace at this injection rate and/or $\mathrm{SO}_{3}$ removal level would not likely be possible, as the particulate emissions rates from the ESP would probably exceed desired levels. 


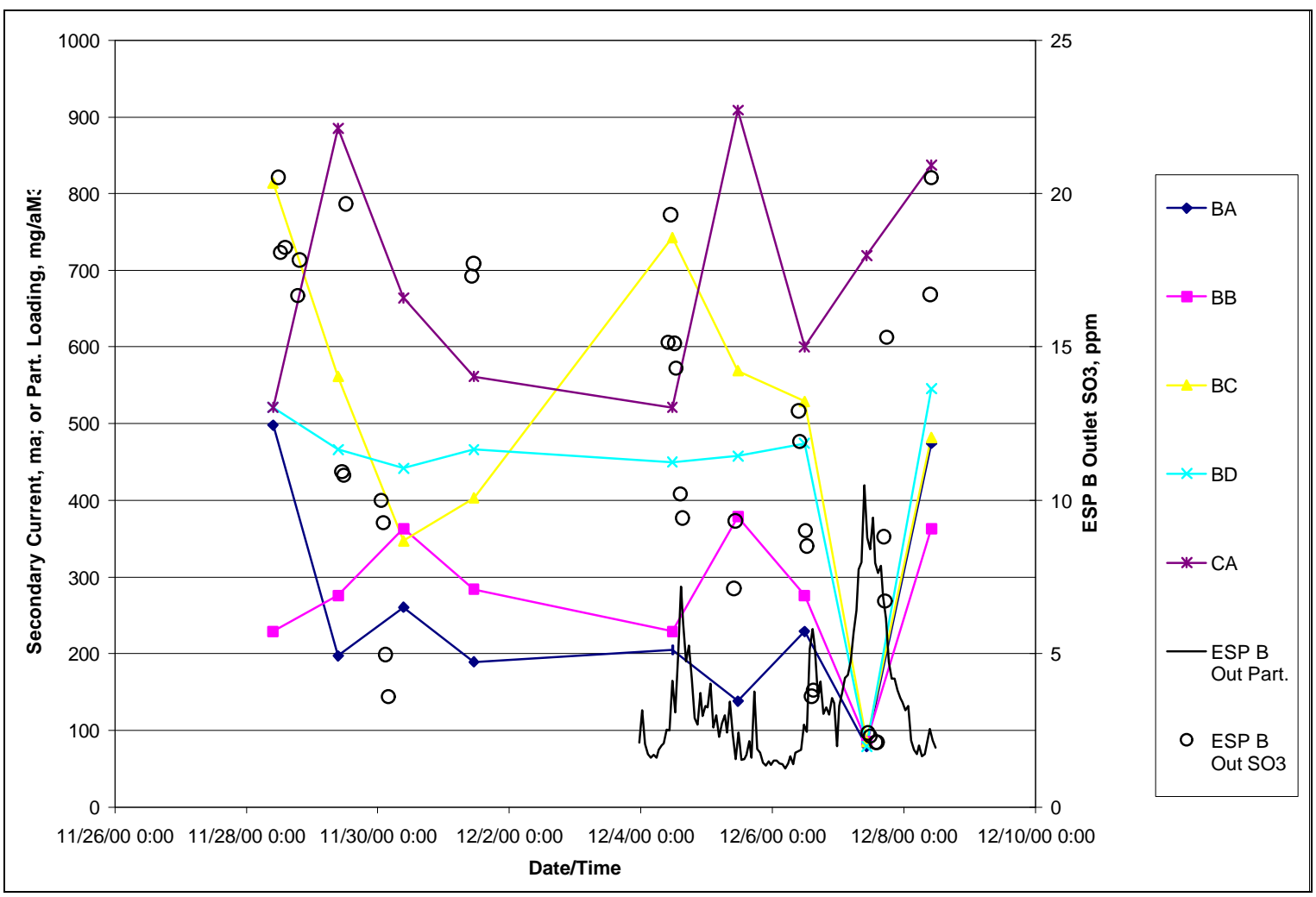

Figure 4-10

Observed Effect of Commercial Mg Injection on ESP B and C Secondary Currents and ESP B Particulate Emissions

The most pronounced effect in the figure is seen for December 7, when the sorbent injection rate was high, and the ESP B outlet $\mathrm{SO}_{3}$ was lowered to approximately $2 \mathrm{ppm}$. ESP operating conditions were measured during the same time period, and show a profound effect on the ESP B electrical conditions. The secondary current values for all four electrical sections were lowered to below 100 ma. Similarly, the power input to those electrical sections (not shown in the figure) was lowered to about $3 \mathrm{~kW}$ during this period, as opposed to normal input values in the range of 20 to $40 \mathrm{~kW}$.

The ESP B outlet opacity shows a dramatic increase in apparent mass loading at the ESP B outlet during this same time period. It is not known how well this instrument output is calibrated to actual mass loading, but note that the indicated highest value of about $400 \mathrm{mg}$ per actual cubic meter would correspond with a loading of about $0.27 \mathrm{gr} / \mathrm{dscf}$. Fortunately, only one of four ESPs was affected to such an extent.

Also note that the observed ESP electrical conditions and outlet emissions levels appear to be directly related to sorbent injection and/or $\mathrm{SO}_{3}$ removal, as values from the next day, after sorbent injection was stopped, were returned to normal. It appears that the commercial $\mathrm{Mg}$ injection rate and/or $\mathrm{SO}_{3}$ removal down to $2 \mathrm{ppm}$ in the ESP B outlet gas had a catastrophic effect on ESP performance. This was not noted during the test, most likely because only one ESP of four was affected to such an extent, and the duration of time over which the ESP was affected 


\section{Byproduct Mg Injection Test}

The byproduct $\mathrm{Mg}$ test was the second slurry injection test successful at achieving approximately $90 \% \mathrm{SO}_{3}$ removal as measured at the ESP B outlet. The ESP B inlet $\mathrm{SO}_{3}$ concentrations were measured to have been lowered into the range of 3 to $4 \mathrm{ppm}$ and the outlet concentrations to 2 ppm. ESP impacts during the byproduct Mg injection test are summarized in Figure 4-11. Due to technical difficulties, ESP operating current and voltage values were not recorded for this test. Therefore Figure 4-11 does not include any secondary current values for ESP B, only the byproduct $\mathrm{Mg}$ slurry injection rate, the ESP B outlet $\mathrm{SO}_{3}$ concentrations measured, and the ESP B outlet particulate loading as indicated by the plant's opacity monitor. The latter are the only available information about the effects of byproduct Mg injection on ESP operation.

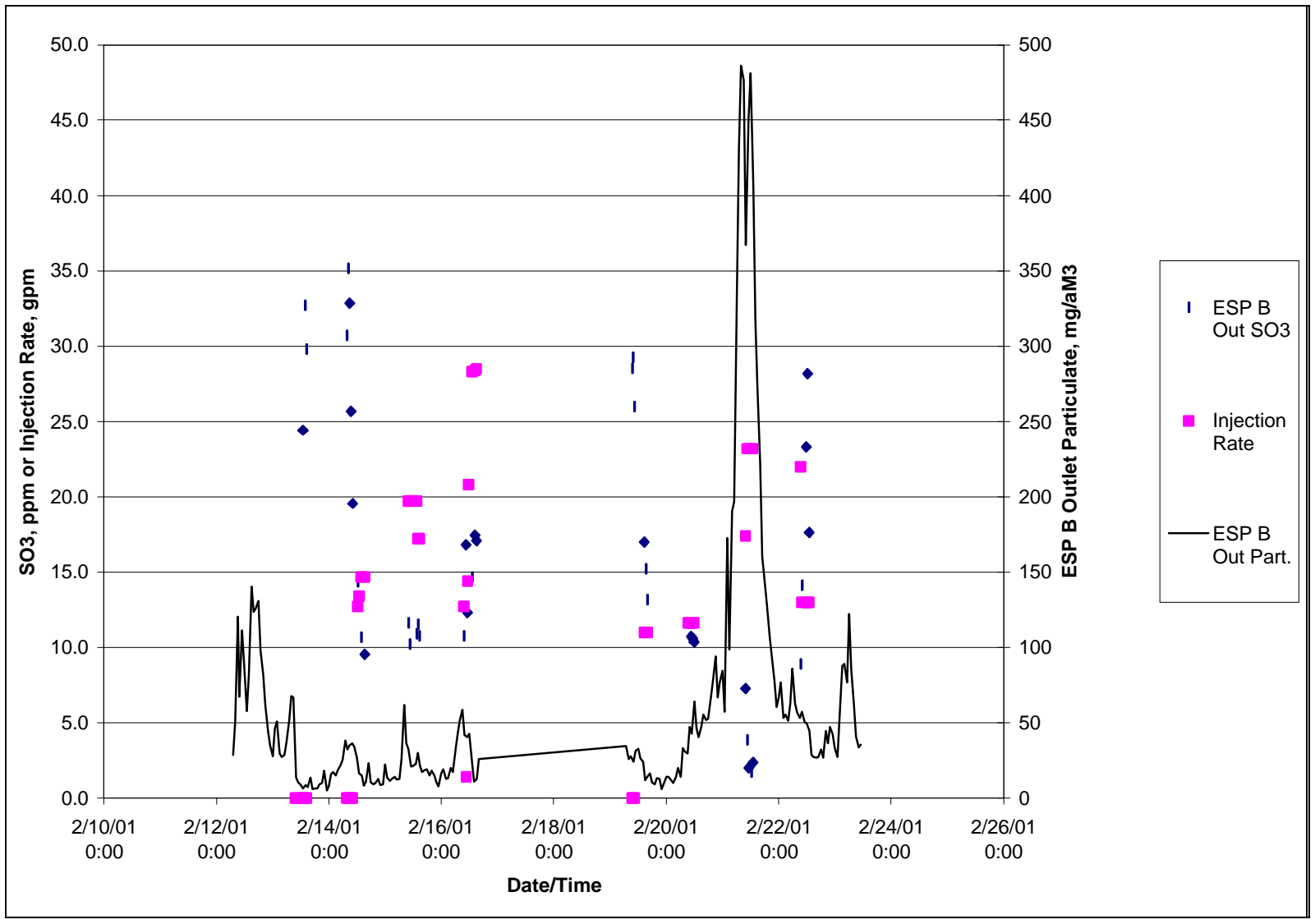

Figure 4-11

Observed Effect of Byproduct Mg Injection on ESP B Particulate Emissions

The most pronounced effect is seen overnight on February 20 and during the day on February 21, when the sorbent injection rate was high, and the ESP B outlet $\mathrm{SO}_{3}$ concentration was lowered to approximately $2 \mathrm{ppm}$. The ESP B outlet opacity shows a dramatic increase in mass loading during this same time period. Note that the observed adverse effect appears to be directly related to the effects of high $\mathrm{SO}_{3}$ removal, as values from the next day returned to normal, after sorbent injection rates were reduced and the ESP B outlet $\mathrm{SO}_{3}$ concentrations increased to $9 \mathrm{ppm}$ and greater. Also note that the adverse effect does not appear to be related to sorbent injection rate per se, as a higher injection rate was experienced the previous week, on February 16, with no 
apparent effect on ESP particulate emissions. The February 16 data were for slurry injection at the $11^{\text {th }}$ rather than $14^{\text {th }}$ floor, and high $\mathrm{SO}_{3}$ removal efficiencies were not seen. Figure 4-12 repeats the data in Figure 4-11 from the second week of the test, but adds outlet emissions levels from the "A" and "D" ESPs. The ESP C data were not available.

The data in Figure 4-12 suggest that the other ESPs were also affected by the byproduct $\mathrm{Mg}$ injection to achieve low $\mathrm{SO}_{3}$ concentrations on the east side of the boiler, but to a much lesser extent than ESP B. ESP A is on the side experiencing injection, but showed only a minor effect on outlet particulate levels during this period. This may be because ESP A receives gas from the "cold" side of the air heater, so the flue gas treated is much cooler than that treated in ESP B. These data suggest that at the lower flue gas temperature, much lower $\mathrm{SO}_{3}$ concentrations are adequate for fly ash conditioning than are required for ESP B. Such a relationship is consistent with theory.

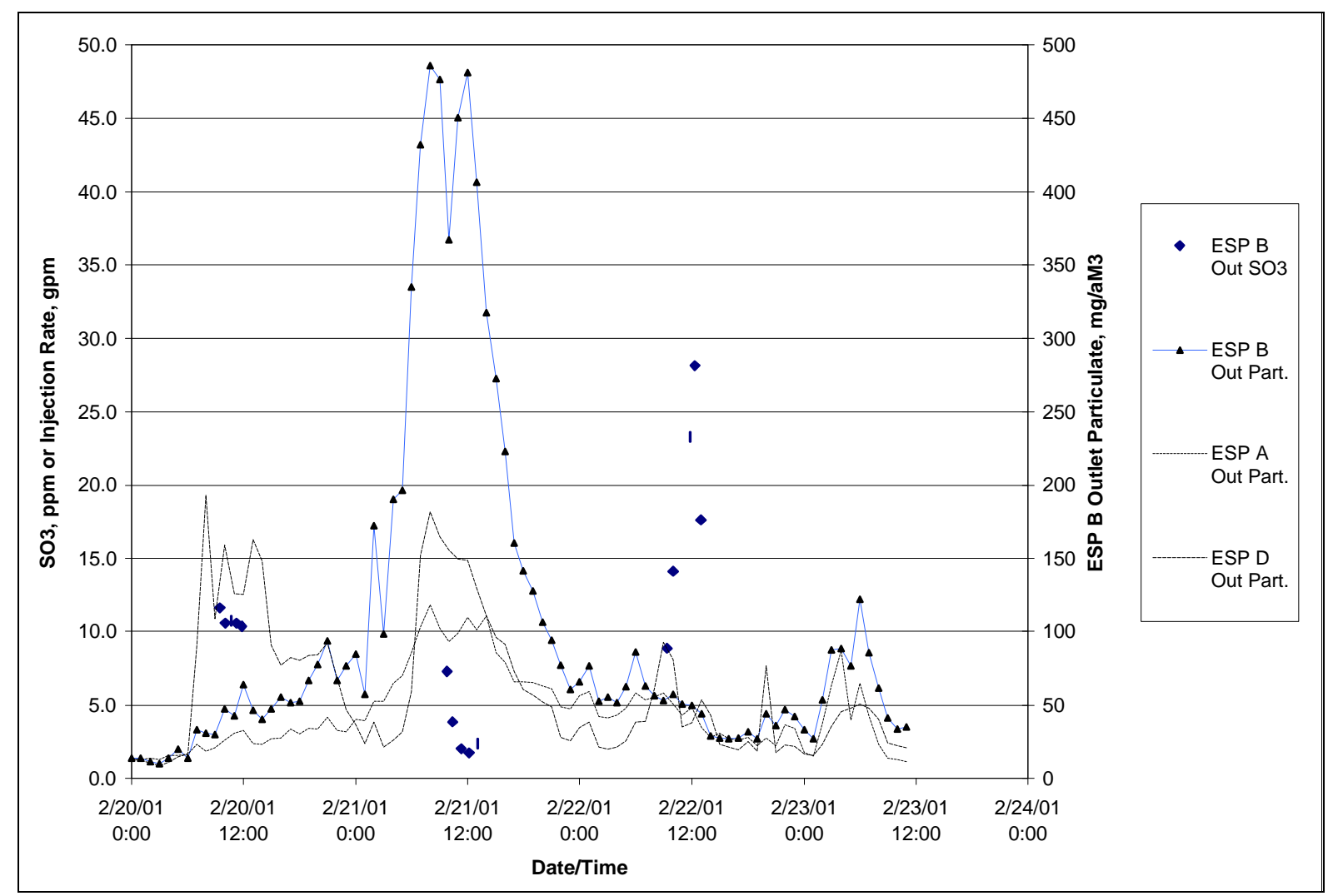

Figure 4-12

ESP Outlet Emissions Data from the Byproduct Mg Injection Test

The ESP D data are from the side of the boiler not receiving slurry injection, but appear to show an adverse affect on outlet emissions. There are two possible explanations for the observed affect. One is that these data support earlier indications that when injecting at high rates on the east side, some sorbent flow and $\mathrm{SO}_{3}$ removal are seen on the west side gas path. It would be surprising, though, that the effect on the "D" ESP would be more pronounced than on the "A" ESP, which is on the side receiving slurry injection. A more likely explanation is that this peak in observed particulate emissions from the "D" ESP is coincidental. A peak of similar magnitude 
was seen in the ESP D outlet on February 20, during a period when both the "A" and "B" ESPs were seeing normal outlet emissions levels. Whatever caused that peak may have similarly affected the ESP D emissions on February 21.

It appears that the $\mathrm{SO}_{3}$ removal resulting from byproduct $\mathrm{Mg}$ injection, down to $2 \mathrm{ppm}$ in the ESP B outlet gas, had an adverse effect on ESP B performance. Again, this was not noted during the test, probably because only one ESP of four was affected to such an extent, and the duration of increased emission rates was only for a few hours. It is clear that for continued operation on the entire furnace, the injection rate and $\mathrm{SO}_{3}$ removal level will be limited by ESP performance. For the long-term test, the slurry injection rate must be optimized to achieve the maximum possible level of $\mathrm{SO}_{3}$ removal while maintaining acceptable ESP particulate control performance. It is not possible to project that control level from the limited amount of data available. However, from the data available it appears that the "B" and "C" $\mathrm{ESP}$ outlet $\mathrm{SO}_{3}$ concentrations will have to be maintained somewhere in the range of 5 to $8 \mathrm{ppm}$ unless some other form of fly ash resistivity conditioning (e.g., flue gas humidification) is employed.

\section{ESP Outlet Particulate Loading}

Baseline measurements were made of the ESP B outlet particulate loadings. These values will be compared to outlet particulate loading measurements during the long-term sorbent injection test, to better evaluate sorbent effects on ESP performance. Measurements were made in two manners. One type was using the sampling train for EPA Method 17, and the second was to collect and weigh fly ash solids captured in the Method 26a sample train (halogens in flue gas). Also, the gas was sampled in three different manners: a full traverse of the ESP B outlet duct, a traverse across a single port, and single-point sampling at a given point in a particular port. The results of ESP B outlet particulate loading measurements by these various techniques are summarized in Table 4-11.

The results in the table show that the ESP outlet loadings averaged about $0.04 \mathrm{gr} / \mathrm{dscf}$, which is equivalent to about $0.08 \mathrm{lb} / \mathrm{MM}$ Btu, when all twelve individual measurements are averaged. The four ESP traverses averaged about the same as the average for the eight individual port and/or point values ( 0.036 vs. $0.044 \mathrm{gr} / \mathrm{dscf})$. However, the individual measurements showed considerably more variability, ranging from as low as $0.02 \mathrm{gr} / \mathrm{dscf}$ to $0.08 \mathrm{gr} / \mathrm{dscf}$. Since a wide range of variability was seen in repeat measurements at the same location, it is likely that the range of values measured is due to some temporal effect (e.g., whether or not a downstream field was rapped during sample collection) rather than reflecting a significant bias among the various sampling locations.

\section{Flue Gas Halogen Species Concentrations}

During the baseline measurements conducted at Unit 3 in early October 2000, Method 26a sampling was employed to measure the concentrations of flue gas halogen species at the ESP B outlet location. Species measured included hydrochloric acid and chlorine, hydrofluoric acid and fluorine. The objective of making these measurements was to determine baseline concentrations of these species for comparison with measurements made during sorbent injection, to determine 
Table 4-11

Summary of ESP B Outlet Baseline Particulate Loading Measurements

\begin{tabular}{|c|c|c|c|c|c|c|}
\hline Date & Method & $\begin{array}{c}\text { Traverse/Single } \\
\text { Point }\end{array}$ & $\begin{array}{c}\text { Weight of } \\
\text { Particulate } \\
\text { Collected, } \\
\text { grams }\end{array}$ & $\begin{array}{c}\text { Quantity of } \\
\text { Flue Gas } \\
\text { Sampled, } \\
\text { dscf }\end{array}$ & $\begin{array}{c}\text { Particulate } \\
\text { Concentra- } \\
\text { tion, } \\
\text { grains/dscf }\end{array}$ & $\begin{array}{c}\text { Approximate } \\
\text { Particulate } \\
\text { Emission } \\
\text { Rate, } \\
\text { Ib/MMBtu }\end{array}$ \\
\hline $10 / 03 / 00$ & $26 a$ & ESP B Full Traverse & 0.1533 & 66.089 & 0.036 & 0.07 \\
\hline $10 / 04 / 00$ & 17 & ESP B Full Traverse & 0.0867 & 46.277 & 0.029 & 0.06 \\
\hline $10 / 05 / 00$ & $26 a$ & ESP B Full Traverse & 0.2204 & 71.137 & 0.048 & 0.10 \\
\hline $10 / 06 / 00$ & 17 & ESP B Full Traverse & 0.0934 & 47.15 & 0.031 & 0.06 \\
\hline \multicolumn{5}{|l|}{ Average } & 0.036 & 0.07 \\
\hline $10 / 04 / 00$ & $26 a$ & Port 4 Traverse & 0.3579 & 66.823 & 0.083 & 0.17 \\
\hline $10 / 04 / 00$ & 17 & Port 4 Traverse & 0.0567 & 38.262 & 0.023 & 0.05 \\
\hline \multicolumn{5}{|l|}{ Average } & 0.053 & 0.11 \\
\hline $10 / 03 / 00$ & $26 a$ & Port 3, Point 3 & 0.089 & 68.162 & 0.020 & 0.04 \\
\hline $10 / 04 / 00$ & 17 & Port 3, Point 3 & 0.0953 & 46.183 & 0.032 & 0.06 \\
\hline \multicolumn{5}{|l|}{ Average } & 0.026 & 0.05 \\
\hline 10/05/00 & $26 a$ & Port 4, Point 3 & 0.2887 & 68.86 & 0.065 & 0.13 \\
\hline $10 / 06 / 00$ & 17 & Port 4, Point 3 & 0.0506 & 40.159 & 0.019 & 0.04 \\
\hline \multicolumn{5}{|l|}{ Average } & 0.042 & 0.08 \\
\hline $10 / 05 / 00$ & $26 a$ & Port 4, Point 2 & 0.269 & 70.587 & 0.059 & 0.12 \\
\hline $10 / 06 / 00$ & 17 & Port 4, Point 2 & 0.1277 & 39.021 & 0.051 & 0.10 \\
\hline \multicolumn{5}{|l|}{ Average } & 0.055 & 0.11 \\
\hline
\end{tabular}

Note: 1 grain $/ \mathrm{dscf}=2.46 \mathrm{~g} / \mathrm{Nm}^{3} ; 1 \mathrm{dscf}=0.0264 \mathrm{Nm}^{3}$.

if any of these species would be effectively removed from the flue gas by the injected slurry sorbent. As mentioned above, corresponding measurements were not made during the short-term slurry injection tests, but will be made during the long-term test.

The results of these measurements are summarized in Tables 4-12 and 4-13. Flue gas concentration data in Table 4-13 show that the hydrochloric acid concentration averaged about $36 \mathrm{ppm}$, while the hydrofluoric acid concentration averaged $14 \mathrm{ppm}$. Both of these values are in the typical range for bituminous coals. The chlorine and fluorine concentrations were measured 
to be much lower, at $0.6 \mathrm{ppm}$ and $0.05 \mathrm{ppm}$, respectively. Again, both of these values are within the expected range.

Mass balance data in Table 4-13 show good agreement between the average measured flue gas chlorine species concentrations and the average of two coal chlorine measurements (samples for October 4, 2000 and for October 6, 2000). The mass balance closed within approximately $2 \%$. The coal was not analyzed for fluorine content, so similar mass balance closures cannot be calculated for those species. 
Table 4-12

Summary of Method 26a Data

\begin{tabular}{|c|c|c|c|c|c|c|c|c|c|c|}
\hline \multirow[b]{2}{*}{ Date } & \multirow[b]{2}{*}{ Test } & \multirow{2}{*}{$\begin{array}{c}\text { Sample } \\
\text { Gas } \\
\text { Volume, } \\
\text { dscf }\end{array}$} & \multicolumn{4}{|c|}{ Hydrogen Halides } & \multicolumn{4}{|c|}{ Halogens } \\
\hline & & & $\begin{array}{l}\text { Chloride, } \\
\text { mg/sample }\end{array}$ & $\begin{array}{l}\text { Fluoride, } \\
\text { mg/sample }\end{array}$ & $\begin{array}{l}\mathrm{HCl}, \text { ppmv } \\
\text { (dry basis) }\end{array}$ & $\begin{array}{l}\text { HF, ppmv } \\
\text { (dry basis) }\end{array}$ & $\begin{array}{l}\text { Chloride, } \\
\text { mg/sample }\end{array}$ & $\begin{array}{l}\text { Fluoride, } \\
\text { mg/sample }\end{array}$ & $\begin{array}{c}\mathrm{Cl}_{2}, \text { ppmv } \\
\text { (dry basis) }\end{array}$ & $\begin{array}{c}F_{2}, \text { ppmv } \\
\text { (dry basis) }\end{array}$ \\
\hline $10 / 03 / 00$ & 1 & 68.16 & 111.6 & 33.5 & 39.2 & 21.9 & 3.20 & 0.090 & 0.56 & 0.03 \\
\hline $10 / 03 / 00$ & 2 & 66.09 & 104.3 & 18.9 & 37.8 & 12.8 & 1.77 & 0.065 & 0.32 & 0.02 \\
\hline $10 / 04 / 00$ & 3 & 66.82 & 107.8 & 14.0 & 38.6 & 9.4 & 1.85 & 0.068 & 0.33 & 0.02 \\
\hline $10 / 05 / 00$ & 4 & 71.14 & 101.6 & 22.6 & 34.2 & 14.2 & 2.51 & 0.388 & 0.42 & 0.12 \\
\hline $10 / 05 / 00$ & 5 & 68.86 & 97.8 & 21.7 & 34.0 & 14.1 & 2.94 & 0.221 & 0.51 & 0.07 \\
\hline $10 / 05 / 00$ & 6 & 70.59 & 89.3 & 20.8 & 30.3 & 13.2 & 8.44 & 0.192 & 1.43 & 0.06 \\
\hline Average & - & - & - & - & 35.7 & 14.2 & - & - & 0.60 & 0.05 \\
\hline
\end{tabular}

Note: $1 \mathrm{dscf}=0.0264 \mathrm{Nm}^{3}$. 
Table 4-13

Hydrogen Halide and Halogen Mass Rates

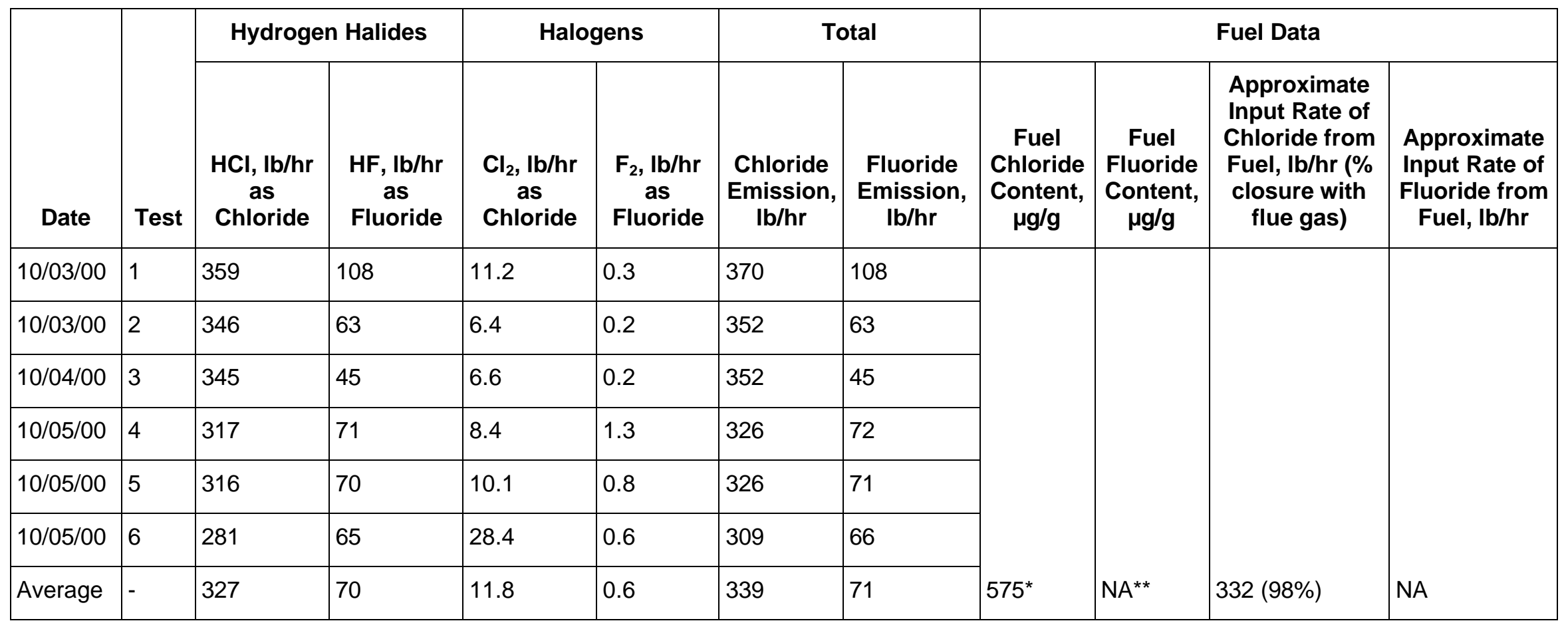

*Average for samples collected 10/4/00 and 10/6/00.

**NA - Not analyzed.

Note: $1 \mathrm{lb} / \mathrm{hr}=0.454 \mathrm{~kg} / \mathrm{hr}$. 


\section{5 \\ SUMMARY AND CONCLUSIONS}

\section{Dolomite Powder Injection Test}

A test was conducted with pulverized dolomite being injected into the furnace of Unit 2 at the FirstEnergy's BMP to lower flue gas sulfuric acid (or $\mathrm{SO}_{3}$ at higher flue gas temperature) concentrations. The unit typically operated close to full load at about $750 \mathrm{MW}$ (gross) during the day, with lower loads overnight. Dolomite was injected almost continuously over a period of 93 hours (there was one interruption of almost 2 hours early in the injection period).

The dolomite was injected in place of coal through the top row of burners on the front wall of the boiler. The injection rate was approximately 8 to $9 \%$ of the coal feed rate to the unit. The coal fired had an average sulfur content of $4.1 \mathrm{wt} \%$. The resulting flue gas prior to dolomite injection had an $\mathrm{SO}_{3}$ concentration that averaged $52 \mathrm{ppm}$ as measured by the Controlled Condensation method at the east economizer outlet location. This corresponds with approximately 1.6 to $1.7 \%$ of the $\mathrm{SO}_{2}$ in the flue gas being oxidized to $\mathrm{SO}_{3}$. The molar ratio of alkalinity in the dolomite (calcium plus magnesium) to sulfur in the coal fired averaged 0.6:1 to $0.7: 1$. The molar ratio of alkalinity in the dolomite injected to $\mathrm{SO}_{3}$ in the baseline flue gas was about 40:1.

The dolomite was effective in greatly reducing flue gas $\mathrm{SO}_{3}$ concentrations. Over the last two days of the test, the $\mathrm{SO}_{3}$ concentrations at the economizer outlet showed an average of $7 \mathrm{ppm}$, or an $86 \%$ reduction from the baseline concentration average of $52 \mathrm{ppm}$. As mentioned above, this was at an average molar ratio of total alkalinity in the dolomite (calcium plus magnesium) to sulfur in the coal of $0.6: 1$ to $0.7: 1$.

During the test, the dolomite injection rate was varied in an attempt to determine $\mathrm{SO}_{3}$ removal as a function of dolomite rate. In general, the injection rate changes were too rapid to ensure that steady-state $\mathrm{SO}_{3}$ removal performance was measured at each rate. However, during two periods where the injection rate was held at a value long enough to approach steady-state performance, $\mathrm{SO}_{3}$ removal was quite sensitive to dolomite injection rate. At a molar ratio of dolomite alkalinity (calcium plus magnesium) to coal sulfur of $0.57: 1$, the apparent $\mathrm{SO}_{3}$ removal was $74 \%$, while at a molar ratio of $0.68: 1$, the apparent removal improved to $95 \%$.

Dolomite injection had little effect on the concentrations of two other acid gases in the flue gas. No removal of hydrochloric acid or hydrofluoric acid from the flue gas was measured. Some removal of chlorine and fluorine from the flue gas was observed, but the uncontrolled concentrations of these gases were already quite low (less than $1 \mathrm{ppm}$ ). 
LOI measurements of ash samples collected from the economizer outlet location indicated that LOI values increased from less than $1 \%$ under baseline operation to as high as $8 \%$ during dolomite injection. LOI measurements were conducted to provide an indication of unburned carbon in the fly ash, which is a measure of the boiler combustion efficiency. It would be expected that significant increases in fly ash LOI would correspond with higher boiler flue gas $\mathrm{CO}$ concentrations; however, this was not the case. Although the LOI results suggest an adverse effect of dolomite injection on unburned carbon concentrations, there is some question as to how representative of current operating conditions each of the economizer ash grab samples might have been. No firm conclusions can yet be made about the effects of dolomite injection on coal combustion efficiency as determined by LOI content in the fly ash.

Another concern about dolomite injection in the furnace was the potential for increased slagging in the upper furnace. Prior to injection of dolomite, the upper furnace side walls, partial division walls and pendants had very little slag accumulations, with $1 / 2$ to 1 inch $(1.2$ to $2.5 \mathrm{~cm})$ of slag build-up. After nearly four consecutive days of injecting dolomite, the slag accumulations on the side wall varied from 0 to 2 inches $(0$ to $5.1 \mathrm{~cm}$ ) in thickness, accumulations on the partial division walls were between 1 and 2 inches $(2.5$ and $5.1 \mathrm{~cm}$ ) and the pendant superheaters had between 2 and 4 inches $(5.1$ and $10.2 \mathrm{~cm}$ ) of slag accumulation. There did not appear to be any bridging of flue gas flow passages. It is not certain whether the slag accumulations observed represent normal day-to-day variations, or represent a tendency for increased slagging during dolomite injection. A longer test duration would be required to establish such an effect. Dolomite injection did appear to have an adverse effect on unit heat rate, as the average air heater exit temperature at a load of 760 gross $\mathrm{MW}$ was observed to increase by $8^{\circ} \mathrm{F}\left(4^{\circ} \mathrm{C}\right)$ over the duration of the test.

Because Unit 2 does not have an ESP for particulate control, the entrained, partially utilized dolomite was removed from the flue gas as particulate matter in the wet-lime FGD scrubbers. Chemical analyses of the scrubber solids indicate that virtually all of the calcium content of the dolomite and about half of the magnesium content was used to react with $\mathrm{SO}_{2}$ removed in the scrubbers. Between the two components, nearly half of the normal FGD system lime slurry makeup should have been offset (replaced) by the injected dolomite. The contribution from the magnesium content was due to magnesium dissolving into the liquid phase of the scrubber slurry. With time, FGD liquor magnesium concentrations would tend to increase due to cycling up of the magnesium dissolving from the dolomite. Solubility limits may begin to reduce the amount of magnesium in the dolomite utilized in the scrubber.

There were concerns about two potential adverse effects of injected dolomite on the FGD system. One is that magnesium oxide not utilized in the scrubber would continue to hydrate and dissolve in the thickener, to the point where magnesium sulfite might precipitate in the thickener. Although the $\mathrm{pH}$ of the thickener underflow and overflow did increase above the scrubber $\mathrm{pH}$ set points, indicating further magnesium oxide hydration there, no magnesium sulfite precipitation was observed. This may become an issue as the liquor magnesium concentration cycles up.

The other concern was about the potential for gypsum scaling in the scrubbers. Analyses of the recycle liquor did not indicate an increase in gypsum scaling potential during dolomite injection. 
However, it remains possible for scaling at localized areas of the scrubber, such as around the wet/dry interface.

Overall, dolomite injection into the furnace appears to be an effective approach for lowering flue gas sulfuric acid concentrations by up to $95 \%$, particularly on Unit 2 , where the dolomite injected actually offsets the consumption of more expensive lime reagent in the FGD system. As described above, though, there are a few technical uncertainties that require additional testing to resolve. Although furnace injection of dolomite shows promise as a sulfuric acid control technology for Unit 2 (or Unit 1), dolomite injection testing was not selected as a reagent for longer-term testing as part of this project. This is largely because this reagent appears to be most advantageous for boilers that use wet scrubbers for particulate and $\mathrm{SO}_{2}$ control, which represent a relatively small percentage of the total population.

However, if this technology is of interest to FirstEnergy for this application, it is recommended that FirstEnergy conduct its own longer-term test of several weeks of dolomite injection on either Unit 1 or Unit 2. The objectives of this test would be to:

- Provide an opportunity to measure $\mathrm{SO}_{3}$ removal as a function of dolomite injection rate, with longer periods of operation at each rate (one to two days each rate) so as to ensure steady state $\mathrm{SO}_{3}$ removal performance at that rate.

- Provide more information about the effects of dolomite injection on combustion efficiency and fly ash LOI.

- Allow an extended period to observe the effects of dolomite injection on slagging and fouling in the furnace and back pass of the boiler, and on air heater performance, to determine whether the buildup seen in this 93-hour test represents a steady-state condition or whether the buildup would continue to grow with time.

- Allow longer-term effects of dolomite injection on the FGD system to be evaluated, such as evaluating steady-state magnesium ion concentrations in the FGD liquor, determining whether magnesium sulfite precipitation in the thickener will become a problem, and determining effects of gypsum scale formation in the scrubbers. For the latter, we recommend trying to inspect one or more scrubber modules immediately before and after the dolomite test to try to quantify scale buildup.

Such a longer-term test would also provide an opportunity to measure the effects of dolomite injection on fly ash resistivity at air heater outlet temperatures.

Also, such a test should try varying the dolomite injection rate with boiler load and coal sulfur variations. It may be possible to maintain low sulfuric acid concentrations in the flue gas by lowering the dolomite injection rate in proportion with overnight load reductions and/or at lower coal sulfur contents. 


\section{Alkaline Sorbent Slurry Injection Tests}

A baseline test and three short-term (two-week) slurry injection tests were conducted on one-half of Unit 3 of FirstEnergy's BMP, to determine the effectiveness of three sorbents injected into the furnace at controlling flue gas sulfuric acid concentrations as measured downstream of the ESP.

Baseline testing on Unit 3 determined that about $1 \%$ of the coal sulfur is oxidized to $\mathrm{SO}_{3}$ rather than $\mathrm{SO}_{2}$ in the furnace and back pass of the boiler. The equivalent value for Unit 2 during the baseline testing for the dolomite powder injection test was higher at 1.6 to $1.7 \%$. The $1 \%$ conversion for Unit 3 was used along with the coal sulfur content in grab samples of coal feed, and one-half of the measured Unit 3 coal feed rates, to estimate the molar rate of formation of $\mathrm{SO}_{3}$ in Unit 3. This, in turn, was used to determine what slurry injection rate was required to achieve a desired sorbent-to- $\mathrm{SO}_{3}$ mole ratio, or to calculate this mole ratio when injecting sorbent slurry at a given rate.

The first sorbent tested was PHDL. The PHDL was injected at molar ratios of calcium plus magnesium hydroxides-to- $\mathrm{SO}_{3}$ in the furnace exit gas as high as 12:1. Even at the highest injection rate, the observed $\mathrm{SO}_{3}$ removal was limited to approximately $60 \%$ or less.

Previous literature data suggest that magnesium hydroxide injected into the furnace is much more reactive with flue gas $\mathrm{SO}_{3}$ than calcium hydroxide. If only the magnesium hydroxide content of the PHDL is considered, the highest $\mathrm{Mg}: \mathrm{SO}_{3}$ ratio tested was only 6:1. However, considering the weight of solids injected, the highest PHDL injection rate was equivalent to injecting commercial magnesium hydroxide at a $\mathrm{Mg}: \mathrm{SO}_{3}$ ratio of almost 14:1.

The PHDL injection was not observed to have a significant effect on ESP operation. This appears to be because high levels of $\mathrm{SO}_{3}$ removal were not achieved, and ample $\mathrm{SO}_{3}$ remained in the flue gas to condition the fly ash/sorbent mixture.

The second sorbent injected, commercial $\mathrm{Mg}$, was able to achieve the target $\mathrm{SO}_{3}$ removal of $90 \%$ or greater. An injection rate equivalent to a $\mathrm{Mg}: \mathrm{SO}_{3}$ ratio in the range of 12:1 to 14:1 was able to lower the ESP B outlet $\mathrm{SO}_{3}$ concentrations to approximately 2 to $3 \mathrm{ppm}$. There was evidence that commercial $\mathrm{Mg}$ injected on the east side of the boiler was crossing over to the west flue gas path, which was not having sorbent injected, potentially diluting the sorbent effectiveness measured on the east side. It is very likely that when injecting sorbent into the entire furnace, lower $\mathrm{Mg}: \mathrm{SO}_{3}$ values would be effective at achieving high $\mathrm{SO}_{3}$ removal percentages than are described above.

Injecting at this rate, and lowering the ESP outlet $\mathrm{SO}_{3}$ concentrations to such a low value was observed to have an adverse effect on ESP operation, though. During the time period of high $\mathrm{SO}_{3}$ removal, the operating currents in the affected ESP were greatly reduced, and particulate emissions from that ESP were observed to increase by a factor of approximately four. This result suggests that it will not be possible to remove $\mathrm{SO}_{3}$ down to the $2 \mathrm{ppm}$ level, as measured at the ESP outlet, and maintain acceptable ESP performance. It appears that an ESP outlet concentration of approximately 5 to $8 \mathrm{ppm}$ will be required to maintain ESP performance. 
The third short-term slurry injection test evaluated a byproduct $\mathrm{Mg}$ sorbent produced from a Thiosorbic ${ }^{\circledR}$ lime FGD process at Allegheny Energy's Pleasants Station. This material was also capable of lowering the ESP outlet $\mathrm{SO}_{3}$ concentrations on the side injected to $2 \mathrm{ppm}$, at a $\mathrm{Mg}: \mathrm{SO}_{3}$ ratio of about 7:1. Because the byproduct $\mathrm{Mg}$ is not pure magnesium hydroxide (it is about $62 \%$ magnesium hydroxide, with most of the balance being gypsum fines) the amount of solids injected at this molar ratio is about the same as when injecting the commercial $\mathrm{Mg}$ at a molar ratio of 11:1 to 12:1. However, for the BMP, this material may be advantageous because it could be produced onsite by lime addition to recover the liquid-phase magnesium in FGD blowdown liquor.

The byproduct $\mathrm{Mg}$ appeared to be more effective at $\mathrm{SO}_{3}$ removal when it was injected higher in the furnace than the $11^{\text {th }}$ floor level where the PHDL and commercial Mg were injected, and the byproduct $\mathrm{Mg}$ was initially injected. The results mentioned in the previous paragraph are for injection at the higher location, on the $14^{\text {th }}$ floor of the boiler structure. The effect is most likely due to the furnace gas temperatures being lower at the $14^{\text {th }}$ floor location, and less likely to cause dead burning of the calcined reagent $(\mathrm{MgO})$.

This observation raises the issue of whether the first two sorbents would be more effective if they were injected at the higher location. However, the project budget did not allow repeat testing of the first two sorbents at the new injection level. Also, as mentioned above, the fact that the byproduct $\mathrm{Mg}$ could be produced on site make it the most favored reagent anyway.

As during the commercial Mg test, ESP operation was adversely affected when the outlet $\mathrm{SO}_{3}$ concentrations were controlled down to $2 \mathrm{ppm}$. Comparing data when injecting at high sorbent rates on the $11^{\text {th }}$ floor, where the $\mathrm{SO}_{3}$ removal percentages were lower, to data when injecting at a $7: 1 \mathrm{Mg}: \mathrm{SO}_{3}$ ratio at the $14^{\text {th }}$ floor, the effect appears to be from lowered $\mathrm{SO}_{3}$ concentrations and not from the sorbent per se. That is, when injecting similar quantities on the $11^{\text {th }}$ floor, where the ESP outlet $\mathrm{SO}_{3}$ concentrations remained well above 2 ppm, no adverse effect on ESP performance was noted. To maintain acceptable ESP operation, it appears that ESP outlet $\mathrm{SO}_{3}$ concentrations will have to be maintained at approximately 5 ppm or greater.

Based on these short-term test results, the byproduct $\mathrm{Mg}$ was recommended for further testing on the whole boiler, and for a longer test duration of 25 to 30 days. Injecting on the whole boiler would allow more accurate measurement of the $\mathrm{Mg}: \mathrm{SO}_{3}$ mole ratio required to achieve high levels of $\mathrm{SO}_{3}$ removal on an on-going basis. This longer-term test would also allow the effects of sorbent injection and high $\mathrm{SO}_{3}$ removal efficiency on ESP performance to be quantified, and provide an opportunity to measure impacts of the sorbent injection on the removal of other acid gas species (hydrochloric and hydrofluoric acids) and gas-phase arsenic. The longer-term test also provides an opportunity to screen the effects of sorbent injection on SCR catalyst coupons.

\section{Comparison of Alkaline Sorbent Performance}

Results from these short-term tests have been reviewed to develop estimates of the quantities of each alkaline sorbent required to achieve two levels of $\mathrm{SO}_{3}$ removal performance. These estimates are compared in Table 5-1. The quantities are expressed in terms of moles of alkaline sorbent per mole of $\mathrm{SO}_{3}$ in the economizer outlet flue gas under baseline (no sorbent injection) 
Table 5-1

Comparison of Furnace Injected Alkaline Sorbents for Sulfuric Acid Control (based on short-term test results)

\begin{tabular}{|c|c|c|c|c|}
\hline Sorbent & Injection Mode & Injection Location & $\begin{array}{c}\text { Estimated Molar } \\
\text { Ratio to Achieve } \\
60 \% \text { Sulfuric Acid } \\
\text { Removal }\end{array}$ & $\begin{array}{c}\text { Estimated Molar } \\
\text { Ratio to Achieve } \\
90 \% \text { Sulfuric Acid } \\
\text { Removal }\end{array}$ \\
\hline Dolomite & Dry Power & $\begin{array}{l}\text { Top Front Row of } \\
\text { Burners, Unit } 2\end{array}$ & $30: 1^{*}$ & $40: 1^{*}$ \\
\hline $\begin{array}{l}\text { Pressure- } \\
\text { Hydrated } \\
\text { Dolomitic Lime }\end{array}$ & Atomized Slurry & $\begin{array}{l}\text { Across from Boiler } \\
\text { Nose }\left(11^{\text {th }} \text { Floor }\right) \text {, } \\
\text { Unit } 3\end{array}$ & $12: 1^{*}$ & Not Achieved \\
\hline $\begin{array}{l}\text { Commercial } \\
\text { Magnesium } \\
\text { Hydroxide }\end{array}$ & Atomized Slurry & $\begin{array}{l}\text { Across from Boiler } \\
\text { Nose }\left(11^{\text {th }} \text { Floor }\right) \text {, } \\
\text { Unit } 3\end{array}$ & $4: 1-5: 1^{\star *}$ & $12: 1^{* *}$ \\
\hline $\begin{array}{l}\text { Byproduct } \\
\text { Magnesium } \\
\text { Hydroxide }\end{array}$ & Atomized Slurry & $\begin{array}{l}\text { Across from } \\
\text { Pendant Superheat } \\
\left.\text { Tubes (14 }{ }^{\text {th }} \text { Floor }\right) \text {, } \\
\text { Unit } 3\end{array}$ & $4: 1^{* *}$ & $7: 1^{* *}$ \\
\hline
\end{tabular}

*Molar ratio of calcium plus magnesium in reagent injected to $\mathrm{SO}_{3}$ at the economizer outlet under baseline conditions

**Molar ratio of magnesium in reagent injected to $\mathrm{SO}_{3}$ at the economizer outlet under baseline conditions

conditions. For the dolomite and PHDL reagents, the ratios are based on calcium- plus magnesium-based alkalinity, whereas for the commercial and byproduct $\mathrm{Mg}$, the ratios are based only on magnesium hydroxide content in the sorbent slurry.

Note that the molar ratios shown in Table 5-1 should be considered approximate, because of variations from test to test and because some values had to be interpolated from test results at other removal levels. Test to test variations, in particular, could appreciably confound these estimates. For example, the dolomite test results are for Unit 2, which showed higher $\mathrm{SO}_{3}$ concentration levels than in Unit 3, and are based on $\mathrm{SO}_{3}$ removal as measured at the economizer outlet, while the removals for the slurry injection tests are based on ESP outlet conditions. Among the slurry injection test results, the PHDL and commercial Mg test results are based on slurry injection at the $11^{\text {th }}$ floor level on Unit 3, while the byproduct $\mathrm{Mg}$ test results are based on injection at the $14^{\text {th }}$ floor, which was more favorable (at least for that reagent).

These comparisons show that the byproduct magnesium hydroxide would require the lowest molar ratios to achieve either the moderate $(60 \%)$ or the high $(90 \%)$ sulfuric acid removal level. However, as mentioned above, the injection location higher in the furnace during the test of this reagent may confound this comparison. Also, because the byproduct magnesium hydroxide is not pure, the amount of solids actually required to be injected would be similar to or greater than that required for the nearly pure commercial product. Finally, recall that ESP performance may be adversely affected when achieving $90 \%$ sulfuric acid removal with any of these reagents. 
The relative costs of these reagents and balance of plant impacts should also figure into this comparison. Raw dolomite stone can be delivered to most locations for approximately $\$ 10$ per ton $(\$ 9$ per metric ton), but this material requires further processing before injection into the boiler as a finely ground powder. The commercial Mg delivered cost would likely be in the range of approximately $\$ 200$ to $\$ 300$ per dry ton ( $\$ 180$ to $\$ 270$ per dry metric ton). The cost of producing the byproduct $\mathrm{Mg}$ is not well documented at this time, but it is estimated that the material could be produced at BMP for less than $\$ 100$ per dry ton of pure magnesium hydroxide (\$90 per dry metric ton).

Balance-of-plant issues could not be fully evaluated in these tests, but will include impacts on the FGD system (Unit 2) or ESP (Unit 3), fly ash sales or other reuse, boiler slagging and fouling, etc. Heat rate penalties (evaporation of water from the slurries, air heater fouling) or benefits (ability to lower air heater exit flue gas temperature) will also impact the relative cost effectiveness of these sorbents. The long-term tests to be conducted as part of this project should provide more information to allow evaluation of balance-of-plant effects. 